\title{
High Temperature Gas-Cooled Reactors Lessons Learned Applicable to the Next Generation Nuclear Plant
}

The INL is a

U.S. Department of Energy

National Laboratory

operated by

Battelle Energy Alliance

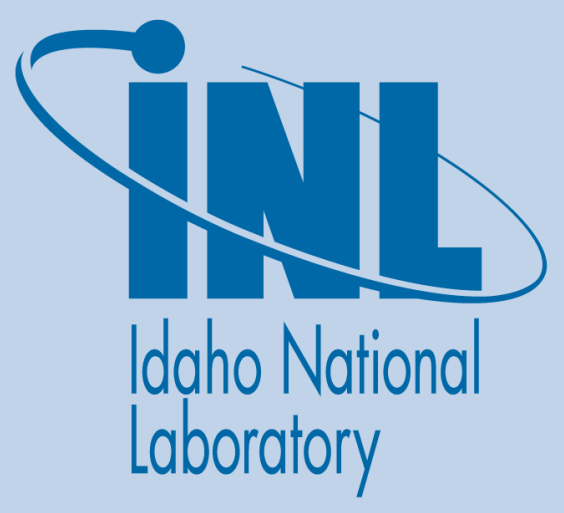

J. M. Beck

L. F. Pincock

April 2011

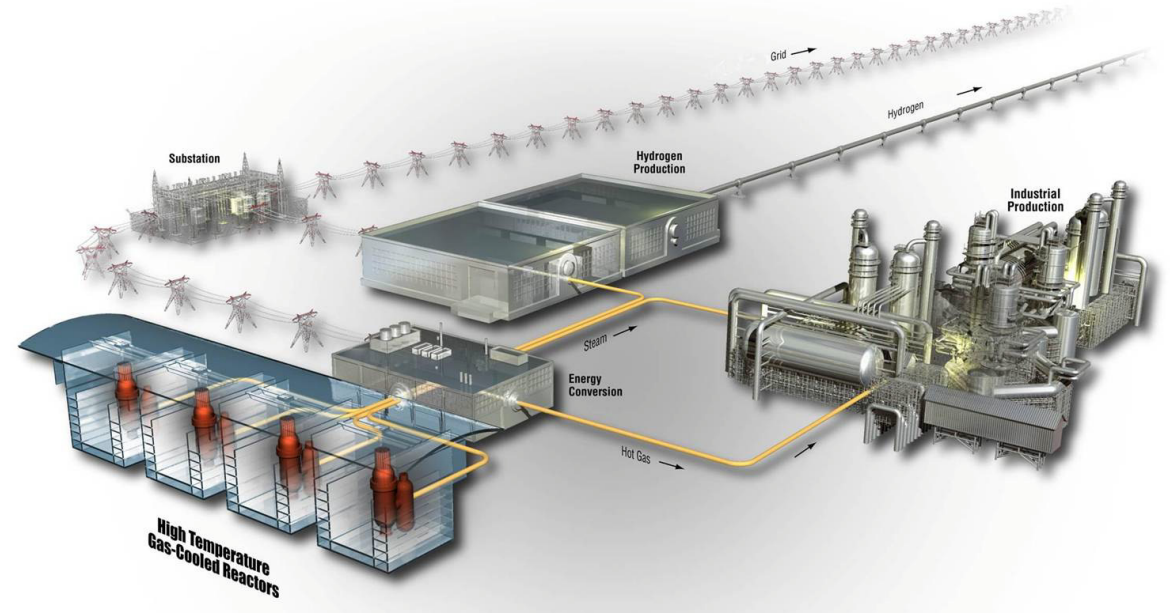




\section{DISCLAIMER}

This information was prepared as an account of work sponsored by an agency of the U.S. Government. Neither the U.S. Government nor any agency thereof, nor any of their employees, makes any warranty, expressed or implied, or assumes any legal liability or responsibility for the accuracy, completeness, or usefulness, of any information, apparatus, product, or process disclosed, or represents that its use would not infringe privately owned rights. References herein to any specific commercial product, process, or service by trade name, trade mark, manufacturer, or otherwise, does not necessarily constitute or imply its endorsement, recommendation, or favoring by the U.S. Government or any agency thereof. The views and opinions of authors expressed herein do not necessarily state or reflect those of the U.S. Government or any agency thereof. 
INL/EXT-10-19329

Revision 1

\title{
High Temperature Gas-cooled Reactors Lessons Learned Applicable to the Next Generation Nuclear Plant
}

\author{
J. M. Beck and L. F. Pincock
}

April 2011

Idaho National Laboratory

Next Generation Nuclear Plant Project

Idaho Falls, Idaho 83415

Prepared for the

U.S. Department of Energy

Office of Nuclear Energy

Under DOE Idaho Operations Office

Contract DE-AC07-05ID14517 

Next Generation Nuclear Plant Project

\title{
High Temperature Gas-cooled Reactors Lessons Learned Applicable to the Next Generation Nuclear Plant
}

\author{
INL/EXT-10-19329 \\ Revision 1
}

April 2011

Authored by:

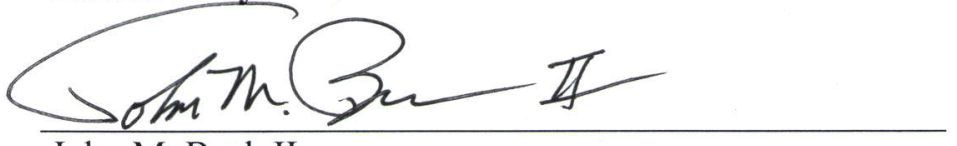

John M. Beck II

NGNP Systems Engineering

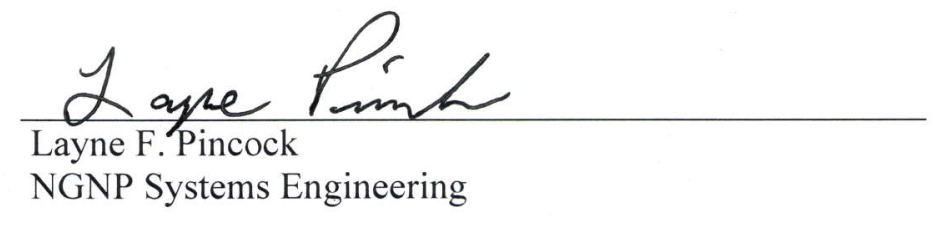

Approved by:

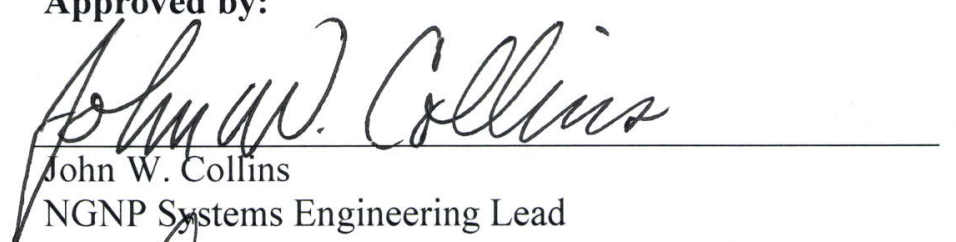

NGNP Systems Engineering Lead

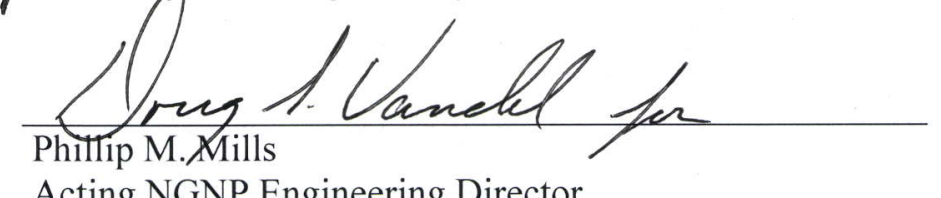

Acting NGNP Engineering Director
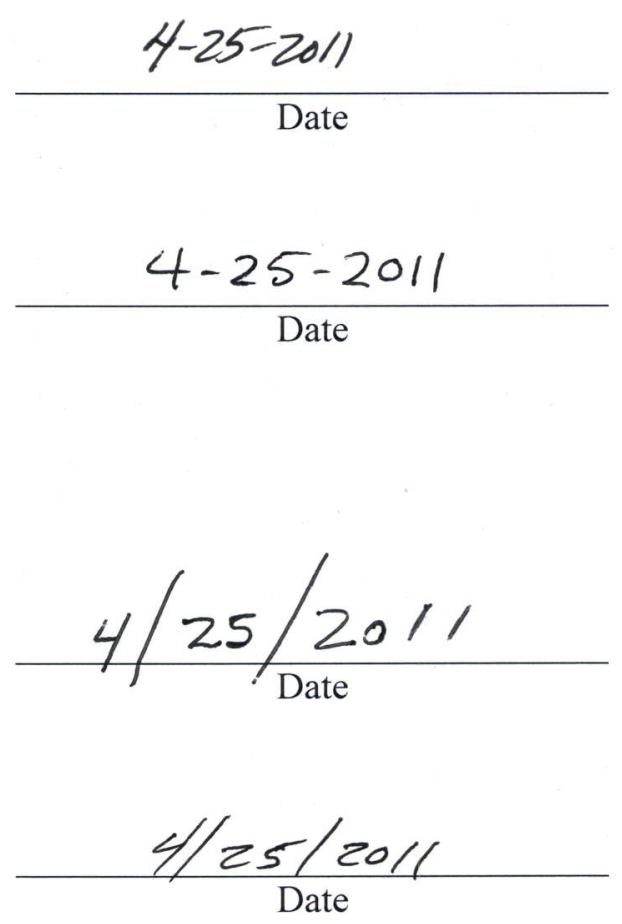



\section{EXECUTIVE SUMMARY}

Over the past five decades, high temperature gas-cooled reactors (HTGRs) have been designed and operated throughout the world. To date, seven HTGR plants (depicted in Figure ES-1) have been built and operated: Dragon (United Kingdom), Arbeitsgemeinschaft Versuchsreaktor (Germany), High

Temperature Test Reactor (Japan), High Temperature Reactor-10 (HTR-10; People's Republic of China), Peach Bottom 1 (United States), Thorium Hochtemperatur Reaktor (Germany), and Fort St. Vrain (United States). Although these seven HTGRs vary in size, outlet temperature, primary fluid, and purpose, there is much the Next Generation Nuclear Plant (NGNP) Project has learned and can still learn from these reactors. This lessons learned report categorizes design, construction, and operational experiences from these reactors.
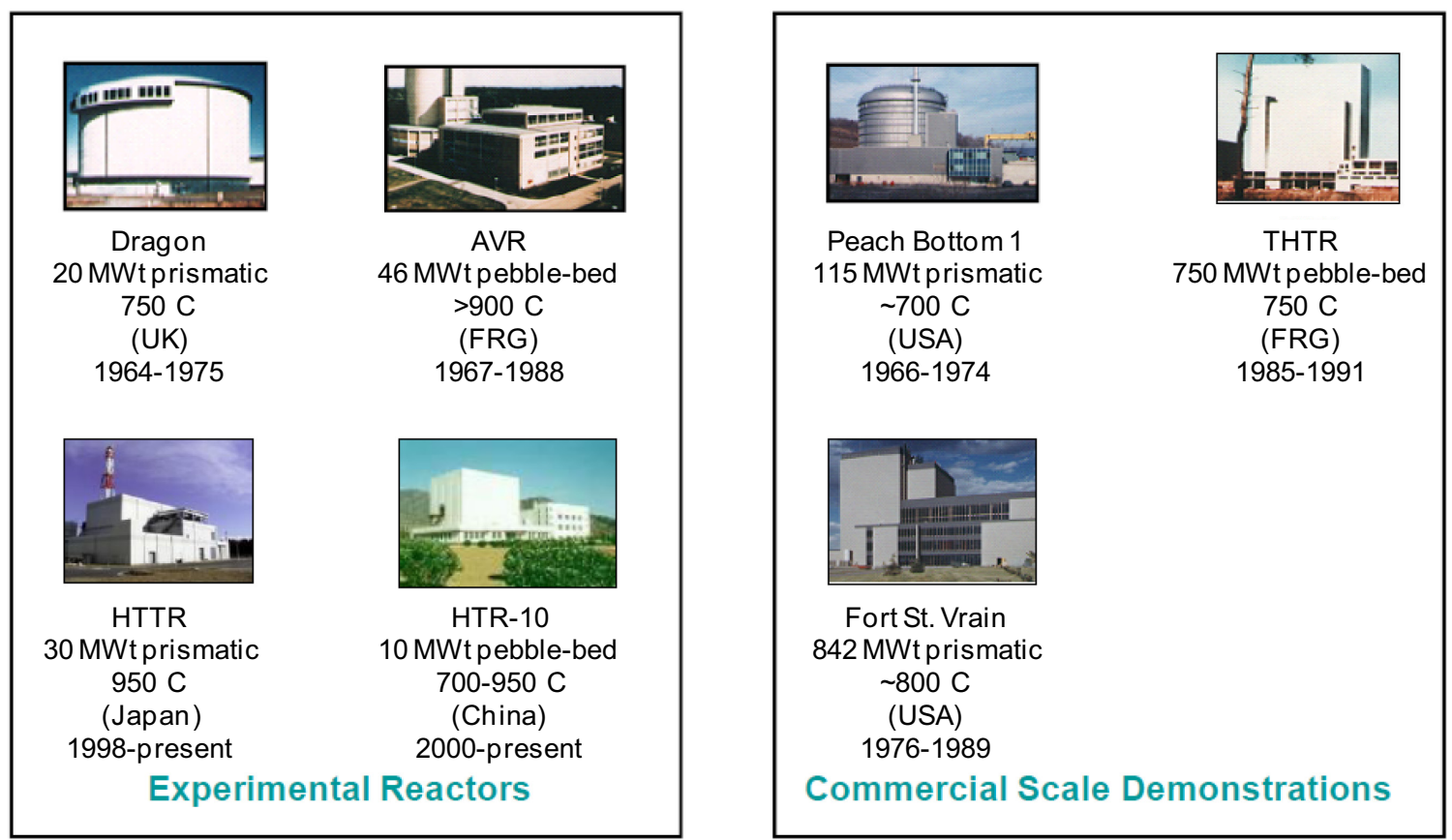

Figure ES-1. Summary of experimental and commercial scale HTGR installations (temperatures are outlet temperatures).

The purpose of this report is to identify possible issues highlighted by these lessons learned that could apply to the NGNP in reducing technical risks commensurate with the current phase of design. Some of the lessons learned have been applied to the NGNP and documented in the Preconceptual Design Report. These are addressed in the background section of this document and include, for example, the decision to use TRISO fuel rather than BISO fuel used in the Peach Bottom reactor; the use of a reactor pressure vessel rather than prestressed concrete found in Fort St. Vrain; and the use of helium as a primary coolant rather than $\mathrm{CO}_{2}$. Other lessons learned, 68 in total, are documented in Sections 2 through 6 and will be applied, as appropriate, in advancing phases of design. The lessons learned are derived from both negative and positive outcomes from prior HTGR experiences. Lessons learned are grouped according to the plant, areas, systems, subsystems, and components defined in the NGNP Preconceptual Design Report, and subsequent NGNP project documents. 
Of the 68 lessons learned, the majority are found in the Nuclear Heat Supply System and can be summarized in the following three areas:

- Ingress or leakage events such as moisture ingress

- Primary coolant flow issues such as bypass flow and flow induced vibrations

- Fuel performance, fission product release, and graphite dust generation.

Other lessons learned will help to inform the design of other reactor components such as circulators, heat transfer systems, and power conversion systems. Past experience will also benefit balance of plant systems and auxiliary systems. Important lessons were also learned other areas not directly applicable to reactor components such as human error, licensing issues, and safety features.

Evaluating these lessons provided by previous and current HTGRs will benefit the NGNP design. The lessons also serve to inform the current design data needs and design philosophy. In the end, all the lessons will help ensure a more reliable design for the next generation of reactors.

It is recommended that NGNP Project develop an implantation status summary of the lessons learned to document the current status of lessons learned implementation applicable to the NGNP. It is further recommended that $R \& D$ activities that address these lessons learned be continued. Overcoming key technology challenges and providing advancement in those areas of concern will improve future HTGR designs and reduce the risks associated with the NGNP and other HTGR technologies. 


\section{ACKNOWLEDGEMENTS}

The authors of this document would like to acknowledge and thank the following for providing technical input and reviewing the content for specific areas of focus:

Robert L. Bratton, Ph.D., Graphite Qualification Engineer, Next Generation Nuclear Plant Engineering, Idaho National Laboratory

Phillip M. Mills, Acting Director, Next Generation Nuclear Plant Engineering, Idaho National Laboratory

David A. Petti, Sc.D., Laboratory Fellow and Director of Very High Temperature Reactor, Technology Development Office, Idaho National Laboratory

William C. Phoenix, P.E., Human Performance Engineer, Human Factors, Controls, and Statistics, Idaho National Laboratory

Doug S. Vandel, Project Manager, Next Generation Nuclear Plant Engineering, Idaho National Laboratory 


\section{CONTENTS}

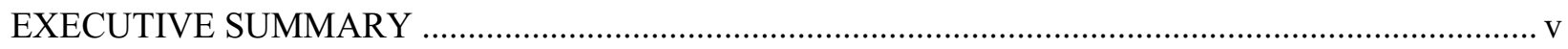

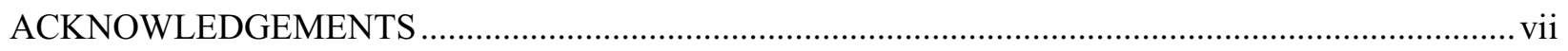

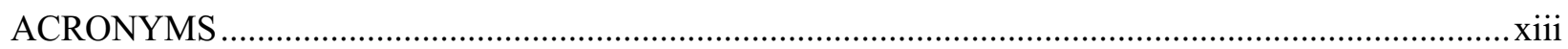

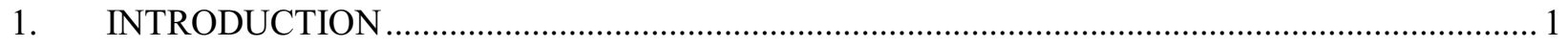

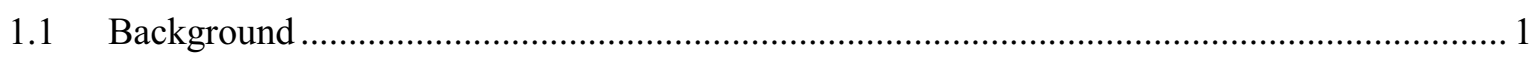

1.2 Independent Technology Review Group .................................................................... 3

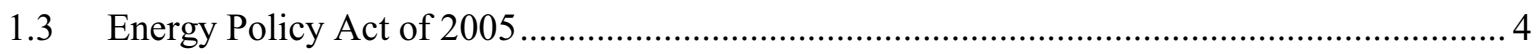

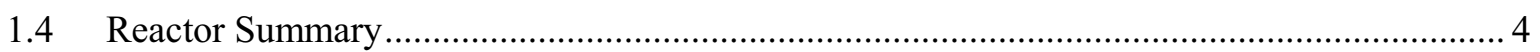

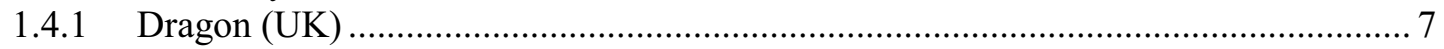

1.4.2 Peach Bottom Unit 1 (United States) …................................................................... 7

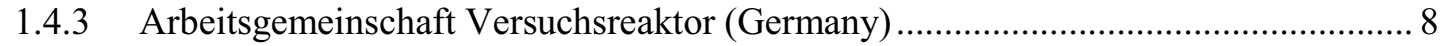

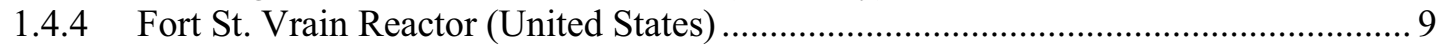

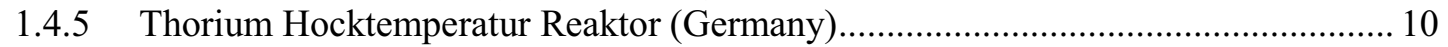

1.4.6 High Temperature Test Reactor (Japan) ............................................................ 10

1.4.7 10-MW High Temperature Reactor (People's Republic of China)............................ 12

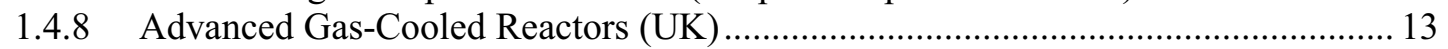

1.4.9 Modular High-Temperature Gas-Cooled Reactor (United States)............................ 14

1.4.10 Gas Turbine-Modular Helium Reactor (United States) ........................................... 14

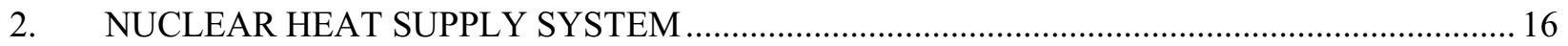

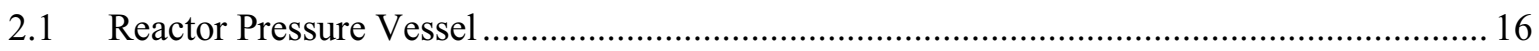

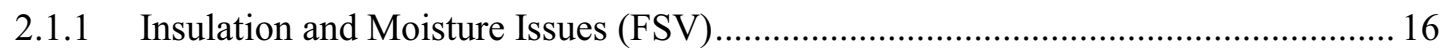

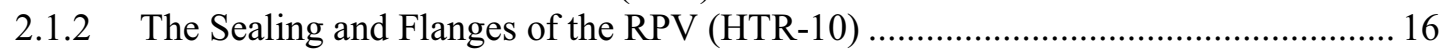

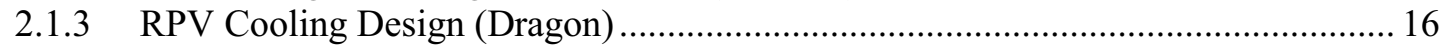

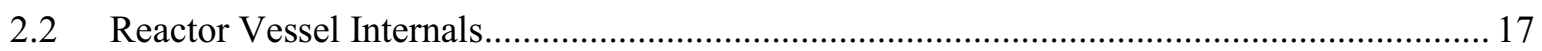

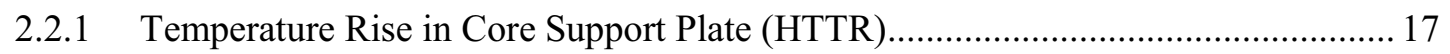

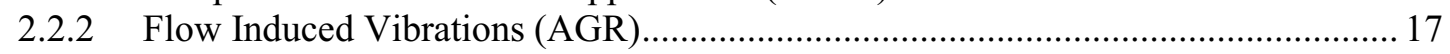

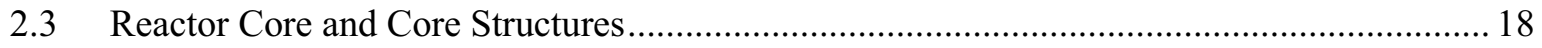

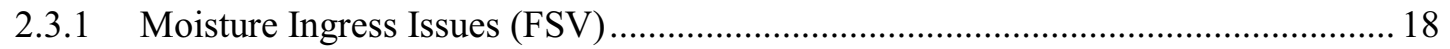

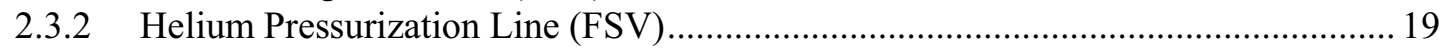

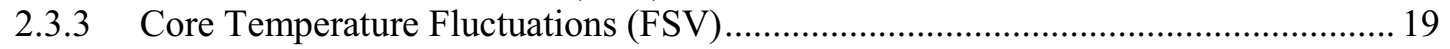

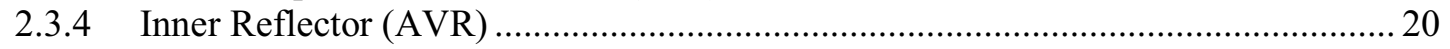

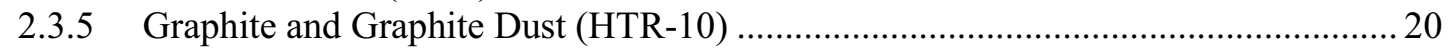

2.3.6 Outer Reflectors Bowing (Peach Bottom Unit 1) ..................................................... 21

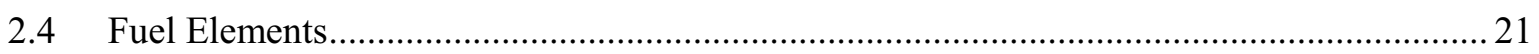

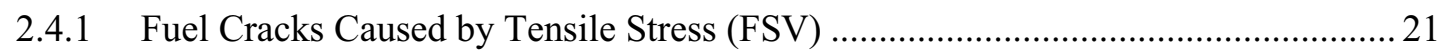

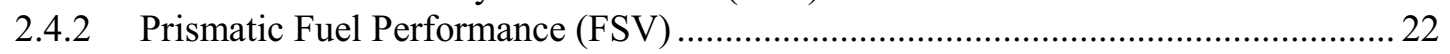

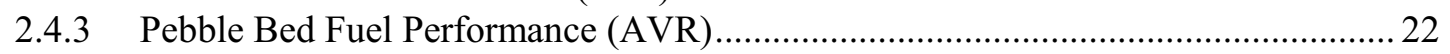

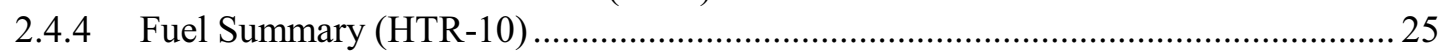

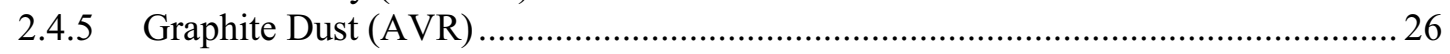

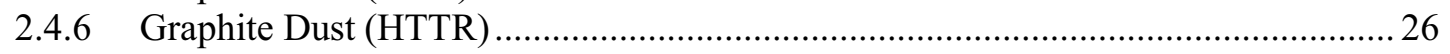

2.4.7 Fission Product Release Monitoring (HTTR) ….................................................... 27

2.4.8 Fission Product Trapping (Peach Bottom Unit 1) ................................................. 28

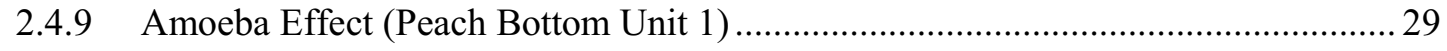




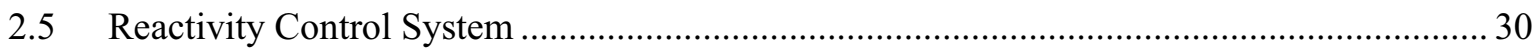

2.5.1 Moisture Effects on RCS (FSV) ………………………………………......... 30

2.5.2 Control Rod Cable Failure (FSV) …………………………………………........... 31

2.5.3 Control Rod Temperature Anomalies (HTTR) ………………………………….... 31

2.5.4 Control Rods, Reserve Shutdown System, and Lubricants in a Helium Environment (HTR-10) ................................................................................. 32

2.5.5 Control Rods Placements (Peach Bottom Unit 1)..................................................... 32

2.5.6 Control Rod Lubrication (Peach Bottom Unit 1) …………………………………......33

2.5.7 Oil Leaks (Peach Bottom Unit 1).......................................................................... 33

2.5.8 Fatigue in Control Rods (Peach Bottom Unit 1) ………………………………..... 33

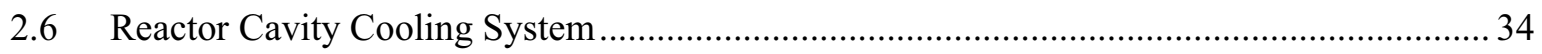

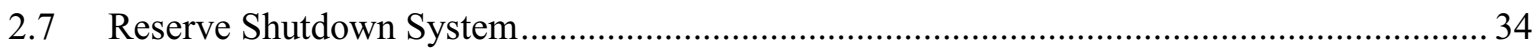

2.7.1 Inadvertent Actuation of RSS (FSV) ………………………………………..... 34

2.7.2 RSS Failure to Deploy Boronated Graphite Balls (FSV)........................................... 35

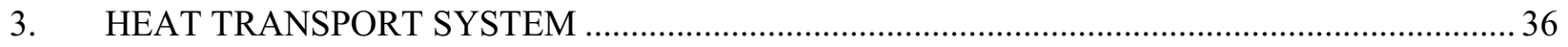

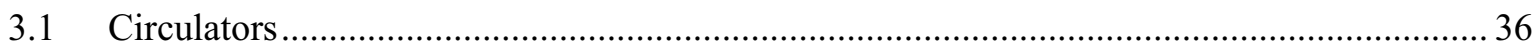

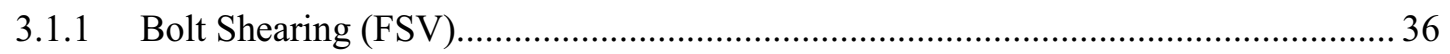

3.1.2 Circulator Seals and Stress Corrosion Cracking (FSV) ............................................36

3.1.3 Use of Active Magnetic Bearings (HTR-10) ............................................................... 36

3.1.4 Oil Ingress in Compressor (Peach Bottom Unit 1) .................................................... 37

3.1.5 Friction Damage (Dragon) …………………………………………………….... 37

$3.2 \quad$ Intermediate Heat Transfer ...............................................................................................

3.2.1 IHX Materials (THTR) …………………………………………………. 37

3.2.2 Successful Operation at High Temperatures (HTTR) ................................................ 38

3.2.3 Helium Leakage in Secondary Loop (HTTR).......................................................... 38

3.2.4 IHX and Steam Generator Integration Design (HTR-10) ………………………......... 38

3.3 Hot Duct and Cross Vessel .............................................................................................. 39

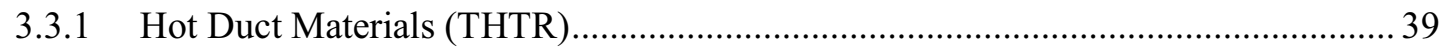

3.3.2 Successful Use of High Temperature Hot Duct (HTTR) …………………………........39

3.3.3 Loadings on Cross Vessel (HTR-10) …………………………………………...... 39

$3.4 \quad$ High Temperature Valves .................................................................................................... 39

3.4.1 Mitigating Air ingress Through Valves (HTR-10) ………………………………. 39

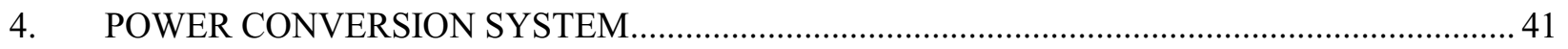

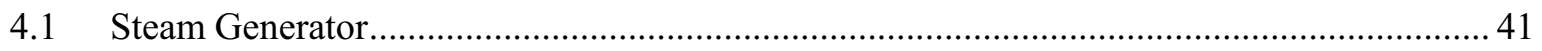

4.1.1 Cracks/Leakage in Steam Generator (FSV) ………………………………….... 41

4.1.2 Tube Rupture (AVR) ………………………………………………………4 42

4.1.3 Hot Steam Headers for the Steam Generators (THTR)............................................. 43

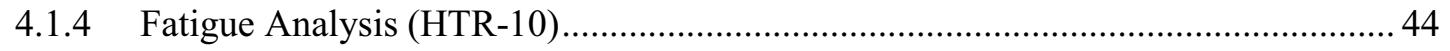

4.1.5 Materials Used and Migration of Tritium (Peach Bottom Unit 1) ………………..... 44

4.1.6 Dynamic Stresses and Side Flow Maldistribution (AGR) ........................................ 45

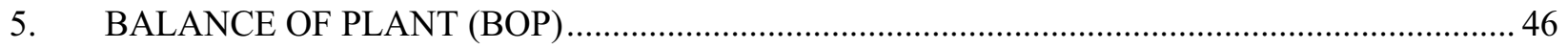

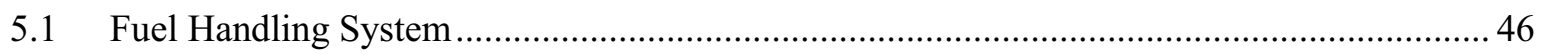

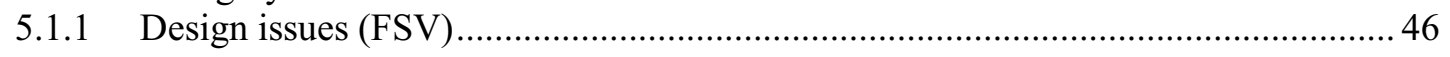

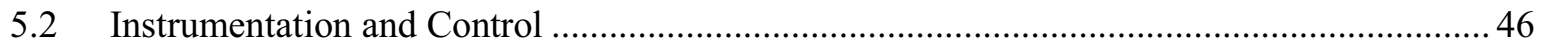

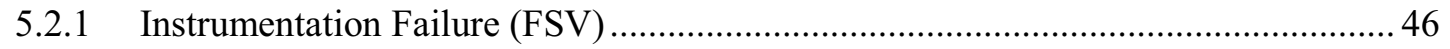

5.2.2 Core Temperature Instrumentation (AVR) …………………………………..... 47 


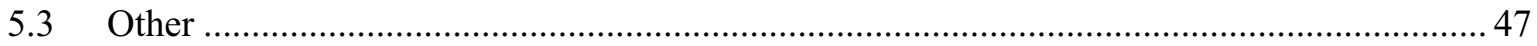

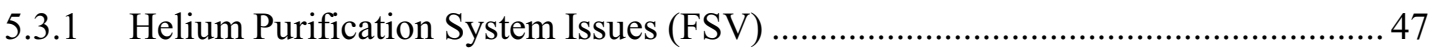

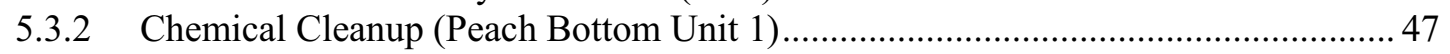

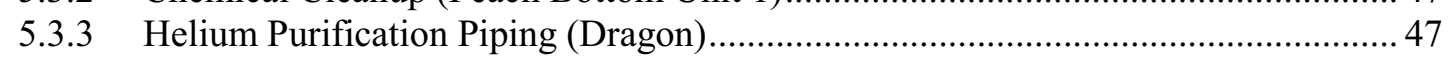

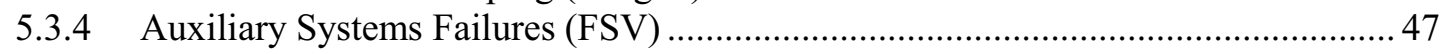

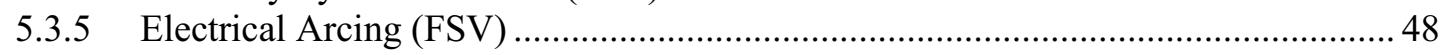

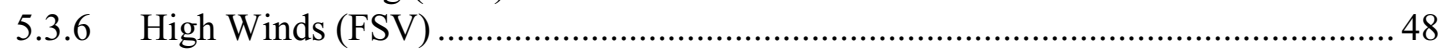

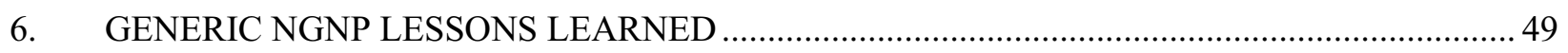

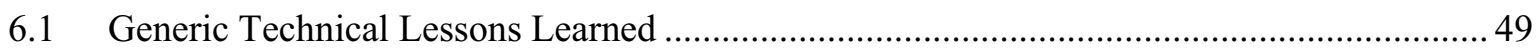

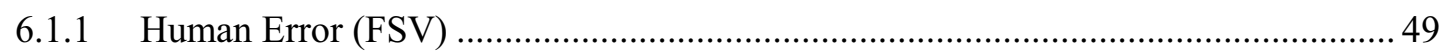

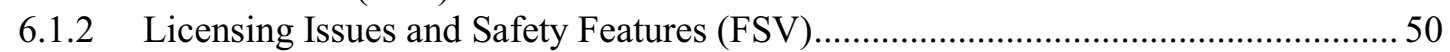

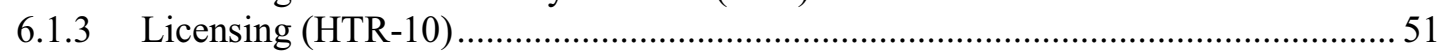

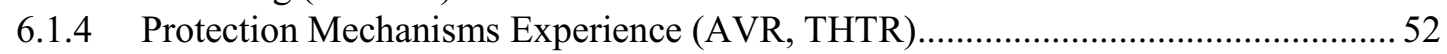

6.1.5 Graphite Disposal for German HTGRs (AVR, THTR) ........................................ 52

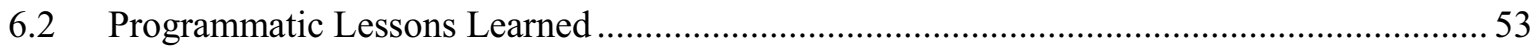

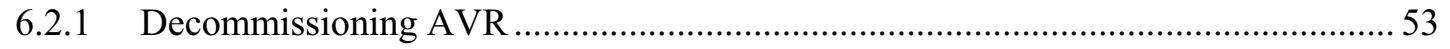

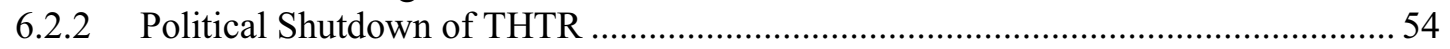

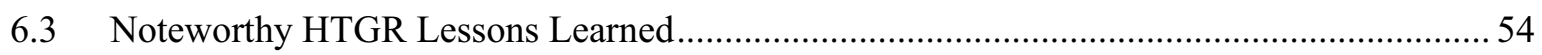

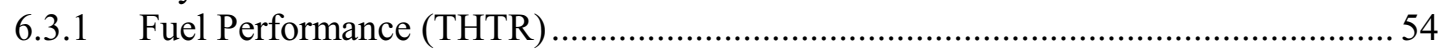

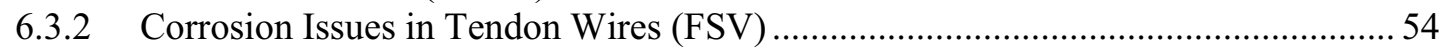

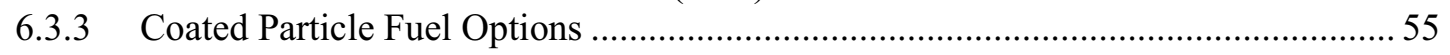

6.3.4 Reactor Cavity Cooling System Leakage (FSV) ............................................... 55

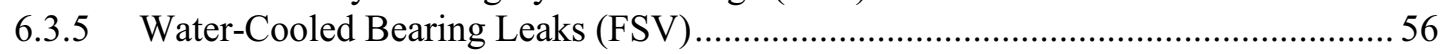

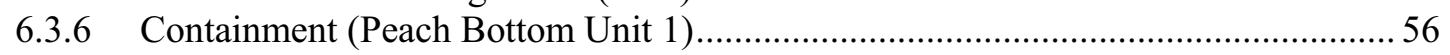

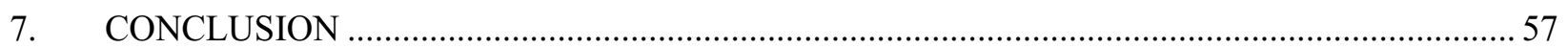

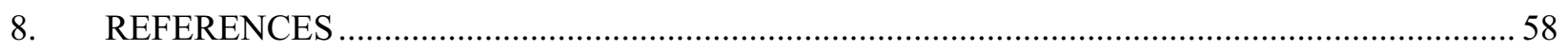

\section{FIGURES}

Figure ES-1. Summary of experimental and commercial scale HTGR installations (temperatures

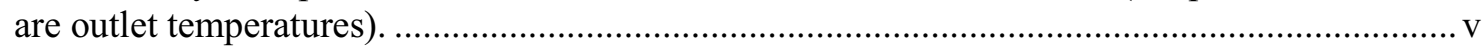

Figure 1. Summary of experimental and commercial scale HTGR installations (temperatures are

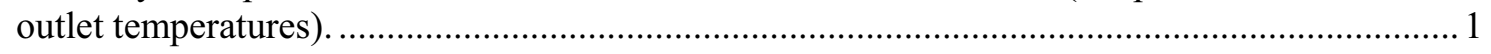

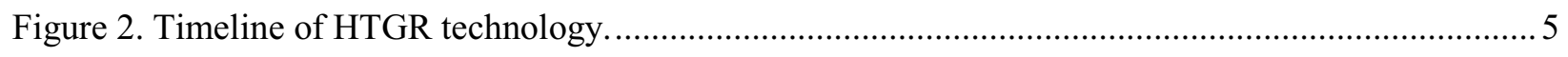

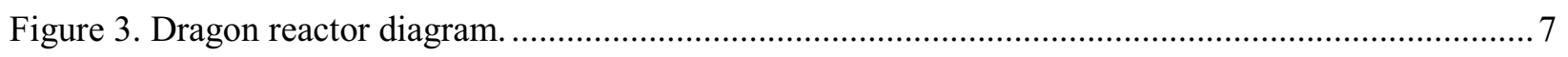

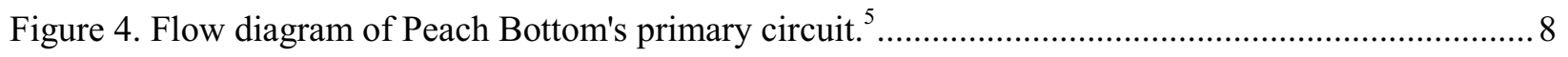

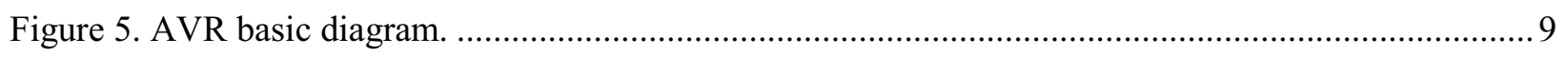

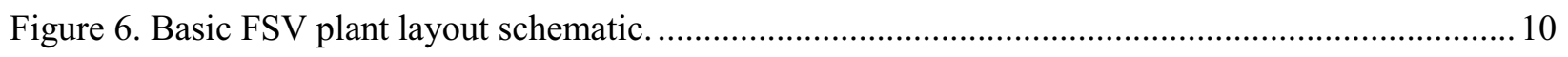

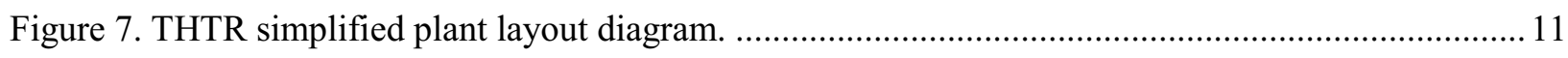

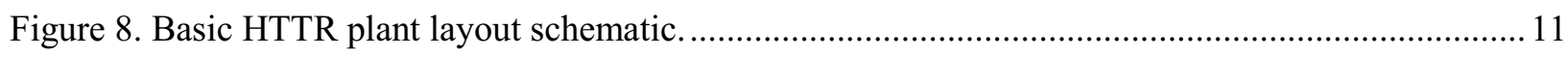

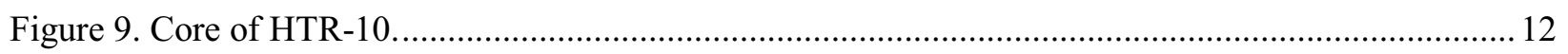


Figure 10. HTR-10 reactor pressure vessel (RPV) and steam generator pressure vessel (SGPV) layout.

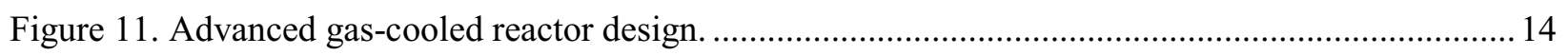

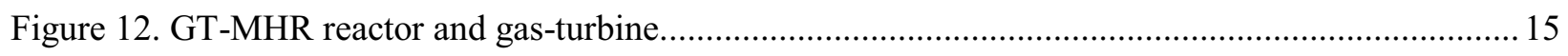

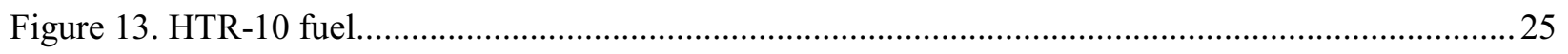

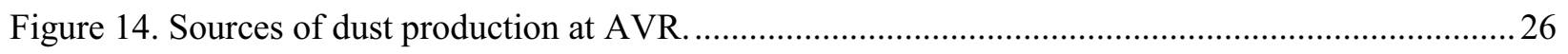

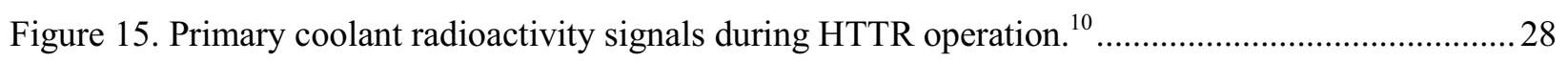

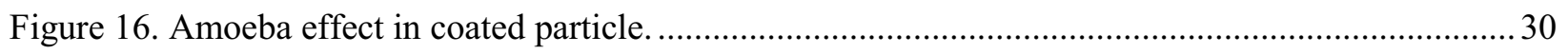

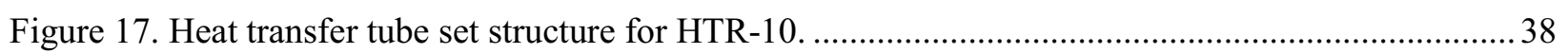

\section{TABLES}

Table 1. Key Specifications for HTGRs evaluated for this report ........................................................ 6

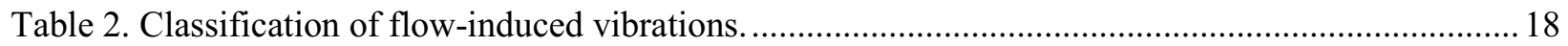

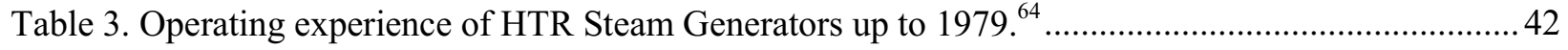

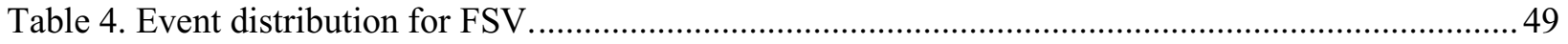




\section{ACRONYMS}

AGR Advanced Gas-cooled Reactor (United Kingdom)

AMB active magnetic bearings

ASME American Society of Mechanical Engineers

AVR Arbeitsgemeinschaft Versuchsreaktor (Germany)

BISO bistructural isotropic or buffer isotropic

CRD control rod drive

DOE U.S. Department of Energy

EPAct Energy Policy Act of 2005

FRG Federal Republic of Germany

FSAR Final Safety Analysis Report

FSV Fort St. Vrain

GT-MHR Gas Turbine-Modular Helium Reactor (United States)

HKG Hochtemperatur-Kernkraftwerk GmbH

HTGR high temperature gas-cooled reactor

HTR high temperature reactor

HTR-10 High Temperature Reactor (People's Republic of China)

HTTR High Temperature Test Reactor (Japan)

IAEA International Atomic Energy Agency

IHX intermediate heat exchanger

MHTGR Modular High Temperature Gas-cooled Reactor (United States)

NGNP Next Generation Nuclear Plant

NPR New Production Reactor

NRC Nuclear Regulatory Commission

PBMR Pebble Bed Modular Reactor (South Africa)

PCRV prestressed concrete reactor vessel

PSI Paul Scherer Institute (Switzerland)

PSID Preliminary Safety Information Document

PyC pyrolitic carbon

R\&D research and development

RAT remote auxiliary transformer

RCCS reactor cavity cooling system

RCD region constraint device

RPV reactor pressure vessel 
THTR Thorium Hochtemperatur Reaktor (Germany)

TRISO tristructural isotropic

UK United Kingdom

VHTR very high temperature reactor 


\section{High Temperature Gas-cooled Reactors Lessons Learned Applicable to the Next Generation Nuclear Plant}

\section{INTRODUCTION}

High temperature gas-cooled reactors (HTGR) have been designed and operated from the 1960s to the present. Seven HTGR plants have currently been built and operated worldwide as shown in Figure 1.
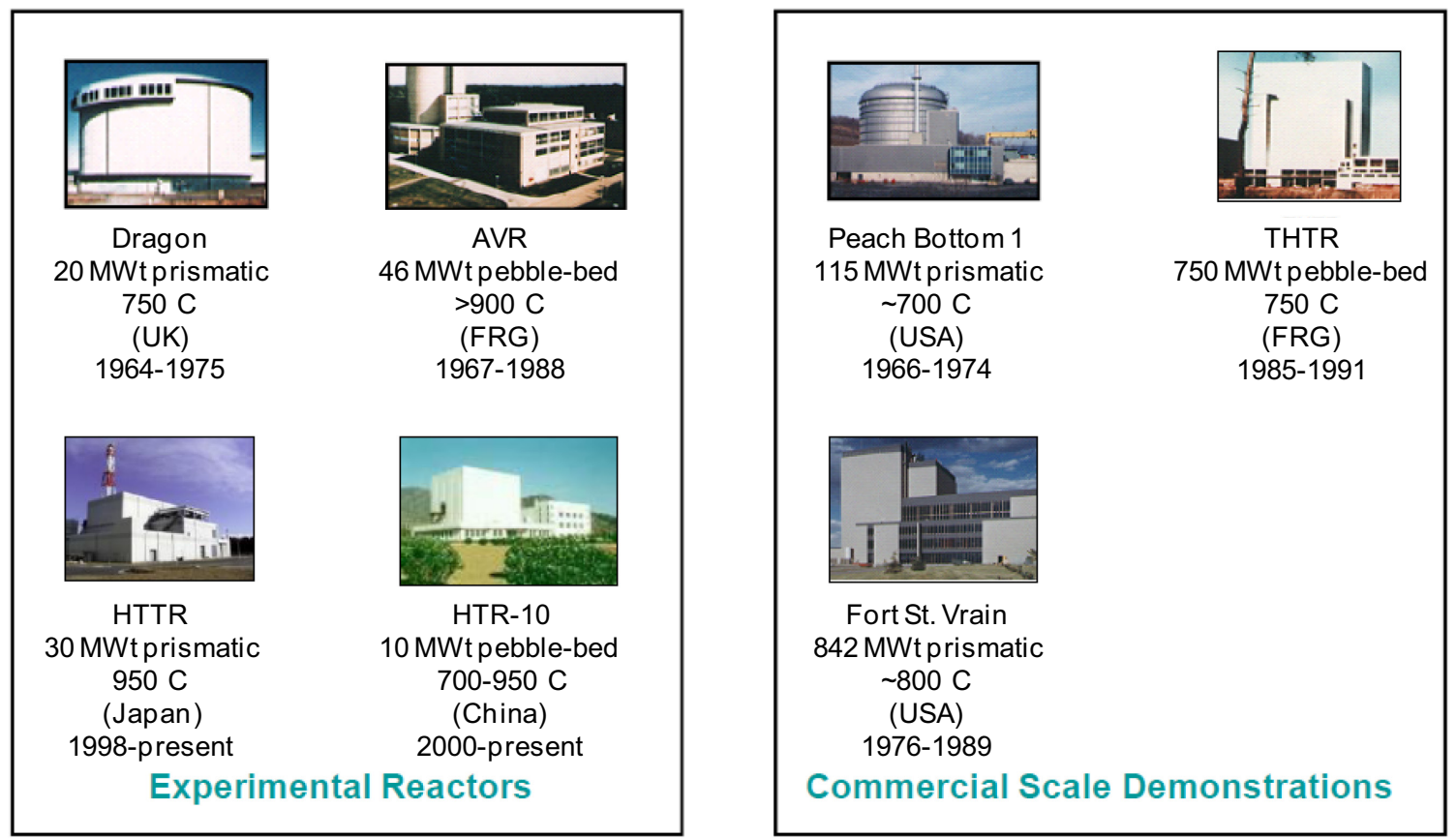

Figure 1. Summary of experimental and commercial scale HTGR installations (temperatures are outlet temperatures).

The Next Generation Nuclear Plant (NGNP) Project has benefitted greatly from the experience gained at each of these experimental and commercial-scale gas-cooled reactor installations. This report captures these various experiences and documents the lessons learned according to the physical NGNP hardware (systems, subsystems, and components) affected thereby.

\subsection{Background}

The first HTGR was the $20 \mathrm{MW}(\mathrm{t})$ Dragon test reactor in the United Kingdom (UK). Following the Dragon reactor, two low-power reactors were constructed: the $115 \mathrm{MW}(\mathrm{t})$ Peach Bottom Unit 1 (prismatic core with cylindrical fuel elements) in the United States and the $46 \mathrm{MW}(\mathrm{t})$ Arbeitsgemeinschaft Versuchsreaktor (AVR; pebble-bed core) in Germany. These two reactors demonstrated electricity generation with an HTGR using the Rankine (steam) cycle. These plants were followed by the construction of two mid-sized steam cycle plants: the $842 \mathrm{MW}(\mathrm{t})$ plant at Fort St. Vrain (FSV) in the United States, and the $750 \mathrm{MW}(\mathrm{t})$ Thorium Hochtemperatur Reaktor (THTR) in Germany. Two additional HTGR experimental reactors were constructed and are successfully operating today: the 30 MW(t) High Temperature Test Reactor (HTTR; prismatic core) in Japan and the 10 MW(t) High 
Temperature Reactor (HTR-10; pebble-bed core) in China, with design reactor outlet temperatures of $950^{\circ} \mathrm{C}$ and $700-950^{\circ} \mathrm{C}$, respectively. In addition to demonstrating the use of helium coolant (campaigns with outlet temperatures as high as $950^{\circ} \mathrm{C}$ ) and graphite moderator, these plants have also successfully demonstrated coated-particle fuel. The use of helium coolant allows higher temperatures versus $\mathrm{CO}_{2}$ coolant used by earlier HTGRs. A wide range of coated particle experiments have been associated with different kernels, different coatings, and ranges of enrichments, burnup, and quality levels. Additionally, reactor vessel designs and deployments migrated from the original use of prestressed concrete reactor vessels (PCRV) to steel vessels and finally to the use of modern alloys in the latest NGNP design.

In the 1970s, HTGR designers at General Atomics developed large prismatic block designs based on the technologies used in the FSV Nuclear Generating Station. Construction permit applications for these designs were submitted to the Nuclear Regulatory Commission (NRC) by utility customers, and a regulatory review, including construction permit safety evaluation reports and an Advisory Committee on Reactor Safeguards letter, was underway prior to cancellation of the projects in the late 1970s.

In the 1980s, HTGR designers at the German company INTERATOM (later Siemens) developed a new pebble-bed design that modified the reactor system in such a way that the decay heat could be removed passively, thus eliminating the need for active emergency core cooling systems. The resulting design was called the HTR Modul. ${ }^{1}$ For several early HTGR reactor designs, the reactor core height and diameter are almost equal for neutron economy reasons. However, in the HTR Modul and other related HTGR designs (both prismatic and pebble bed), the core height was three-times larger than the diameter. The advantage of this core geometry is that decay heat can be removed radially and fully passively; the disadvantages are increased neutron leakage and a higher core flow resistance. Unlike the other HTGR designs, the HTR Modul was not intended exclusively for electricity production but included other possible missions as well, namely, heat and power co-generation, process heat and/or steam, district heating, etc. The geometry of the HTR Modul was carried over to subsequent HTGR designs, which carry some of the same advantages and disadvantages. Neutron leakage associated with this geometric configuration ultimately became part of the passive safety features.

The U.S. modular HTGR concept began in 1984 when Congress challenged the HTGR industry to investigate the potential for using HTGR technology to develop a "simpler, safer" nuclear power plant design. The goal was to develop a passively safe HTGR plant that was also economically competitive. In 1986, a consortium led by the U.S. Department of Energy (DOE) produced the Preliminary Safety Information Document (PSID) for the Standard MHTGR, which discusses a detailed preliminary design for a modular high temperature gas-cooled reactor (MHTGR). To maintain the coated-particle fuel temperatures below damage limits during passive decay heat removal, the core's physical size had to be limited. The maximum reactor power capacity was found to be about $250 \mathrm{MW}(\mathrm{t})$ for a solid, cylindrical core geometry; however, this rating was projected to not be economically competitive for electric power generation. This led to the development of an annular core concept to enable larger cores with increased power capacity - currently up to $600 \mathrm{MW}(\mathrm{t})$. The annular core design was applied to both the pebble-bed core and to the prismatic core designs noted above. This work, combined with the extensive experience in gas-cooled reactor technology and fuel fabrication in the German plants, forms the basis for the current generation of HTGRs.

In 2001, the Generation IV International Forum, a 10-nation international assembly working together with DOE's Nuclear Energy Research Advisory Committee, agreed to proceed with the development of a technology roadmap and identify Generation IV nuclear reactor systems to "... develop future generation nuclear energy systems that can be licensed, constructed, and operated in a manner that will provide competitively priced and reliable energy products while satisfactorily addressing nuclear safety, waste, proliferation, and public perception concerns." 
Of the six alternative nuclear technologies recommended by the Generation IV International Forum, the very high temperature reactor (VHTR), is the nearest-term reactor (NGNP incorporates the VHTR technology) and the only reactor exceptionally suited for both high-efficiency electricity production and nuclear-assisted hydrogen production. In addition, the VHTR excels in achieving safety, even beyond design basis events, resulting in no significant fission product release from the core as passive cooling mechanisms prevent core melting.

In FY 2006, DOE initiated the NGNP Project at Idaho National Laboratory (INL), as directed by the Energy Policy Act of 2005 (EPAct). The objective of the NGNP Project is to commercialize HTGR technology for application in the United States and internationally. In FY 2007, preconceptual designs of pebble-bed and prismatic based plants were developed based on the prior work on the Pebble-bed Modular Reactor (PBMR) Demonstration Pilot Plant, the General Atomics Gas Turbine-Modular Helium Reactor (GT-MHR), and MHTGR and the AREVA Antares designs. These new plants were designed for production of electricity and hydrogen with reactor ratings that varied from 500 to $600 \mathrm{MW}(\mathrm{t})$ and reactor outlet temperatures of 900 to $950^{\circ} \mathrm{C}$. Subsequent to the preconceptual design work, significant interaction with potential industrial end users of the HTGR technology and completion of trade studies concluded that the NGNP should be viewed as a source of high-temperature process heat that can be used to meet the energy needs of industry in such forms as electricity, steam, high-temperature gas, hydrogen, and oxygen. This work has refined the configurations and operating conditions of the pebble-bed and prismatic reactor-based plants to ensure they meet the energy needs of industry. This report documents lessons learned from the progress and experiences of these prior gas-cooled reactors.

\subsection{Independent Technology Review Group}

A review of existing VHTR Technology was performed from November 2003 through April 2004 by a group of 26 subject matter experts and professionals in the nuclear industry, known as the Independent Technology Review Group. The purpose of the Independent Technology Review Group was to conduct a review of technology alternatives for meeting the functional objectives for the NGNP. The group members were broadly experienced in the design, construction, and operation of nuclear systems, representing a national and international perspective largely influenced by past experience with HTGRs. Their report, Design Features and Technology Uncertainties for the Next Generation Nuclear Plant, enumerated recommendations for the following areas: NGNP Fuel Development, NGNP Reactor Outlet Temperature, Power Conversion Concept, Hydrogen Production Capability, and Design Uncertainties. The recommendations are as follows: ${ }^{2}$

- Fabrication, testing, and qualification of coated-particle designs and manufacturing processes that have the most extensive worldwide experience base $\left(\mathrm{UO}_{2}\right.$ kernel) should be the initial focus.

- Acceptable fuel burnup of $10 \%$ fission per initial metal atom should be achieved.

- International collaboration for technology development should be considered, and when necessary, approved/accepted by the NRC.

- Both $\mathrm{UO}_{2}$ and UCO should be examined within the U.S. fuel program to determine which performed best in thermal hydraulics and neutronics.

- The reactor outlet temperature for the NGNP should be in the range of 900 to $950^{\circ} \mathrm{C}$ (This recommendation was later reduced to 750 to $800^{\circ} \mathrm{C}$ by the Senior Advisory Group).

- An indirect cycle power conversion concept fulfills the high-level functional objectives with reasonable development risk.

- The development of a high-temperature hydrogen production capability for the NGNP should be accelerated. 
- Equipment risks exist with the intermediate heat exchanger (IHX) and the hot gas valves that isolate the primary loop gases from secondary gases (associated with the power conversion system and/or the hydrogen production system).

- A comprehensive licensing strategy needs to be developed.

- Early buy-in by the various stakeholders, such as reactor suppliers, is imperative.

- NGNP design and development should involve collaboration with the international community.

- Credible cost estimates for the design, construction, and operation of the NGNP are needed.

\subsection{Energy Policy Act of 2005}

The NGNP project was formally established by EPAct 2005, designated as Public Law 109-58, 42 USC 16021. Under Section 641, the EPAct states, "The secretary shall establish a project to be known as the 'Next Generation Nuclear Plant Project'." It continues, "The Project shall consist of the research, development, design, construction, and operation of a prototype plant...." The EPAct resulted from the promising benefits of a high temperature reactor (HTR) in creating electricity and process heat for applications such as hydrogen production. The EPAct was largely influenced by the successes of past national and international reactors.

\subsection{Reactor Summary}

The HTGRs discussed in this report come in different sizes and designs. In the United States, for example, Peach Bottom was a small plant that used bistructural isotropic or buffer isotropic (BISO) fuel; FSV was a larger plant that used tristructural isotropic (TRISO) fuel. HTGRs have two different principle designs: pebble-bed, which is found in AVR and HTR-10, and the prismatic block, which is found in Peach Bottom, FSV, HTTR, and Dragon. Figure 2 shows a timeline of the history of HTGR technology and provides a perspective of HTGR technology prior to the formalized development of the NGNP Project. A more in-depth overview of the specification for these reactors and reactor designs can be found in Table 1 and in the subsections that follow. These can be used as a guide in comparing how applicable a reactor may be to NGNP. The prior experiences with HTGRs have demonstrated that the basic operations work and form the basis for NGNP to demonstrate process heat. 


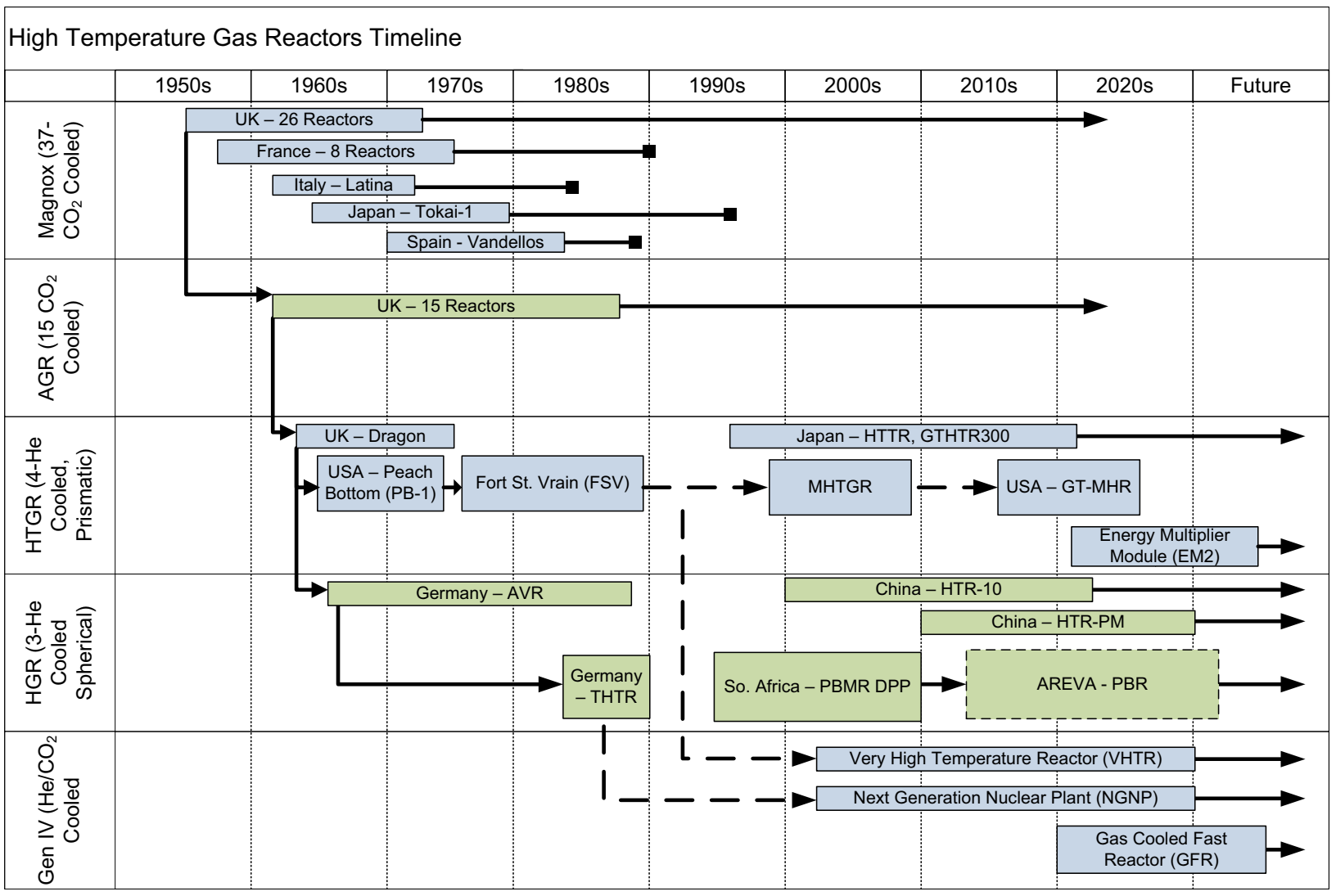

Figure 2. Timeline of HTGR technology. ${ }^{a}$

a. Magnox reactors are not directly applicable to NGNP. 


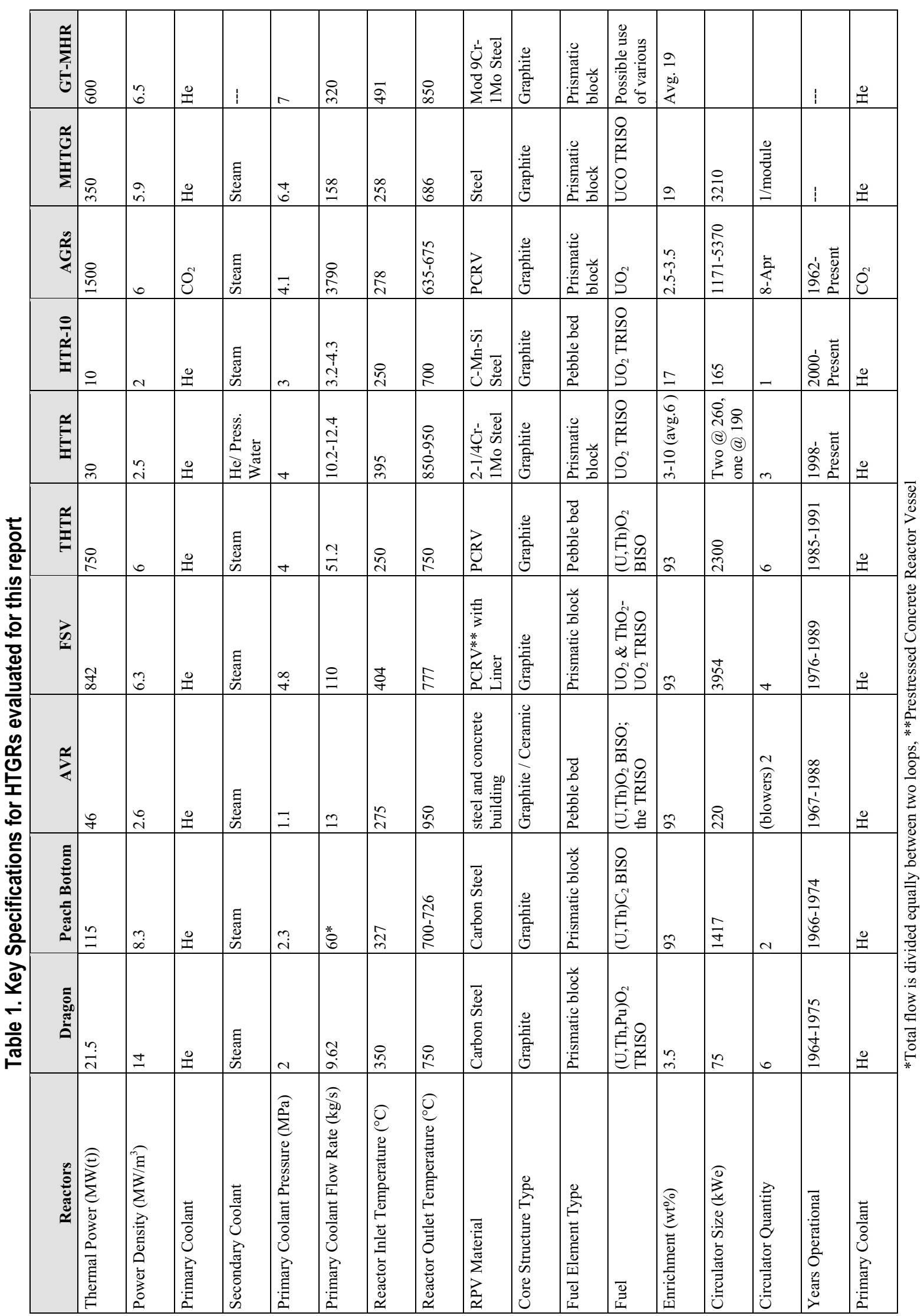




\subsubsection{Dragon (UK)}

The Dragon reactor was built to be a test reactor for the High Temperature Reactor (HTR) programs in Europe and was based in Winfrith, UK (see Figure 3). The Dragon Project was managed by the Organization for Economic Co-operation and Development and operated from 1964 to 1975. The main focus of the Dragon reactor was the testing of fuel, fuel elements, and structural materials. More specifically, new fuel coatings, design philosophy, and irradiation behaviors were tested. The Dragon reactor operated at $20 \mathrm{MW}(\mathrm{t})$ and used helium as a primary coolant with an inlet and outlet reactor temperature of $350^{\circ} \mathrm{C}$ and $750^{\circ} \mathrm{C}$, respectively. The core was of a prismatic block design. The fuel initially used was highly enriched uranium and thorium, but because of doubts about long-term availability, Dragon switched to low enriched uranium. Although designed for fuel testing, the Dragon reactor has lessons that may apply to NGNP, such as heat exchanger usage.

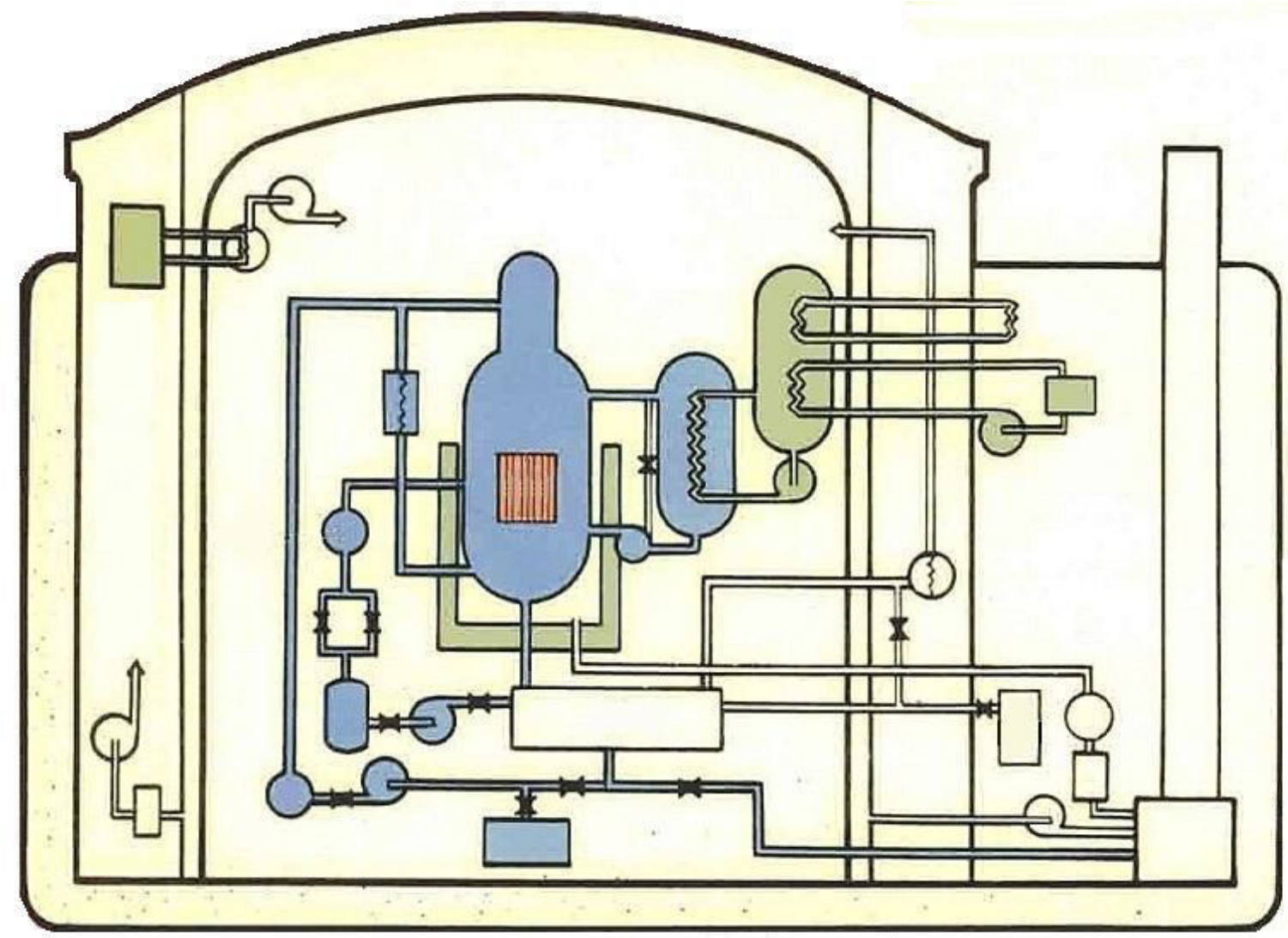

Figure 3. Dragon reactor diagram.

\subsubsection{Peach Bottom Unit 1 (United States)}

Peach Bottom Unit 1 was built a few years after Dragon and was the first HTGR built in the United States. ${ }^{3}$ The reactor was owned and operated by Philadelphia Electric Company, and remained operational from March 3, 1966, to October 31, 1974. ${ }^{4}$ Peach Bottom was closed because it completed its demonstration mission and was considered uneconomical because of its small size. A flow diagram of Peach Bottom Unit 1 is shown in Figure 4. 


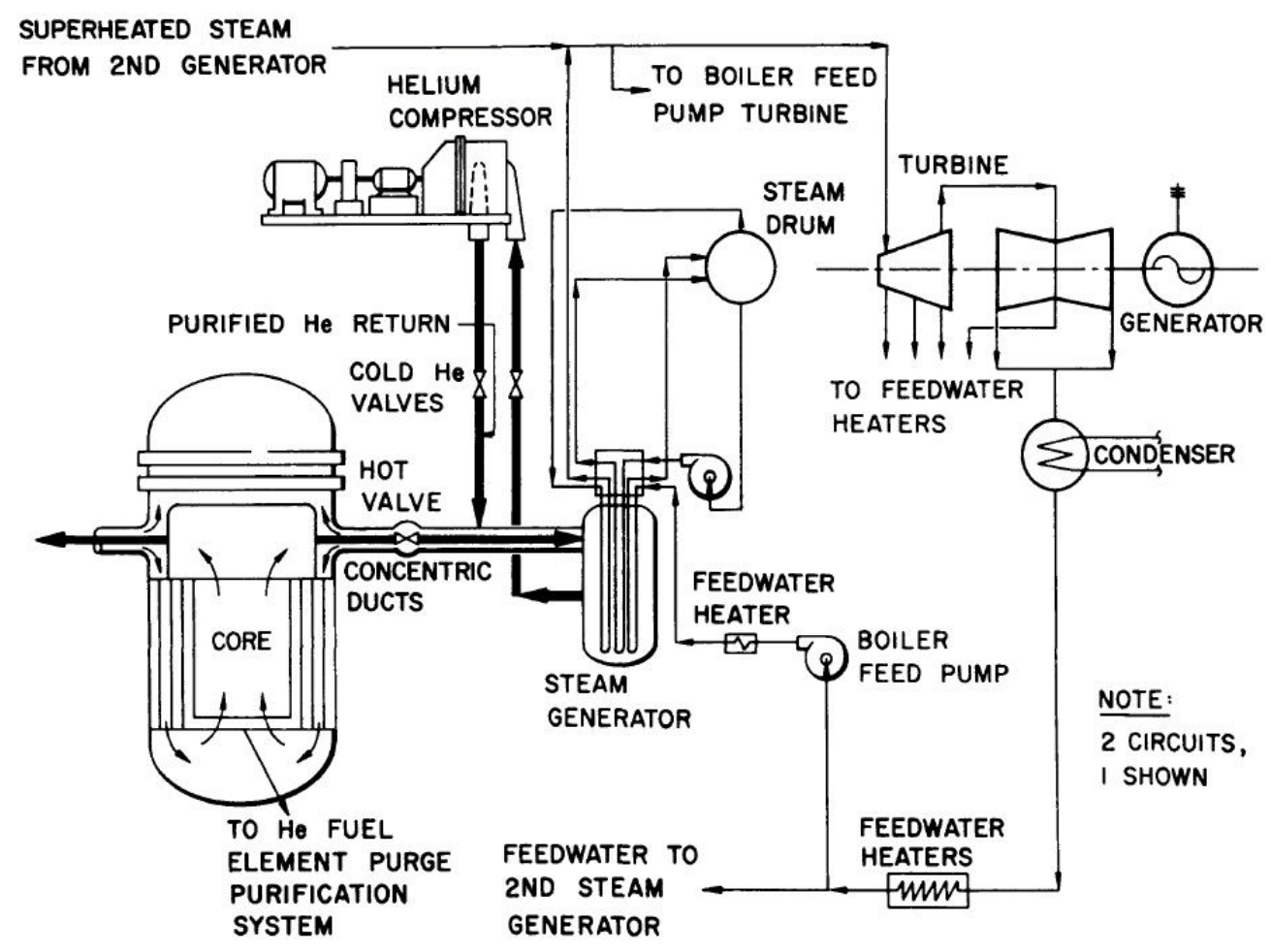

Figure 4. Flow diagram of Peach Bottom's primary circuit. ${ }^{5}$

The reactor was able to produce $115 \mathrm{MW}(\mathrm{t})$ and equivalent of $40 \mathrm{MW}(\mathrm{e})$. It used helium as its primary coolant, which entered and exited the reactor at $327^{\circ} \mathrm{C}$ and $700^{\circ} \mathrm{C}$, respectively. The fuel kernels, originally coated with one layer of pyrolitic carbon $(\mathrm{PyC})$, were prismatic and used uranium and thorium carbides as fuel. After running for some time, the reactor activity would continually increase because of failure of the fuel coating. The fuel was replaced with BISO fuel, which has an inner layer that acts as a buffer from recoiling fission products and an outer layer to retain the noble fission gasses. BISO worked well at Peach Bottom but had shortcomings at higher temperatures. A layer of silicon carbide (SiC) was later added to the fuel coatings, now called TRISO fuel, which lead to the use as fuel in FSV and showed much improved fission product retention. This improvement also led to the abandonment of the purge-gas system needed for BISO-fueled reactors, such as Peach Bottom. Peach Bottom provided several lessons that may be applied to NGNP, such as oil ingress from the circulators. ${ }^{5}$

\subsubsection{Arbeitsgemeinschaft Versuchsreaktor (Germany)}

Arbeitsgemeinschaft Versuchsreaktor (AVR) was one of the first nuclear reactors in the Federal Republic of Germany (FRG). AVR was constructed as an experimental power station for pebble-bed reactors with an additional purpose of testing fuels. AVR was located at Jülich Research Center and remained operational for approximately 20 years, from 1967 to 1988. Figure 5 shows a diagram of the AVR. AVR was able to produce $46 \mathrm{MW}(\mathrm{t})$ and equivalent of $15 \mathrm{MW}(\mathrm{e})$, and used helium as a primary coolant. The temperatures for the helium entering and exiting the reactor are $275^{\circ} \mathrm{C}$ and $950^{\circ} \mathrm{C}$, respectively. The fuel used was uranium and thorium oxides with a BISO coating. One of AVR's larger issues seems to be graphite dust, which may apply to the pebble bed version of NGNP. ${ }^{6}$ 


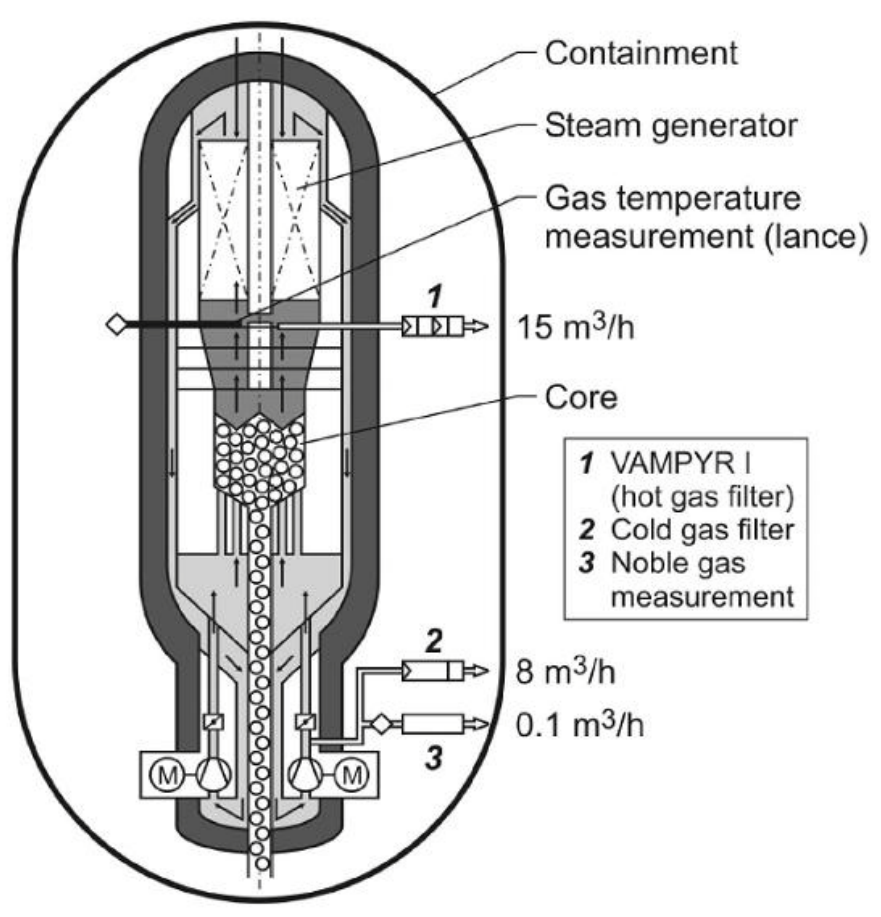

Figure 5. AVR basic diagram.

\subsubsection{Fort St. Vrain Reactor (United States)}

The reactor at Fort St. Vrain (FSV) was an HTGR designed by General Atomics that used Peach Bottom as a basis for the design. The plant was part of the U.S. Atomic Energy Commission Power Reactor Demonstration Program and was operated by Public Service of Colorado at Platteville, CO. The FSV reactor was operational from 1974 to 1989. A diagram of FSV's plant layout is shown in Figure 6. The reactor operated at $842 \mathrm{MW}(\mathrm{t})$ and output $330 \mathrm{MW}(\mathrm{e})$ of electricity. High-temperature helium was used as the primary coolant to produce superheated and reheated steam at approximately $538^{\circ} \mathrm{C}$. The helium entered the reactor at $404^{\circ} \mathrm{C}$ and left the reactor to the steam generator at $777^{\circ} \mathrm{C}$. The reactor was contained within a PCRV and used a prismatic block design for the fuel elements. The fuel used was a mixture of carbides of uranium and thorium with TRISO coatings. FSV had several mechanical issues and lessons that apply to NGNP, such as the helium circulator water-lubricated bearings and reactivity control balls sticking together. ${ }^{7}$

Many of the lessons learned from the FSV reactor come from NUREG/CR-6839 in which Oak Ridge National Laboratory (ORNL) performed continuous operational experience studies of FSV for the NRC Office for Analysis and Evaluation of Operational Data from 1981 through 1989. FSV submitted monthly licensee event reports to NRC describing operational events. These events were screened for only the events that were significant to plant safety and were subsequently reported in NUREG/CR-6839.

In 1989, the Electric Power Research Institute requested a summary from Public Service Company of Colorado on the operating experience of Fort St. Vrain. ${ }^{8}$ The summary was delivered to the requestor in February 1990. The report findings align with all other reference experiences at FSV. 


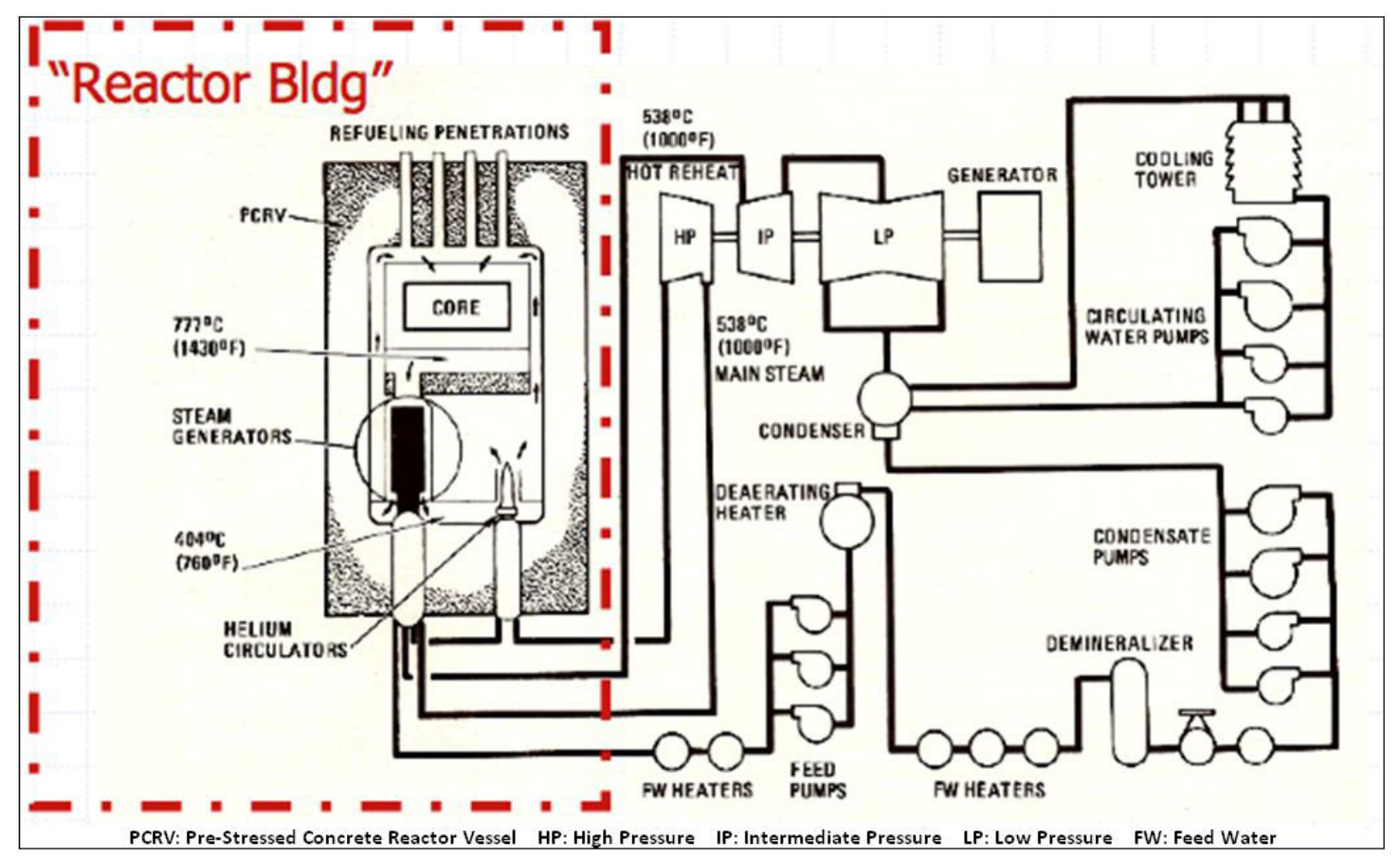

Figure 6. Basic FSV plant layout schematic.

\subsubsection{Thorium Hocktemperatur Reaktor (Germany)}

The THTR power plant was sponsored by the FRG and Nordrhein Westfalen. Plant construction began in 1971 but, primarily because of changing licensing requirements, was not completed until 1984. This pebble-bed reactor plant was connected to the electrical grid of the Hochtemperatur-Kernkraftwerk GmbH (HKG) utility in November 1985. In August 1989, the decision was made to permanently shut down the THTR for sociopolitical reasons, not because of technical difficulties associated with the plant. These sociopolitical reasons were enacted by an application by HKG for early decommissioning based on a projected shortfall in funding and contractual changes in the allocation of decommissioning costs between the FRG, Nordrhein Westfalen, and HKG that would take effect upon the termination of the demonstration phase in 1991. Figure 7 shows a diagram of THTR, which had a power output of 750 $\mathrm{MW}(\mathrm{t})$ or an equivalent of $300 \mathrm{MW}(\mathrm{e})$, and used helium as a primary coolant. The helium entered the reactor at $250^{\circ} \mathrm{C}$ and left the reactor at $750^{\circ} \mathrm{C}$. The reactor vessel was a PCRV, and the fuel particles used were uranium and thorium oxides. THTR demonstrated inherent safety features of HTGRs, including core and plant transient data, which are applicable to the NGNP. ${ }^{9}$

\subsubsection{High Temperature Test Reactor (Japan)}

The HTTR, the first HTGR in Japan, was constructed at the Oarai Research Establishment of the Japan Atomic Energy Research Institute. The HTTR was built to establish and improve HTGR technologies and the use of nuclear heat. The reactor first reached criticality in November 1998 and reached full power of $30 \mathrm{MW}(\mathrm{t})$ in December 2001. Figure 8 shows the basic HTTR plant layout. Helium is used as the coolant in the primary loop. The helium enters the reactor from the IHX at approximately $400^{\circ} \mathrm{C}$. The temperature of the helium exiting the reactor is $850^{\circ} \mathrm{C}$ but can go as high as $950^{\circ} \mathrm{C}$. The reactor core uses prismatic fuel elements and TRISO-coated $\mathrm{UO}_{2}$ (uranium oxide) fuel particles. HTTR is useful to NGNP because of its current operation and high-temperature capabilities. A few concerns, such as temperature anomalies, can be considered as lessons learned for NGNP. ${ }^{10}$ Graphite oxidation was a 
concern at HTTR during the design (but never an operational problem) and should be an issue considered in NGNP design.

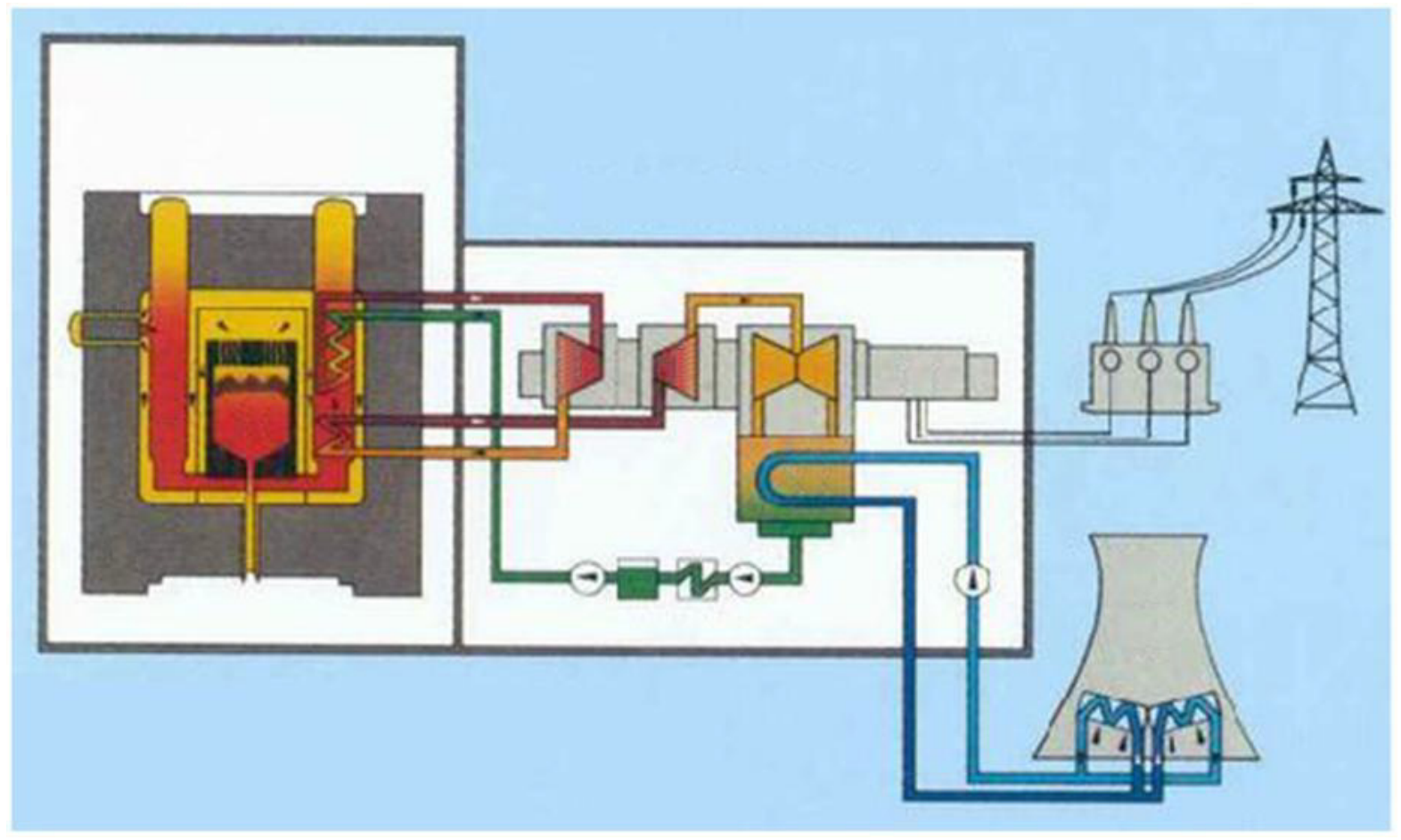

Figure 7. THTR simplified plant layout diagram.

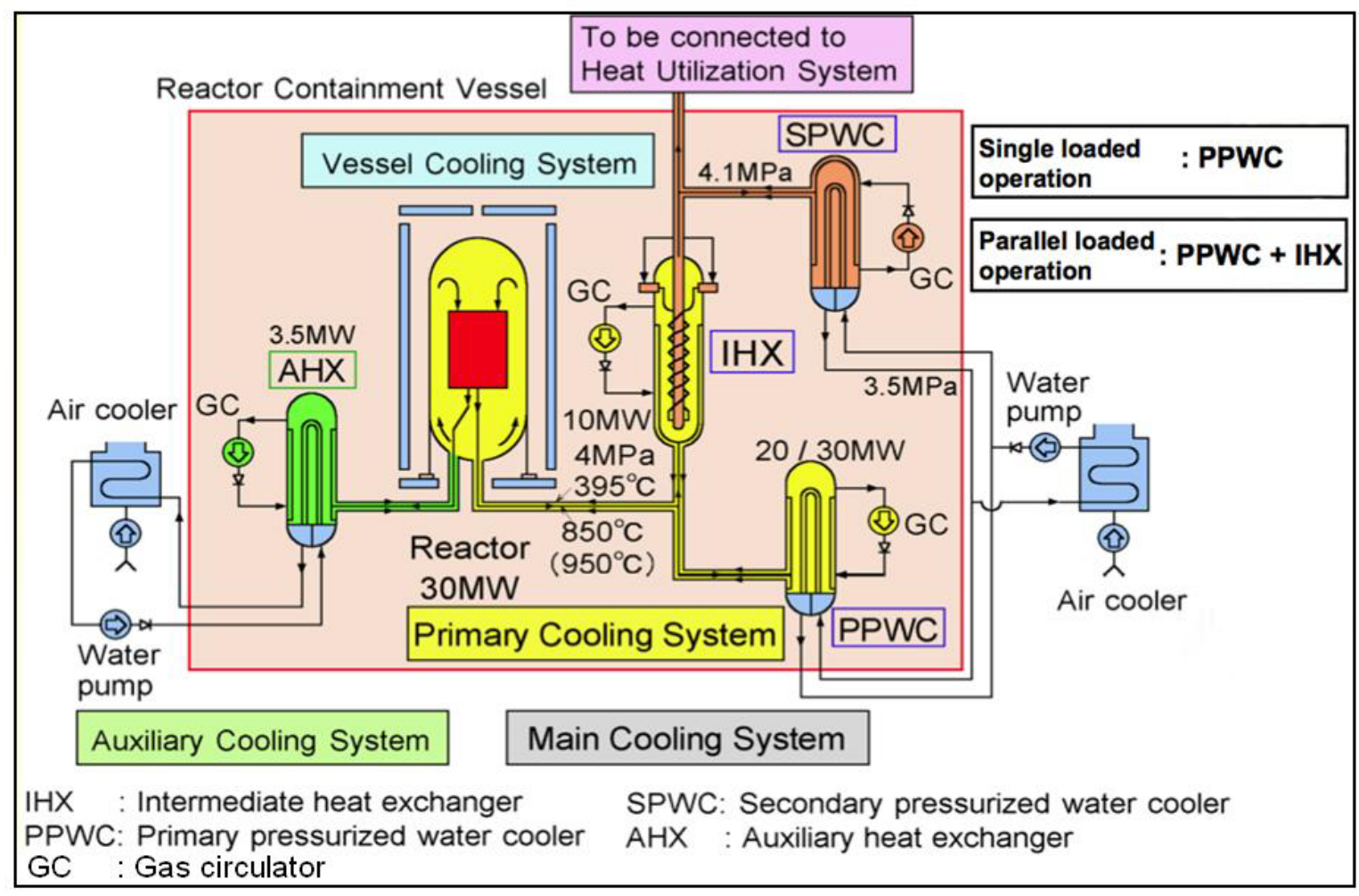

Figure 8. Basic HTTR plant layout schematic. 


\subsubsection{0-MW High Temperature Reactor (People's Republic of China)}

The HTR-10 was designed and constructed by the Institute of Nuclear and New Energy Technology in China as a test reactor to further test HTGRs and demonstrate electric power generation. It was the first HTGR built at Tsinghua University. The reactor first went critical in 2000 and produced full power in 2003. The reactor is currently operating at $10 \mathrm{MW}(\mathrm{t}) .{ }^{11}$ A photo of the HTR-10 core is shown in Figure 9, and a diagram of the primary circuit is shown in Figure 10. The helium inlet and outlet temperatures from the core are $250^{\circ} \mathrm{C}$ and $700^{\circ} \mathrm{C}$, respectively. The HTR- 10 core is of a pebble-bed design that uses $\mathrm{UO}_{2}$ with a TRISO coating for fuel particles. ${ }^{12}$ HTR-10 has been faced with issues, such as China not having a licensing basis for HTGRs, which may provide lessons to NGNP, in conjunction with the experiences from the FSV reactor and Peach Bottom.

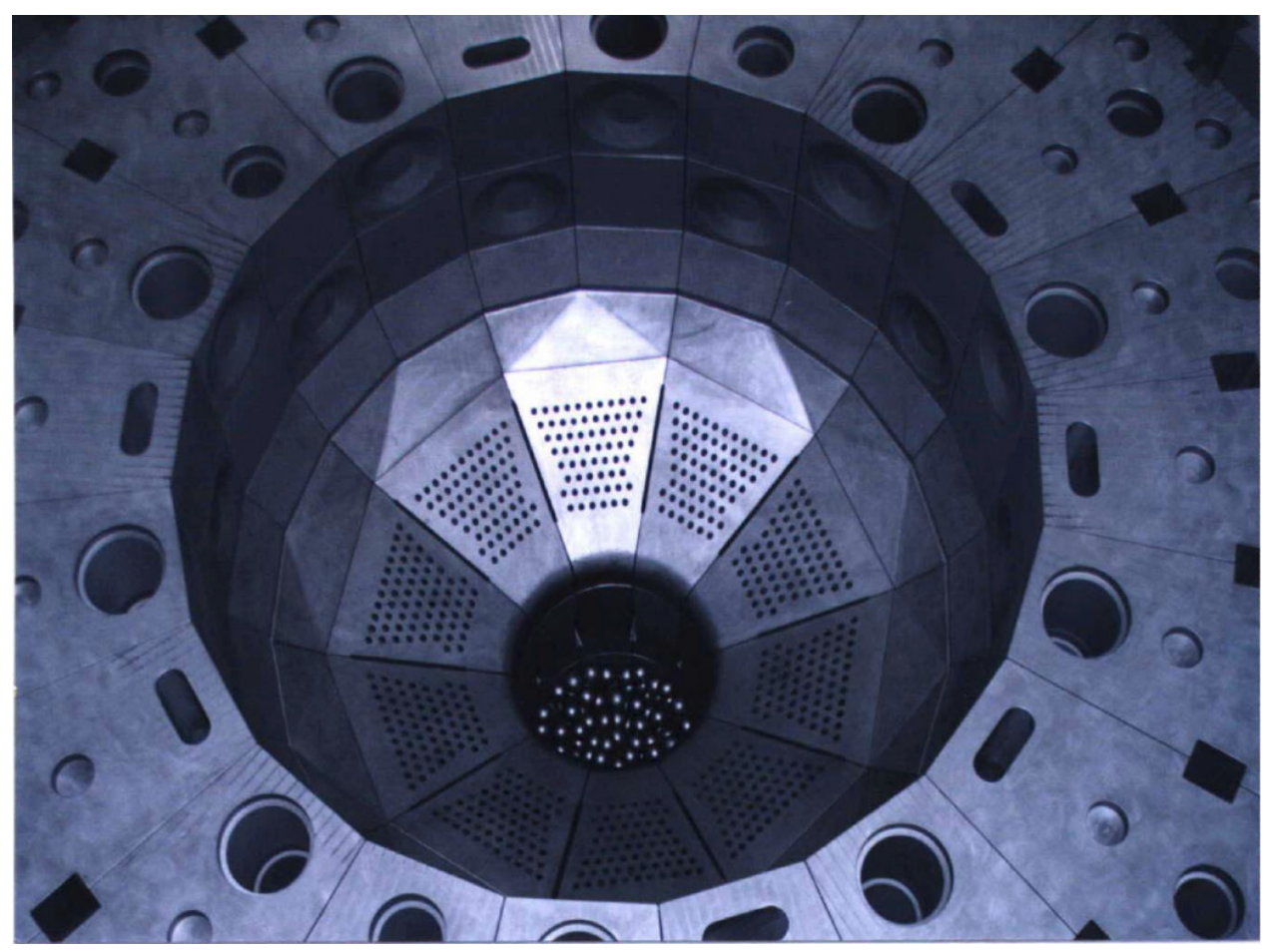

Figure 9. Core of HTR-10. ${ }^{13}$ 


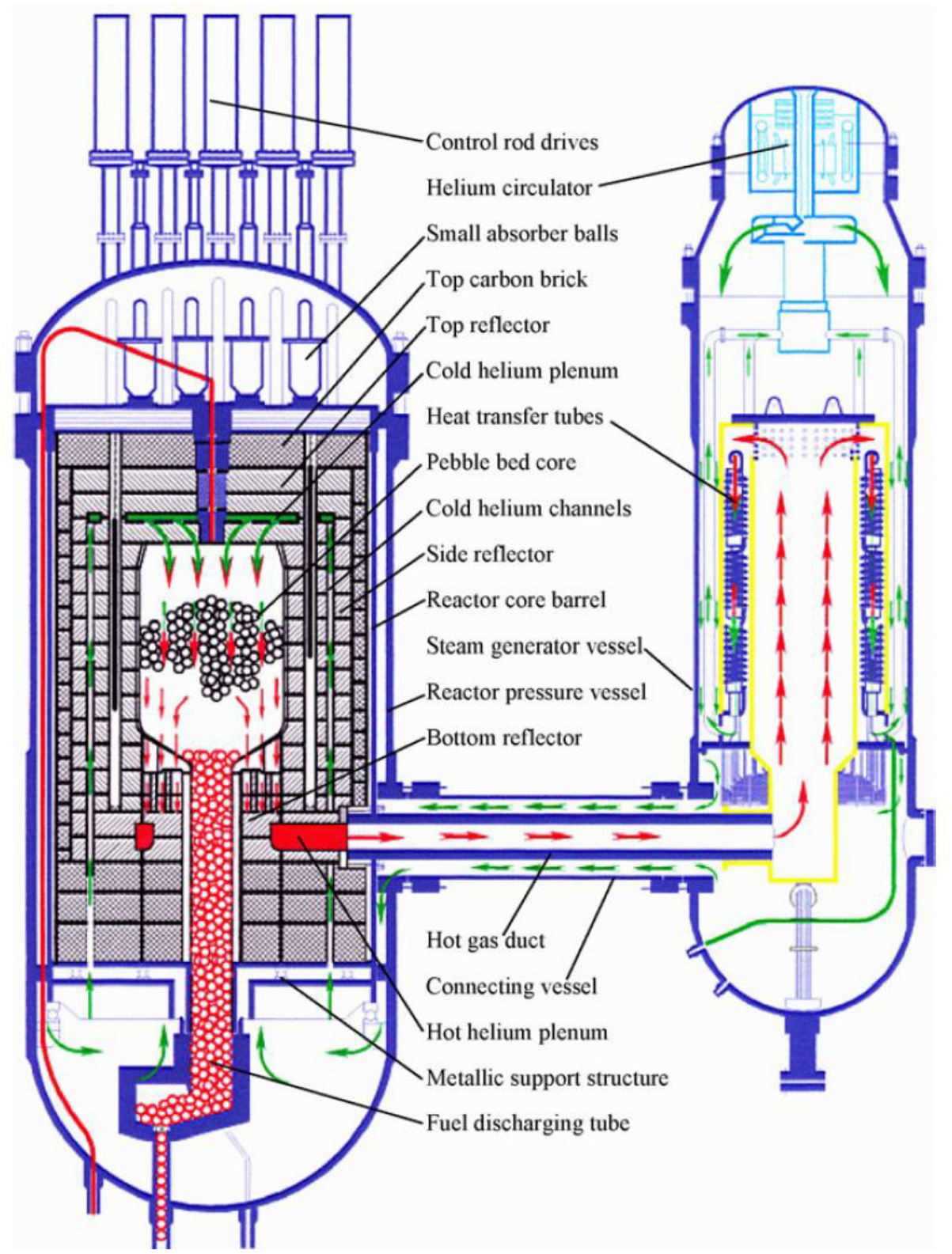

Figure 10. HTR-10 reactor pressure vessel (RPV) and steam generator pressure vessel (SGPV) layout. ${ }^{14}$

\subsubsection{Advanced Gas-Cooled Reactors (UK)}

The Advanced Gas-cooled Reactor (AGR) was a fleet of reactors built in the UK, similar to Magnox $^{15}$ (see Figure 11). The prototype for AGR was built at Windscale in 1962 and produced 32 MW(e). The rest of the 14 reactors, built in the 1970s and 1980s, generated approximately $600 \mathrm{MW}(\mathrm{e})$ per reactor. Like Magnox, the AGRs used $\mathrm{CO}_{2}$ as a primary coolant and had reactor inlet and outlet temperature of $280^{\circ} \mathrm{C}$ and $675^{\circ} \mathrm{C}$, respectively. The AGRs used a prismatic core that was loaded with uranium. "Although [the AGR and Magnox] pioneering programs have now concluded, experience from the over 1,000 reactor-years of operation comprises a very valuable database for ongoing development and design programs on higher temperature gas cooled reactors." 16 


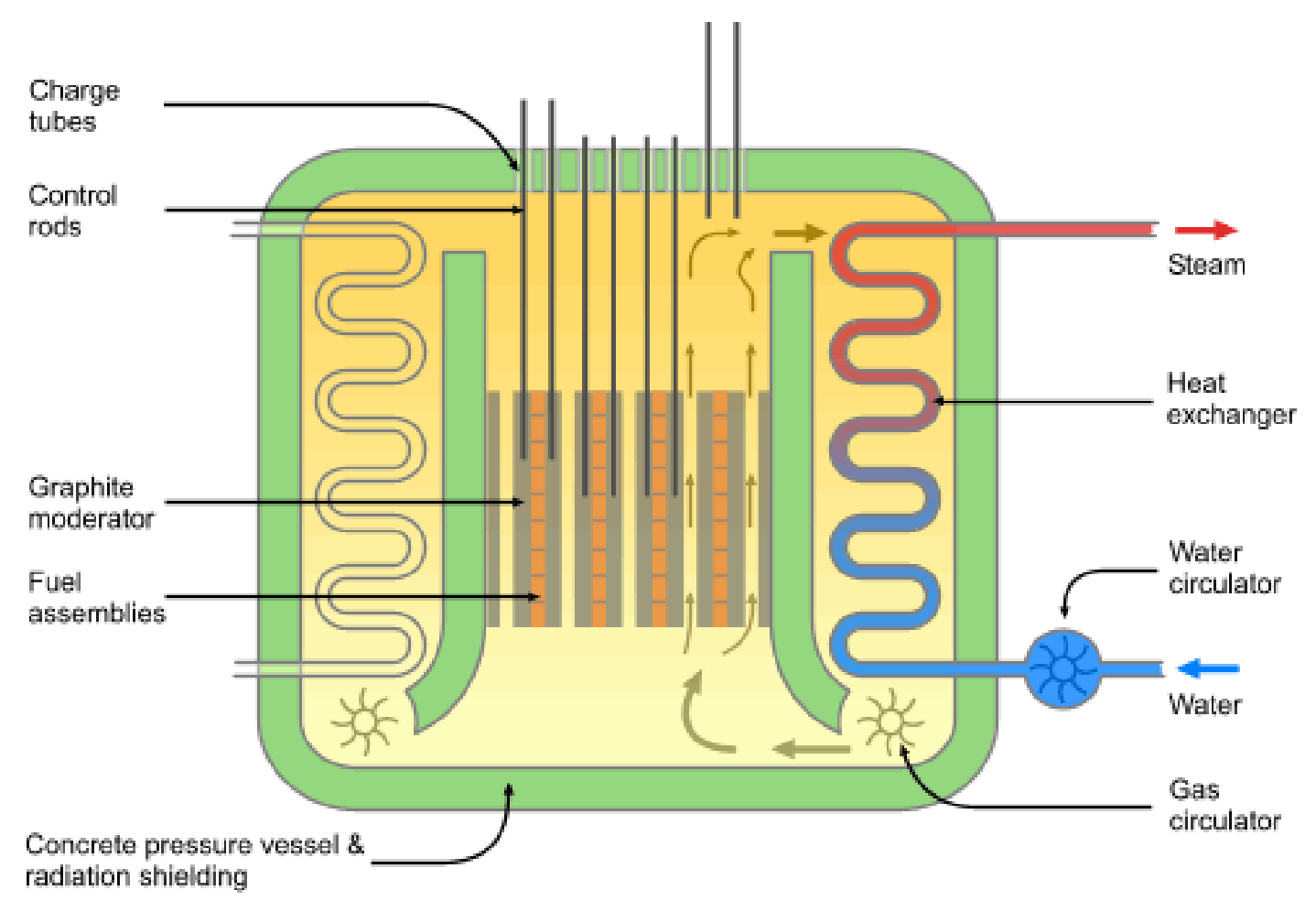

Figure 11. Advanced gas-cooled reactor design.

\subsubsection{Modular High-Temperature Gas-Cooled Reactor (United States)}

The Modular High-Temperature Gas-cooled Reactor (MHTGR) was designed to have inherent, passive safety features and was meant to be competitive with light water reactors (LWRs) and fossil fuels. Its design takes advantage of the decades of development and experience from the design, licensing, and operation of previous HTGRs. The MHTGR was also designed to have the ability to prove system concepts, such as direct power generation from a gas turbine or high temperature heat for processing. DOE submitted a PSID for the MHTGR in 1986. There have been several MHTGR designs in the past, including New Production Reactor (NPR) and GT-MHR. The GT-MHR is further discussed in Section 1.4.10. ${ }^{17}$

The MHTGR was one of the designs pursued for the NPR. The project began in 1988 and ended in 1993, shortly after conceptual design was complete. ${ }^{18}$ In summary, "The MHTGR-NPR plant consisted of eight $350 \mathrm{MW}(\mathrm{t})$ reactor modules installed as two 4-module production blocks with the associated auxiliary systems and services necessary to manufacture, handle, irradiate, and process driver fuel and tritium producing targets." The NPR conceptual design also incorporated the generation of electricity as a byproduct. The core design was going to be a prismatic block and loaded with TRISO-coated, high-enriched uranium fuel. ${ }^{19}$

\subsubsection{Gas Turbine-Modular Helium Reactor (United States)}

The Gas Turbine-Modular Helium Reactor (GT-MHR) is a commercial reactor design by General Atomics, with partial sponsorship by the National Nuclear Security Administration. It is designed to generate power with a gas turbine instead of a steam generator. According to Shropshire and Herring, "The GT-MHR development was refocused as a burner of plutonium coming from dismantled nuclear 
weapons." 20 The reactor is considered to be passively safe and have a compact operating system. The design is a prismatic block that is directly coupled to a Brayton cycle turbine generator. One of the passive safety features is that the decay heat will dissipate via conduction and radiation without reaching a temperature that damages the fuel particles coating. The GT-MHR uses a prismatic core design with helium as the coolant. Helium is used because it is a neutronically and chemically inert gas with relatively good heat transfer and heat transport properties. The power conversion system is made up of a generator, turbine, and two compressor sections mounted on a single shaft bearing. ${ }^{21}$ The GT-MHR and gas turbine design is shown in Figure 12.

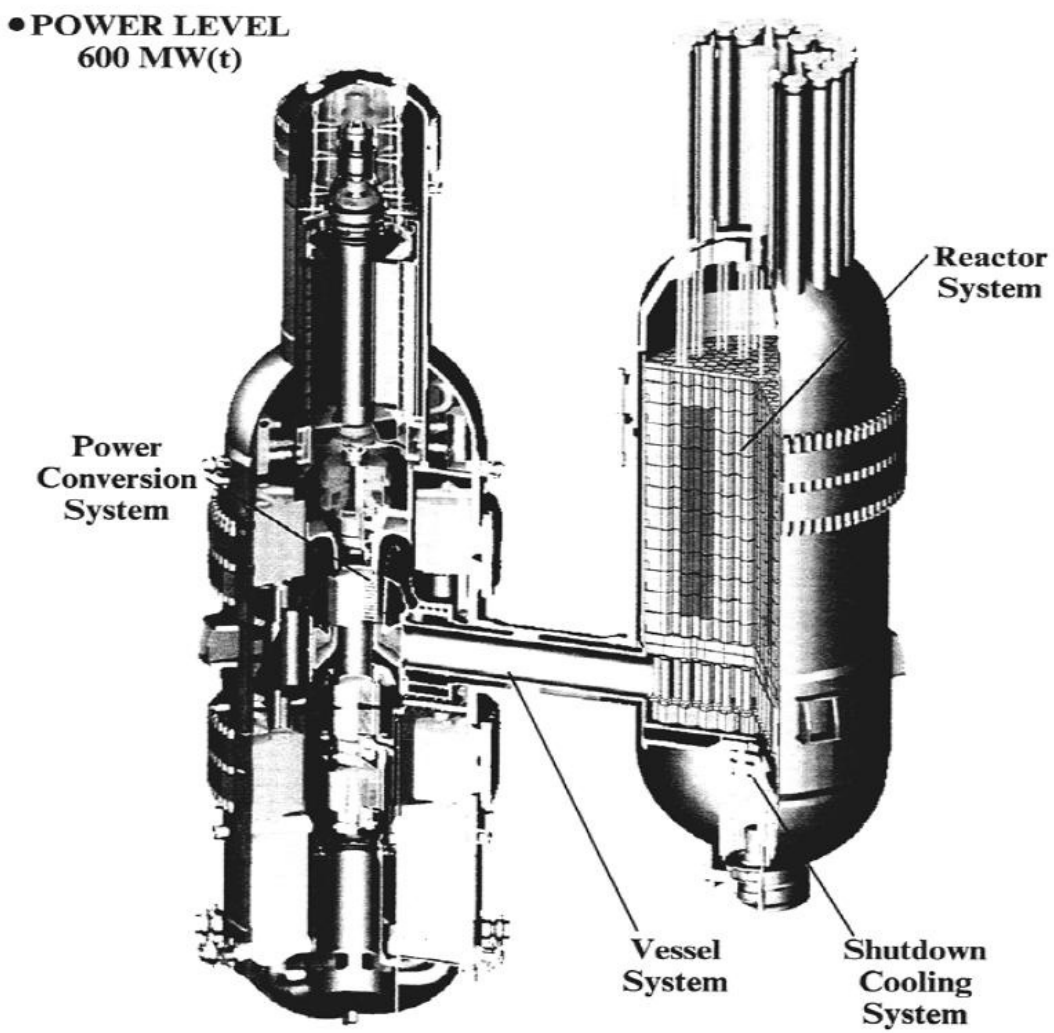

Figure 12. GT-MHR reactor and gas-turbine..$^{22}$ 


\section{NUCLEAR HEAT SUPPLY SYSTEM}

\subsection{Reactor Pressure Vessel}

\subsubsection{Insulation and Moisture Issues (FSV)}

Water at the FSV reactor was inadvertently injected into the primary system through the circulator bearings. The moisture tended to be absorbed into the PCRV insulation (Kaowool: a ceramic fiber blanket material) adjoining the circulator. Desorption of water from the insulation and into the primary coolant helium was usually the longest activity during moisture clean up. ${ }^{7}$ The Kaowool also out-gassed moisture that was entrained in the insulation during shutdown. Water trapped in the PCRV liner is another potential source of moisture ingress into the helium during startup because of small cracks in the weld; they would seal up because of thermal expansion when exposed to high power. ${ }^{7}$

Lessons Learned: Water from the circulator bearings in FSV was a source of moisture ingress into the primary system. Some of this moisture was absorbed by insulation or small cracks in welds. This moisture was then released later during various reactor operations. The NGNP project should learn from this experience and take water ingress, including moisture absorption and desorption into consideration in the NGNP design of RPV components.

\subsubsection{The Sealing and Flanges of the RPV (HTR-10)}

The RPV for HTR-10 is an important part used to prevent the leaking of helium from the reactor core. As stated by $\mathrm{Yu}$, et al., 2002, the importance is "...therefore the pressure vessel flanges are the key structures that must very reliably seal as well as meet the reactor strength requirements during the pretightening and pressurizing conditions." The sealing behavior is affected by the form of the sealing structure and the size of the flange and head closer. "HTR-10 flanges can use a welded $\Omega$-ring to seal the pressure vessel as well as a metallic O-ring, which is a unique sealing advantage for pebble-bed HTGRs over other nuclear reactors." 23

The sealing of HTR-10 relies on the O-ring. Yu continues, "If the rebounding distance of the O-ring is smaller than the opening of the flange seal surface, the O-ring will lose its sealing ability." Leaking can also occur from damage to the O-ring if the radial shaft is too large. A second defense to these leaks is the welded $\Omega$-ring; however, the plastic deformation is large enough to affect the sealing behavior of the flanges. A study showed that increasing the height of the flange and the closer head thickness would help reduce the deformation in the flanges. ${ }^{23}$

Lessons Learned: HTR-10 is significantly smaller than the proposed NGNP and not directly applicable to it; however, the O-rings could be a potential source of leakage, and the flanges should be designed to ensure minimal leakage will occur. Seal welding is also an option. If NGNP reactor designs do not require removing vessel heads for routine refueling or other evolutions, this type of seal welding would be a good option to consider. O-rings are applicable to both pebble-bed and prismatic reactor designs associated with the NGNP. It would be beneficial to NGNP operations to determine during the design process the best method to replace graphite reflectors.

\subsubsection{RPV Cooling Design (Dragon)}

The RPV for the Dragon reactor was "a long, bottle-shaped steel construction divided vertically into two parts by the main shield plug." The pressure-bearing walls of the RPV were not to come into contact with the hot helium. Dragon was then designed so that the cool helium from the heat exchangers is used to keep the RPV from overheating. In the case of a complete power failure the reactor would trip and only the latent heat and decay heat would have to be removed. The natural convection flow amounted to about 
$3 \%$ of the full circulator flow, which was enough to keep the RVP below maximum design temperatures. ${ }^{24}$ Additionally, having the core barrel in the reactor pressure vessel (RPV) and a shroud in the steam generator to direct the flow of the lower temperature coolant against the pressure boundary is well understood and was incorporated into the designs for MHTGR and PBMR.

Lessons Learned: NGNP design would benefit by directing the flow of the hot and cool gas, similar to the Dragon reactor, to ensure that pressure-bearing walls do not over heat. This strategy has already been incorporated into the HTGR designs that are under consideration for the NGNP.

\subsection{Reactor Vessel Internals}

\subsubsection{Temperature Rise in Core Support Plate (HTTR)}

During a power rise test, the core support plate showed an unexpected temperature rise. Since it was impossible to repair the reactor internal structure, temperature and integrity evaluations were carried out to confirm the integrity of the core support plate. ${ }^{25}$

In the core support structures, there are many gaps between graphite blocks. To reduce the helium leakage flow in the gaps, called bypass flow, seal elements are placed on the gaps. Almost all helium flows from the hot plenum into the hot gas duct; however, pressure drop between the hot plenum and inside of the hot gas duct causes a small amount of helium to flow into gaps between graphite blocks from the hot plenum. In the HTTR, the bypass flow became large because of the large driving force of bypass flow caused by the much larger core flow rate. Reevaluations of the core support plate temperature were carried out considering the effect of bypass flow.

In the temperature rise of the core support plate, temperature analyses were carried out considering the bypass flow in the core support structures. From the reevaluation, the core support plate's temperature at $30 \mathrm{MW}$ was estimated and the design temperature was revised. Core support plate at that power level showed good agreement with the reevaluation results and were below the revised design temperature.

Lessons Learned: Bypass flow for HTGRs should be considered, and the information will be helpful for future HTGR designs. Bypass flow is part of the core design for both NGNP reactor designs (but with different behaviors). Also, the ability to determine the cause of temperature fluctuations would be of use to NGNP.

\subsubsection{Flow Induced Vibrations (AGR)}

The $\mathrm{CO}_{2}$ coolant in the AGR created severe problems that are difficult to detect with out-of-pile loops. These problems are highlighted in Table 2 and can still happen with helium as a coolant, though the forces are much smaller than in $\mathrm{CO}_{2}$ at similar velocities. ${ }^{26}$ These problems are from flow induced vibrations driven by highly energized gas flow that contacts a relatively flexible structure, such as reactor internals or heat exchanger tubes. These problems may also occur in cross flows of closely spaced arrays of tubes, leaving them damaged. If not designed correctly, flow induced vibrations can cause the structures to become more flexible. The phenomena that are induced by time are not dependent on structural vibrations but are dependent on naturally occurring eddies; other phenomena, on the other hand, are dependent on the position and velocity of the structure. The problems from these phenomena should still be considered in future designs.

These problems are from flow induced vibrations driven by highly energized gas flow that contacts a relatively flexible structure, such as reactor internals or heat exchanger tubes. These problems may also occur in cross flows of closely spaced arrays of tubes, leaving them damaged. If not designed correctly, flow induced vibrations can cause the structures to become more flexible. The phenomena that are 
induced by time are not dependent on structural vibrations but are dependent on naturally occurring eddies; other phenomena, on the other hand, are dependent on the position and velocity of the structure. The problems from these phenomena should still be considered in future designs. ${ }^{27}$

Table 2. Classification of flow-induced vibrations.

\begin{tabular}{|l|l|l|}
\hline \multicolumn{1}{|c|}{ Phenomena } & \multicolumn{1}{|c|}{$\begin{array}{c}\text { Instantaneous Fluid Forces is } \\
\text { Explicitly Dependent On }\end{array}$} & \multicolumn{1}{c|}{$\begin{array}{c}\text { Systems Subject to the } \\
\text { phenomena }\end{array}$} \\
\hline $\begin{array}{l}\text { Vortex-induced structural } \\
\text { vibration }\end{array}$ & $\begin{array}{l}\text { Time; amplitude of structural } \\
\text { vibration }\end{array}$ & $\begin{array}{l}\text { Slender bluff structures in a cross- } \\
\text { flow }\end{array}$ \\
\hline Galloping and flutter & $\begin{array}{l}\text { Translation velocity of structure; } \\
\text { rotation of structure; rate of rotation } \\
\text { of structure }\end{array}$ & $\begin{array}{l}\text { Slender structures in a cross flow; } \\
\text { tubing, plates, and shells in a } \\
\text { parallel flow (rare) }\end{array}$ \\
\hline Whirling & $\begin{array}{l}\text { Position of one tube relative to } \\
\text { adjacent tubes }\end{array}$ & $\begin{array}{l}\text { Closely spaced tube array in a } \\
\text { cross flow }\end{array}$ \\
\hline Turbulence-induced vibration & Time (random) & $\begin{array}{l}\text { Any structure subject to turbulent } \\
\text { flow }\end{array}$ \\
\hline $\begin{array}{l}\text { Vortex-induced acoustic } \\
\text { vibration }\end{array}$ & Time & $\begin{array}{l}\text { Acoustic cavities containing bluff } \\
\text { structures in a cross flow }\end{array}$ \\
\hline
\end{tabular}

Acoustic vibrations, another form of flow induced vibrations, are defined as "a disturbance that causes fluctuation in pressure to propagate at the speed of sound through an unbound gas." The acoustic wave travels at the speed of sound, but the flow of the coolant will augment the speed of sound. "However, since the speed of sound is much greater than typical flow velocities through the reactor, the shift in the speed of travel of an acoustic wave from the speed of sound is usually insignificant in a helium-cooled reactor." The sound waves are reflected from rigid walls where the density of the wall material multiplied by the speed of sound in the wall is much greater than the corresponding value in the gas. The sound wave can interact with and transfer energy to the wall and back again into the circuit. ${ }^{27}$

Lessons Learned: Both the PSID ${ }^{28}$ and Preapplication Safety Evaluation Reports ${ }^{29}$ for the MHTGR address this issue and are applicable to NGNP. These reports mention that flow induced vibrations could potentially affect the safe operation and shutdown of the reactor. As such, it would be beneficial to measure flow-induced vibration using scaled demonstrations and flow models. Similarly, NGNP will undergo analysis and scaled testing of the internals.

\subsection{Reactor Core and Core Structures}

\subsubsection{Moisture Ingress Issues (FSV)}

Moisture ingress can cause hydrolysis of the fuel particle with exposed kernels resulting in a fuel failure and subsequent release of fission products. Moisture was also found to cause hydrolysis and corrosion of the $\mathrm{PGX}^{\mathrm{TM}}$ (a product available from GrafTech International) graphite core support post. ${ }^{7}$ One source of moisture ingress - especially prevalent at FSV - is the moisture out-gassing that occurs when the graphite is heated up and a so-called "drying out" of the graphite takes place. This issue proved not to be a safety concern; rather, it was primarily a plant availability issue.

The moisture challenges FSV battled for years did not, however, originate from the steam generators. The water-lubricated bearings of the helium circulators were another source of the moisture ingress problems. Moisture removal was impeded because of the lack of a reactor drain. ${ }^{7}$ 
Lessons Learned: Graphite may contain residual moisture prior to operations. For NGNP, it would be beneficial to allow the graphite the necessary time in ascent to power before running the plant to maximize moisture out-gassing. Water from the circulator bearings in FSV was a source of moisture ingress into the primary system. However, current proposed NGNP designs do not include water cooled circulator bearings. Additionally, consideration should be given to adding a drain to the RPV or helium purification system to facilitate moisture removal in the event of moisture ingress.

\subsubsection{Helium Pressurization Line (FSV)}

Several helium pressurizing lines became plugged because of corrosion. The helium pressurizing lines were connected to the refueling interspace and to the control rod drive mechanisms located in refueling penetrations. Corrosion was caused by moisture in contact with the carbon steel piping and collected at the interface between the three-quarter-inch supply line and one-eighth-inch inlet line. ${ }^{7}$

Lessons Learned: NGNP designs would benefit by avoiding the use of carbon steel to reduce corrosion to vital pressurized lines resulting from moisture contact and other corrosion mechanisms. It is advised that NGNP evaluate all components susceptible to moisture, and design with materials that have corrosion resistance in a relevant environment. Also, compliance with ASME codes will require use of appropriate materials for the NGNP design.

\subsubsection{Core Temperature Fluctuations (FSV)}

In November 1977, FSV experienced some dynamics to the power levels and small fluctuations of temperature. The small periodic fluctuations in core region outlet gas temperatures and steam generator module inlet helium temperatures became a major problem. During nearly $2-1 / 2$ years of operation, following the detection of fluctuations, 37 fluctuation events were observed under a variety of core conditions at power levels between 30 and $70 \%$. Over this period, the plant spent about 100 hours in the fluctuating mode. Test data showed that these fluctuations were not caused by nuclear instabilities, although the core nuclear behavior was responding to fluctuations. Further, core pressure drop was identified as an important operating parameter. A fluctuation threshold line was established (as a function of core pressure drop and core flow rate). Based on this threshold, the core was operated up to $70 \%$ power without fluctuations. ${ }^{7}$

Plant test data and scale model test results showed that core region flow control valve position also had an effect on core stability. The most probable explanation for the temperature fluctuations was small movements of reactor components, such as fuel elements and reflector columns. The motion of the reactor components was most likely induced by pressure differences between gaps and thermal gradients in the core components, which caused component deformations and bowing. The pressure differences between gaps can result in bypass flow, which is varying coolant flow between gaps within regions and/or blocks. This bypass flow can induce high tensile stress on components, adding to the components deformation. The fluctuations were sustained by the interplay of these two phenomena (pressure differences and thermal gradients). This hypothesis was supported by analysis, test data, out-of-pile model tests, and in-core inspection results.

Region constraint devices (RCD) were designed and installed to stabilize the gap size between refueling regions at the top of the core, thus preventing, or at least reducing, the extent of core component motion and eliminating the core fluctuations. Eighty-four RCDs were installed and able to stabilize the movement of gaps around the core components. The RCDs "...prevent, or at least reduce, the extent of the core component motion." 30

Lessons Learned: Cross/bypass flow can cause fluctuating outlet temperatures and movement of components. The NGNP design could benefit by accounting for and minimizing bypass flow in the reactor. Conceptually, the installation and application of RCDs, or something similar, in the current 
NGNP designs would stabilize the movement of core components within a prismatic core design. This use of RCDs has already been incorporated into the HTGR designs that are under consideration for the NGNP and is being validated by the NGNP Design and Safety Methods Validation Program. ${ }^{31}$

\subsubsection{Inner Reflector (AVR)}

The inner graphite reflectors within the AVR were visually inspected in May 1986. The cylindrical core structure that held the spherical fuel elements was made of graphite bricks, and the graphite brick structure was enclosed in an envelope of carbon brick, which provided shielding and isolation. The whole composition was surrounded by a dual-walled steel liner. The top and bottom reflectors consisted of layers of graphite and carbon bricks. ${ }^{32}$

The inner reflectors of the AVR were made from an extruded, anisotropic petroleum coke graphite, manufactured by Sigri Elektrographit GmbH. The graphite "...is based on needle coke and densified by extruding, so that a rather high anisotropy factor is not surprising." 32

During the AVR's operational temperature of $950^{\circ} \mathrm{C}$, the “...top reflector having the highest temperatures of about $1000^{\circ} \mathrm{C}$ had accumulated a fast neutron fluence of only about $1.3 \times 10^{21} / \mathrm{cm}^{2}$ during the 16 years of operation. On the other hand, the upper side reflector received four times higher fluence at temperatures, where the anisotropy of dimensional changes is rather small." 32

Because of the unique core design and accessibility, unique lighting and camera methods were developed to view the inner reflectors. Other challenges also needed to be overcome to conduct the inspections. According to Haag, et al. ${ }^{32}$ :

Because of the black graphite surfaces of the reactor core it has been necessary to introduce four high power lights through the four corner fuel supply tubes while the camera itself was introduced into the core via the center tube.

Not until after 8 months of engineering, manufacturing, and testing was the inspection device able to be installed. To install the camera correctly, all five supply tubes needed to be examined for obstacles so cameras and lighting equipment could be inserted. Once inserted, the transmitted images were compared to the images of the pre-irradiation reflectors taken in 1965. The visual inspection found no cracks or fractures and no corrosion effects.

Lessons Learned: The design of the NGNP visual inspection capabilities for the core of the HTGR would benefit by evaluating methods from previous HTGR designs (e.g., AVR). The NGNP design will follow American Society of Mechanical Engineers (ASME) Section XI for in-service inspections.

\subsubsection{Graphite and Graphite Dust (HTR-10)}

The core and core structure of HTR-10 is made mostly of graphite grade IG-11. As the fuel elements move through HTR-10's pebble bed, they come into contact with the side reflector, the steel loading pipes, and other fuel elements. Also, because of the nonuniform temperature distribution and stress and deformation from irradiation, there is movement inbetween the graphite reflector blocks. From this movement and contact, the graphite can wear and create graphite dust and small particles. These particles can collect at the bottom of the core or be carried off and collect onto surfaces in the primary circuit, including the heat exchanger, thus decreasing its efficiency. ${ }^{33}$ Luo et al. clarifies:

There are many factors that influence the wear properties of graphite, which can be classified into inherent factors and external conditions. The inherent factors include crystallinity, porosity, and composition of graphite, impurities, grain size and crystal shape. The external conditions include temperature, load 
and environment. Surface, point, and line contact wear of the graphite was studied. The wear properties of nuclear grade IG-11 used in HTR-10 were studied at different loads because the forces acting on fuel elements vary with place in core. $^{33}$

Wear between fuel elements and the reflectors and the wear between fuel elements and the loading pipes were studied. The experimental loads were related to the static pressure, with the tests conducted at room temperature. Test results showed that the most serious wearing of the graphite happens at the beginning of the test, but as the test continues the wear rate of the graphite decreases. This occurred because the contact area at the beginning is small, but the contact area grows and becomes smooth as the wear continues. This increases the load distribution and decreases the wear rate. ${ }^{33}$

Lessons Learned: Graphite dust can be produced from the contact and movement of the pebbles or movement of the graphite blocks caused by temperature gradients, coolant flow, or vibrations. This graphite wear should be considered in NGNP design to reduce dust accumulation throughout the primary circuit. More research on tribology of graphite at expected operating conditions, including temperature and pressure in helium, is needed before making any attempt to quantify the amount of dust the NGNP will produce. The evolution, deposition, and other effects of graphite dust should be studied. The NGNP design would benefit by evaluating methods for dust minimization throughout the primary circuit.

\subsubsection{Outer Reflectors Bowing (Peach Bottom Unit 1)}

The graphite reflectors selected at Peach Bottom were B16-01 and of AGOT grade. These outer reflectors were shown to work well within the reactor. Changes in length and bowing were measured by holes drilled into the graphite reflectors. ${ }^{34}$ These changes were within established limits and within predictions. The length changes and bowing are caused by neutron fluence at high temperatures.

Lessons Learned: Neutron fluence and temperature gradients can cause graphite reflectors to bow. This needs to be accounted for within the NGNP design and is part of the NGNP Graphite Technology Development (R\&D) Program. ${ }^{35}$

\subsection{Fuel Elements}

\subsubsection{Fuel Cracks Caused by Tensile Stress (FSV)}

Sometime before October 1981, the FSV licensee discovered that a crack had propagated through two stacked fuel elements. The licensee and the reactor vendor concluded, based on calculation models, that induced high tensile and irradiation stresses resulted from incompatible peak factors in high stresses on the interregional faces of the two cracked fuel elements. Further, they thought that the use of $\mathrm{H}-451$ graphite would improve the strength of the elements, although cracking in this material was still possible. It was noted that if the mechanism for crack propagation is high tensile stress, then crack propagation may be reduced or stopped altogether in the presence of a crack that acts to reduce stress. Load tests indicated that even with cracks, the fuel elements' strength was essentially unaffected. Additionally, postirradiation examination of the cracked fuel element webs indicated that controlling key parameters, such as peaking factors, during plant operation would limit the cracking phenomenon (self-arresting). ${ }^{7}$

Lessons Learned: Irradiation can cause high tensile stress in the fuel elements. NGNP would benefit by considering the factors contributing to fuel cracking discovered from FSV and applying them to the design of the fuel used for NGNP. 


\subsubsection{Prismatic Fuel Performance (FSV)}

Experience with fuel design, development, and manufacture for FSV provided the basis for the fuel technology used for the GT-MHR and guided subsequent fuel quality and performance improvements. For FSV, 2,448 hexagonal fuel elements, 7.1 million fuel compacts, and 26,600 kg of TRISO-coated fuel particles were produced. The fuel was irradiated at temperatures greater than $1300^{\circ} \mathrm{C}$ to a maximum burnup in the fissile particles of $16 \%$ fissions per initial metal atom and to a maximum fast neutron fluence of $4.5 \times 10^{25} \mathrm{n} / \mathrm{m}^{2}$ (E $>29 \mathrm{fJ}$ ) with no evidence of significant in-service coating failure. ${ }^{36} \mathrm{FSV}$ provided invaluable fuel performance, fission product release, and plateout data that have been used for validation of General Atomics' design methods.

Lessons Learned: The experience gained from the comparison of the FSV helped to measure and predict fission product release and plateout, which may be applied to the validation and verification of fuel methods for NGNP and VHTRs. The effect of differences in fuel kernel composition can be estimated by using performance models for the particular kernel type, and the effect of differences in the primary circuit components can be estimated by revising the plateout geometric model for differences in configuration and materials. ${ }^{36}$

\subsubsection{Pebble Bed Fuel Performance (AVR)}

Numerous reports and studies discuss the various lessons learned from the fuel elements used in the AVR. Several reports, such as those by Dr. Moormann, ${ }^{37}$ the Jülich Institut für Reaktorwerkstoffe $\mathrm{GmbH},{ }^{38}$ and the International Atomic Energy Agency (IAEA) ${ }^{36}$ discuss the fission products of the elements. Reports from the second International Topical Meeting on High Temperature Reactor Technology ${ }^{39}$ mention a lack of irradiated TRISO fuel data. Other reports ${ }^{40}$ describe the experiments conducted and operations of AVR.

\subsubsection{Fission Products at Elevated Temperatures}

During the time of decommissioning and fuel removal of AVR, Dr. Rainer Moormann developed a reevaluation of the AVR. Dr. Moormann focuses most of his assessment on metal fission products that were produced at temperature levels above what was anticipated by the various models. Moormann concludes:

- A major fraction of this contamination is bound on graphitic dust and thus partly mobile in depressurization accidents, which has to be considered in safety analyses of future reactors.

- Metals diffuse in fuel kernel coatings and graphite and their break through takes place in long-term normal operation, if specific temperature limits of fission products are exceeded.

- Activity released from fuel elements is distributed all over the coolant circuit surfaces and on graphitic dust in HTRs where it accumulates.

A final recommendation from Dr. Moormann states, "Comparative probabilistic safety assessments on pebble-bed HTRs, HTRs with block type fuel and Generation III LWRs are proposed in order to generate a reliable figure of current pebble-bed reactor safety: Former safety studies for pebble-bed HTRs are expected to be too optimistic in light of improved knowledge."

In September 1988, the Jülich Institut für Reaktorwerkstoffe GmbH published a report documenting the fission products released for pebble-bed fuel elements containing TRISO particles. The experiments were conducted in the temperature range of 1500 to $2500^{\circ} \mathrm{C}$ to show that TRISO fuel would perform correctly at accidental temperature scenarios without degradation and with minimal fission product release. The summary report shows that near $1600^{\circ} \mathrm{C}$, fission products of cesium, strontium, iodine, and noble gas were negligible in measure. 
The Jülich report reaffirmed the safety and design of spherical fuel elements and the control of fission products within TRISO is obtainable.

In the tested temperature range 1400 to $1800^{\circ} \mathrm{C}$, the release of fission gas from fuel elements with TRISO particles remains very small, even after a longer period of heating. Any $\mathrm{Kr} 85$ activity due to contamination is heated and driven off during heating up. When defects occur in the coating, fission gases are released from the fuel particles.

The experiments performed on the TRISO fuel included evaluating SiC failure mechanisms. This includes corrosion experiments of the $\mathrm{SiC}$ layer by fission products. The report states:

In order to be able to judge the corrosive effect of individual groups of fission products, unirradiated $\mathrm{UO}_{2}$ TRISO particles were tested at 1600 to $2400^{\circ} \mathrm{C}$, to which various fission products were added during manufacture. It was found that rare metals particularly caused the greatest damage to $\mathrm{SiC}$.

In heating tests between 1600 and $1900^{\circ} \mathrm{C}$ on irradiated particles, which were exposed to a steep temperature gradient, the degradation rate of the $\mathrm{SiC}$ layer was determined. These experiments give relatively unfavorable results, because high fission product concentrations occur on the hot particle side, which accelerate the $\mathrm{SiC}$ corrosion. The temperature gradient in a fuel particle is very small during an accident.

$\mathrm{SiC}$ damage behavior is reported as:

- No SiC failure were found up to 200 hours at $1600^{\circ} \mathrm{C}$

- Fission product corrosion in the SiC layers starts within 100 hours at 1700 to $1800^{\circ} \mathrm{C}$, and increases with higher temperatures and longer periods of heating

- Above $2000^{\circ} \mathrm{C}$, the $\mathrm{SiC}$ is also decomposed by heat. This damage mechanism leads to $\mathrm{SiC}$ damage above $2200^{\circ} \mathrm{C}$, during heating at $50^{\circ} \mathrm{C}$ per hour. ${ }^{37}$

Lessons Learned: Previous work done for the AVR regarding fission product mobility and high temperature fuel degradation could benefit the NGNP fuel design. NGNP fuel experiments are evaluating fuel temperatures in excess of $1600^{\circ} \mathrm{C}$ and rapid temperature gradients. Additionally, the NGNP Fuel Development and Qualification Program ${ }^{41}$ has taken the following into account:

- Development of a new fuel element that retains metallic fission products in long-term operation. For hot gas temperatures as in process heat applications, the retention of metallic and nonmetallic fission products needs to be consistent with the desired source term.

- Development of a reliable quality control for fuel element manufacturing.

- Full understanding and reliable modeling of core temperature behavior and of pebble bed mechanics, including pebble rupture.

- Fast and reliable local measurement (direct or indirect) of safety relevant parameters in the pebble bed core (e.g., temperatures).

- Full understanding of fission product transport in the coolant circuit, including development of measures to avoid the reported uncontrollable activity accumulation in the circuit.

- Development of a fast detection and retention system for metallic fission product release from core. 


\subsubsection{Immediate Post-AVR Perspective}

Another report, ${ }^{40}$ prepared immediately following shutdown of AVR, discusses the experiments performed at the AVR from an operational perspective. The report noted that:

- The deposition of solid fission products in the primary loop is also determined to a significant extent by dust; a high fine dust fraction with grain sizes in the range of $1 \mu \mathrm{m}$ has been ascertained; this is the principal carrier of mobilized activity.

- During 21 years of AVR operation the reactor has been a valuable tool for a number of experiments on operating behavior, plant safety, HTR fuel element testing, and testing of HTR-relevant measuring techniques. The experiments at the AVR have also significantly contributed towards improving and qualifying the computer codes used for studies on core physics, thermohydraulics, and fission product behavior in HTRs. Some of the experiments have successfully demonstrated the special safety characteristics of small HTRs.

- Certain more extensive plans have not been feasible. The most important project involved the conversion of the AVR into a nuclear process heat facility for demonstrating the safe extraction and use of HTR heat for coal-refining processes. In-depth investigations concerning the condition of the AVR were carried out for this project. They proved that all plant components were in a good state and suitable for long-term further operation after almost 17 years of operation. ${ }^{40}$

Lessons Learned: This overview of AVR operations highlights fine dust and AVR experience with safety and testing, and process heat plans. Since dust is a principal carrier of mobilized activity, NGNP's design would benefit by taking into account dust generation and removal. Methods to minimize the amount of dust that can be generated and to capture dust would also be beneficial. The NGNP project has benefitted from the AVR experience in improving and qualifying core physics computer codes. The NGNP project has also built on the process heat application investigations done for AVR and developed proposed designs that are very amenable to process heat applications.

\subsubsection{Direct Operational AVR Experience}

Over the course of operation, the AVR used almost two million spherical fuel elements. The rate of damage to the fuel elements was negligible. Additionally, fuel elements with high burnup had only negligible fission product release when heated up to $1600^{\circ} \mathrm{C} .{ }^{38}$ It should be noted that safety experiments at AVR proved that, in case of a failure of both the cooling system and the nuclear control systems, the reactor was stabilized solely by the negative temperature coefficient and the decay heat was removed by conduction and radiation without doing any damage to the reactor. ${ }^{42}$

When the AVR first started up, it experienced a higher than expected damage rate of the fuel elements. This was determined to be the result of overly dense packing on the initial fuel load. Through continuous cycling of the initial fuel, the damaged fuel was removed and loosened the fuel bed to a lower density; thus, the damage rate decreased to expected levels. ${ }^{42}$

Another difficulty experience at the AVR was a mechanical problem with pebble element discharge rate as power levels increased. This problem was resolved by mechanically incorporating a bypass flow system in the discharge pipe. ${ }^{42}$

Lessons Learned: NGNP design would benefit by considering AVR issues such as the pebble elements becoming too tightly packed for proper operations, difficulty discharging the fuel pebbles from the reactor, and keeping fission products low for temperatures up to $1600^{\circ} \mathrm{C}$. The AVR program provided a large amount of fuel performance data that the NGNP Project has already used and will continue to use for fuel design. 


\subsubsection{Fuel Summary (HTR-10)}

An irradiation test of the first batches of fuel for HTR-10 (see Figure 13) was reported in 2006. The report discusses specific tests of four spherical fuel elements conducted at the Russian reactor IVV-2M. ${ }^{43}$ Results for the tests focused on fission product releases, specifically releases of $\mathrm{Cs}, \mathrm{Ce}$, and $\mathrm{Xe}$.

During these irradiation tests, some positive and negative attributes were found in the different batches of fuels. One set of fuel elements in the experiment was the SFE7. A conventional high-temperature furnace that can reach $1600^{\circ} \mathrm{C}$ was not available for use at the irradiation facility for these experiments. Instead of using the usual furnace testing method, researchers determined to heat the fuel spheres within the reactor itself by increasing the thermal neutron flux; however, the actual temperature was not recorded because a thermocouple failed. The SFE7 temperatures were instead calculated based on the fission power of the SFE7.

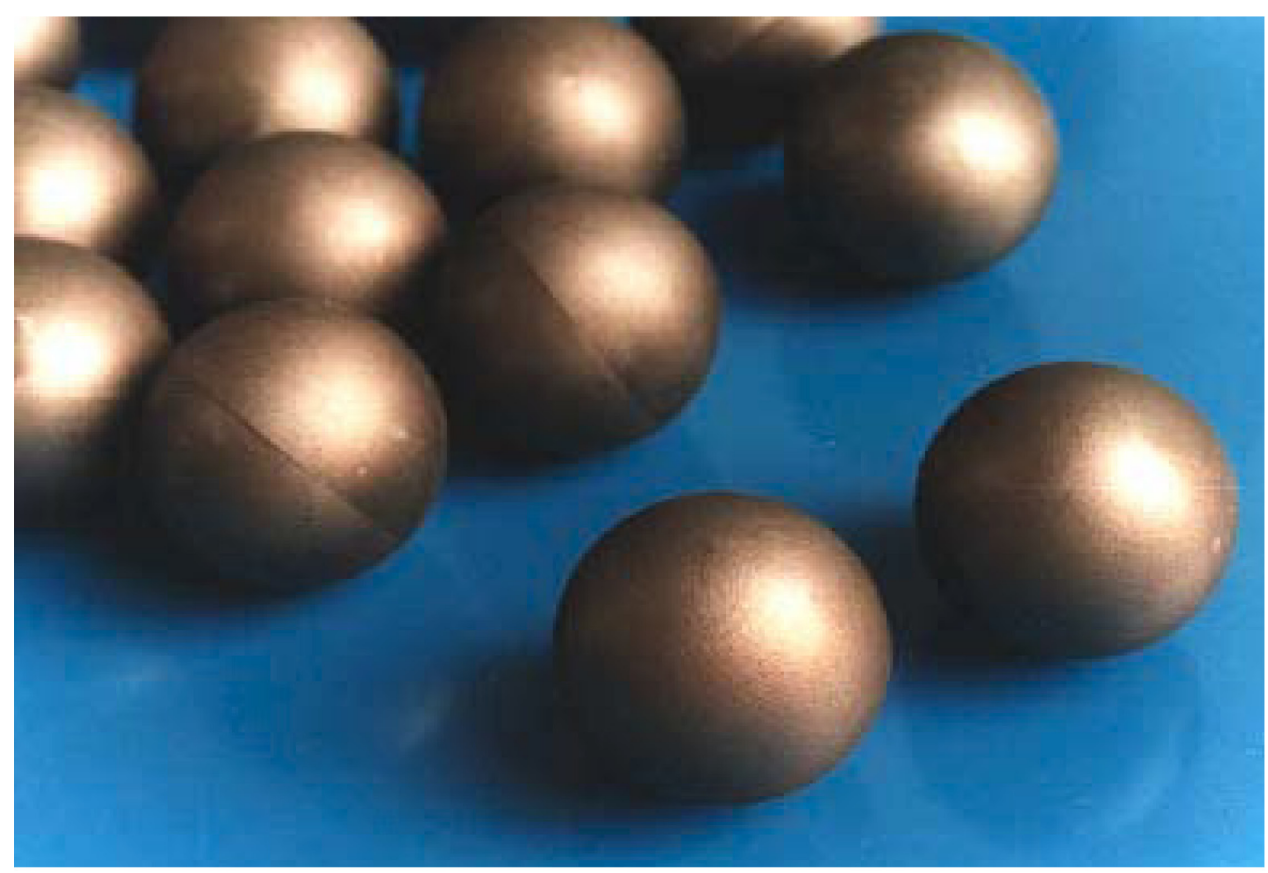

Figure 13. HTR-10 fuel.

This inpile heating test led to failures in coated particles within SFE7. Post irradiation examination determined that the fuel temperature had gone much higher than the intended $1600^{\circ} \mathrm{C}$, resulting in the failure of coatings on the fuel particles. A large portion of the particles that encountered the high-temperature inpile testing were observed to have defects. The type of defects observed include radial cracks, tangential cracks, cracks in the buffer PyC layer, and through failures in the PyC and $\mathrm{SiC}$ layers.

Another test showed failure because of a chemical reaction between the graphite of element SFE 8 and impurities such as air. In one instance, there was a high release-to-birth ratio for gaseous fission products because of manufacturing defects. One of the positive results found during HTR-10 fuel testing was that "irradiation of up to approximately $100,000 \mathrm{MWd} / \mathrm{tU}$ at $1000^{\circ} \mathrm{C}$ did not cause any failure of coated particles." 43

Lessons Learned: Testing of HTR-10 fuel provides useful information for the NGNP fuel design program. From this testing of HTR-10 fuel, fuel failures were experienced above $1600^{\circ} \mathrm{C}$. Fuel failure 
was also experienced as a result of impurities that were present and from manufacturing defects. The HTR-10 experience provides examples of fuel failure mechanisms and provides justification for NGNP using quality control of the fuel manufacturing process.

\subsubsection{Graphite Dust (AVR)}

AVR experienced numerous dust sources, each associated with the handling of the fuel pebbles. Examples of AVR fuel pebble failures are shown in Figure 14: (a) notching, (b) spalling, (c) pitting, (d) fuel sphere fracturing, and (e) peeling because of air ingress. ${ }^{44}$

The dust from these sources has contributed to activity concentration in the coolant and dust. Within the coolant, the activity nuclides within the hot and cool gases of the coolant include ${ }^{90} \mathrm{Sr},{ }^{110 \mathrm{~m}} \mathrm{Ag},{ }^{131} \mathrm{I}$, ${ }^{134} \mathrm{Cs}$, and ${ }^{137} \mathrm{Cs}$. The nuclides within the dust are ${ }^{137} \mathrm{Cs},{ }^{134} \mathrm{Cs},{ }^{90} \mathrm{Sr},{ }^{89} \mathrm{Sr},{ }^{110 \mathrm{~m}} \mathrm{Ag},{ }^{131} \mathrm{I}$, and ${ }^{60} \mathrm{Co}$. These activity nuclides are the source of difficulty in decontaminating the various components. Even though experiments were performed within the AVR, only the amount of dust generated can be estimated, so the estimated range is quite large, between 46 and $200 \mathrm{~kg}$ over the lifetime of the AVR. ${ }^{44}$

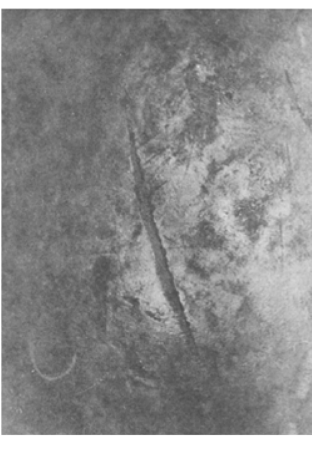

(a)

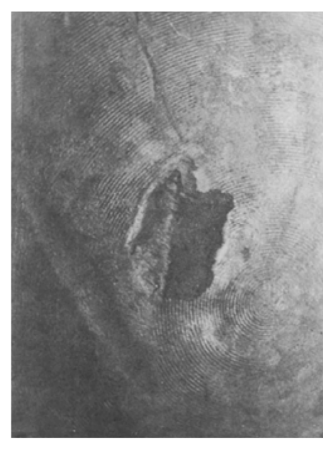

(b)

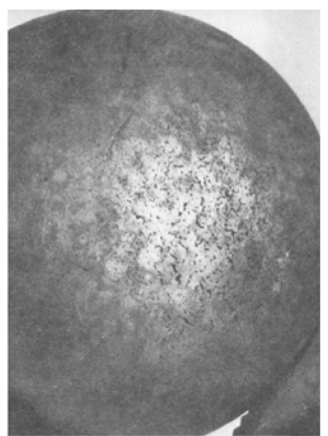

(c)

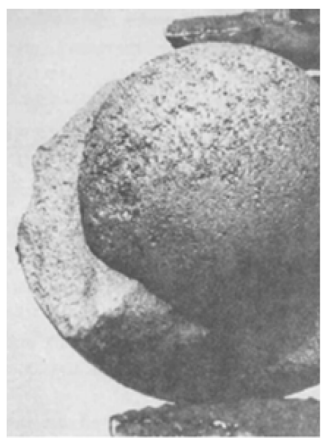

(d)

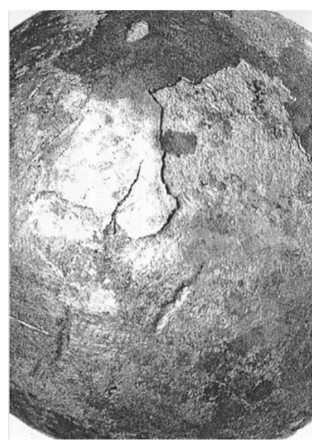

(e)

Figure 14. Sources of dust production at AVR. ${ }^{45}$

Lessons Learned: Several sources of graphite dust were identified at the AVR, including notching, spalling, pitting, fuel sphere fracture, and peeling of the fuel. NGNP design would benefit by considering graphite wear with methods to reduce dust accumulation on heat exchanging surfaces. NGNP would also benefit by defining the requirements for fuel manufacturing in order to use the qualified fuel in NGNP.

\subsubsection{Graphite Dust (HTTR)}

In November 2009, the Paul Scherer Institute (PSI) in Villingen, Switzerland, sponsored a meeting of researchers and subject matter experts on HTR graphite dust. ${ }^{46}$ The intent of the meeting was to develop and formalize a preliminary project proposal to study HTR graphite dust generation and transport. Under the direction of PSI, many subject matter experts presented historical and proposed research findings relating to the generation and transport of graphite dust within HTRs. The meeting provided a venue to present PSI's intensions to get involved in the 'HTR graphite dust issues' to a broader audience. The interest of PSI getting involved in the graphite dust issue was suggested by the Laboratory for Thermal Hydraulics Scientific Advisory Committee members in 2008. Subsequent activities and meetings resulted in a literature survey, a workshop, and report being produced. ${ }^{47}$

The report ${ }^{47}$ discusses the key issues with graphite dust. Two phenomena are identified in the report: tribology of graphite in impure helium environments and graphite dust generation. More specifically, the report highlights various gaps of information in wear, dust formation, and transport. Gas-cooled reactor safety analysis requires further understanding for dust production during normal operations and accident 
scenarios. The report further states the importance of fission products on graphite dust and how it contributes to fission product source term. There is a need to quantify both the amount of dust and the inventory of fission products. NRC licensing of any HTR reactor concepts requires R\&D focused in the area of dust generation. Carbonaceous dust formation (via tribology plus other mechanisms) needs to be addressed within the graphite community. Dust formation studies need to know the correlation between dust and fission products.

The report recommends four areas of research to advance graphite technologies for the VHTR community. Those recommendations are: (1) oxidation modeling of kinetics and diffusion behavior, (2) accelerated ASME code development for core components, (3) graphite tribological behavior in helium, and (4) oxidative reactivity of the graphite dust powder compared to the graphite blocks. ${ }^{47}$

HTTR has experienced carbonaceous dust deposits in the mesh filter of the primary helium circulator. The sources for the dust are identified to be from the core graphite materials within the reactor and from the slide member of the helium compressor. ${ }^{48}$ JAEA has proposed new methods to identify the origins of the carbonaceous dust with a high degree of accuracy.

Lessons Learned: Graphite wear, and the recommendations noted above, should be considered in NGNP design with methods to reduce dust accumulation. NGNP graphite research results will be used in NRC acceptance of graphite for the NGNP and follow-on VHTR reactors. The use of HTTR data on carbonaceous dust source analysis will also benefit the NGNP Project.

\subsubsection{Fission Product Release Monitoring (HTTR)}

Fuel and fission product gas behavior was monitored to evaluate the release behaviors of the fission product gases and to confirm that the levels of the released fission product gases were within their limits during the operation. Primary coolant radioactivity instrumentation, a fuel failure detection system, and a primary coolant sampling system were installed in the HTTR to measure primary coolant radioactivity. Over the course of numerous years, HTTR had a goal to achieve an operational state with a reactor outlet temperature of $950^{\circ} \mathrm{C}$. On April 21, 2004, the HTTR was able to achieve operation at full temperature of $950^{\circ} \mathrm{C}$. Primary coolant radioactivity was measured continuously during this full temperature operation, as shown in Figure 15. Results show that not only were all signals less than the alarm level of $10 \mathrm{GBq} / \mathrm{m}^{3}$, which corresponds to $0.2 \%$ of fuel failure, but all signals were also less than the detection limit $\left(1 \mathrm{GBq} / \mathrm{m}^{3}\right) .^{10}$ 


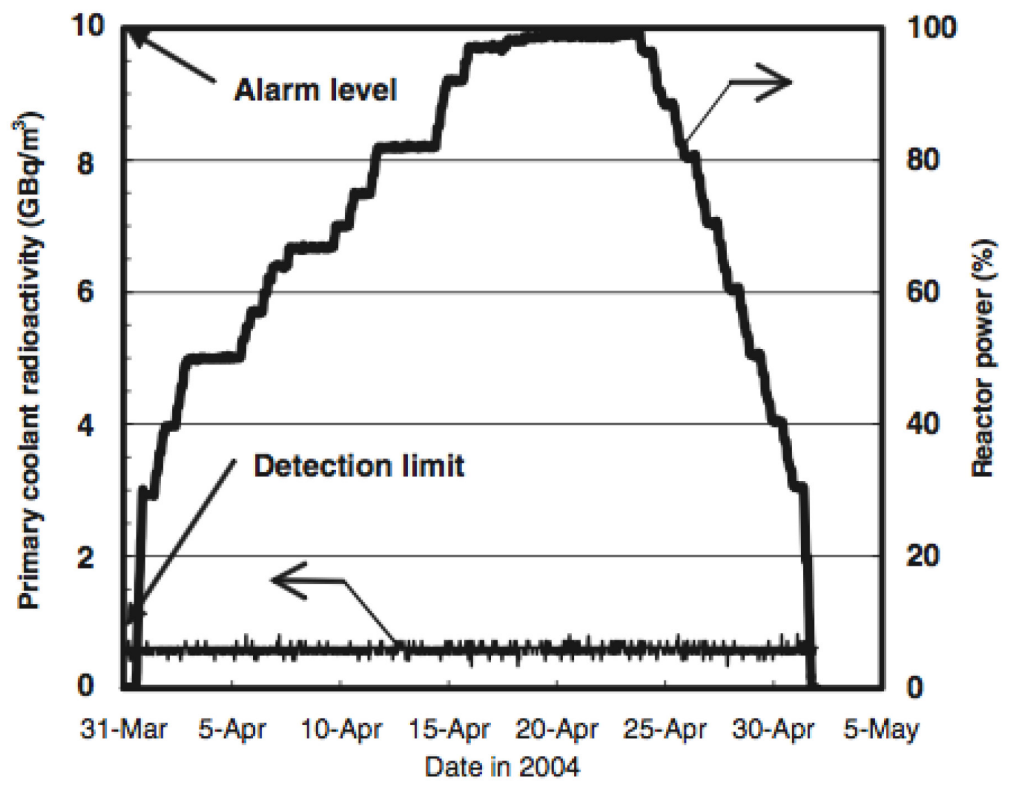

Figure 15. Primary coolant radioactivity signals during HTTR operation. ${ }^{10}$

Lessons Learned: HTTR experience shows a positive example that an HTGR can be run at full power $\left(\right.$ at $\left.950^{\circ} \mathrm{C}\right)$ without releasing any detectable amounts of fission products. The successful use of instrumentation, detection, and sampling systems at HTTR will be of benefit to the NGNP design.

\subsubsection{Fission Product Trapping (Peach Bottom Unit 1)}

A fission product trapping system was used at Peach Bottom to purify the primary coolant. Helium would enter the fission product trapping system after going through the fuel purge line in the reactor core. This helium would collect fission products from the core, such as krypton and tritium, and then travel through water- and Freon-cooled delay beds. From the delay beds, the helium would go through a series of fission product traps. ${ }^{49}$ One of the traps was a liquid nitrogen/charcoal trap, which would remove moisture, chemical impurities, argon, and krypton. Other components of the fission product trapping system were a dehydrator and an oxidizer. ${ }^{4}$

The fission product trapping system and the purge system worked efficiently. It was observed that the primary circuit at the end of life was remarkably clean and the activity was never greater than $1 \mathrm{Ci}$. The dominant gamma emitters were ${ }^{137} \mathrm{Cs}$ and ${ }^{134} \mathrm{Cs}$. These emitters were found to be the only ones above background activity. The only other fission product found was ${ }^{90} \mathrm{Sr}$ at end of life, and it was three orders of magnitude lower than the cesium. ${ }^{49}$

It has been determined that tritium can be produced in the core in three ways. The first is from ${ }^{3} \mathrm{He}$, which depends on the helium inventory within the core. The inventory in the cores at Peach Bottom was significantly lower than in other larger HTGRs. Since the helium inventory was low, the burnout rate of ${ }^{3} \mathrm{He}$ was not considered significant. The other methods of tritium production are from ${ }^{6} \mathrm{Li}$ and ${ }^{10} \mathrm{~B}$ in graphite, either directly or through a chain. The lithium in Peach Bottom was found to be one of the impurities in the radial reflectors. The tritium production from ${ }^{10} \mathrm{~B}$ is dependent on the neutron energy. The tritium may migrate from the fuel and eventually into the purge gas flow, while tritium formed from the control rods and reflectors would pass directly into the gas flow. Some of the tritium in Peach Bottom was caught in the fission product trap at the base of each fuel element. The rest passed into the fission product trapping system. ${ }^{50}$ 
The trapping system did have a setback in retaining tritium. During reactor shutdown, the delay beds were regenerated and allowed to warm up. The adsorbed tritium gas then desorbed. This happened because hydrogen is physically adsorbed on charcoal in increasing amounts with decreasing temperature. This is true for temperatures below $70^{\circ} \mathrm{C}$. On the other hand, tritiated water molecules (a small portion of the total tritium) were permanently retained in the delay bed. ${ }^{49}$

Lessons Learned: Peach Bottom's fission product trapping system demonstrated the ability to control fission product release and showed the difficulty of containing fission products within a trapping system. NGNP would benefit from the positive aspects of a trapping system, but needs to use a better method of controlling the amount of tritium and other fission product releases, like krypton. NGNP would benefit by evaluating current and advanced fission product trapping and helium purification systems as part of its overall fission product management strategy.

\subsubsection{Amoeba Effect (Peach Bottom Unit 1)}

The fuel elements in Core 1 were of a prismatic design and used thorium-UC $\mathrm{C}_{2}$ particles in a graphite matrix as fuel. ${ }^{51}$ The uranium was initially highly enriched to $93.15 \mathrm{wt} \%{ }^{235} \mathrm{U}$. The fuel particles had a diameter of approximately 485 microns $^{4}$ and were coated in a thin PyC layer to prevent moisture from contacting the carbides and causing hydrolysis. ${ }^{52}$ It was also used to contain the fission products.

However, the fuel particle is susceptible to the amoeba effect. This amoeba effect is the migration of the nuclear fuel kernel across the fuel particle driven by high temperature thermal gradients through the fuel element cross section as shown in Figure 16. As the $\mathrm{UC}_{2}$ travels, it appears to consume the PyC.

The PyC coating had a couple of other drawbacks: it could suffer dimensional changes that were caused by fast neutrons, and it could be damaged by gaseous fission product release and fission recoil. In Core 1, 45 to $84 \%$ of the fuel particles had failed. The fuel particles were found cracked and distorted, causing some compacts to bind against the sleeve. ${ }^{4}$ From the binding of the sleeves, $10 \%$ of the sleeves were also cracked. ${ }^{4}$ These cracks and distortions were detected by an increase in activity throughout the system that was still well below design specifications, but increasing rapidly. ${ }^{5}$

The fuel element design for Core 2 was very similar to that of Core 1 . One main exception was that it used BISO fuel particles, which had two layers of carbon coating (porous and PyC) versus just one. The inner buffer layer protected the outer layer from product recoil and gaseous product release. This buffer layer also eliminated the swelling problem found in the other core and provided better fission retention. ${ }^{4,36}$ 


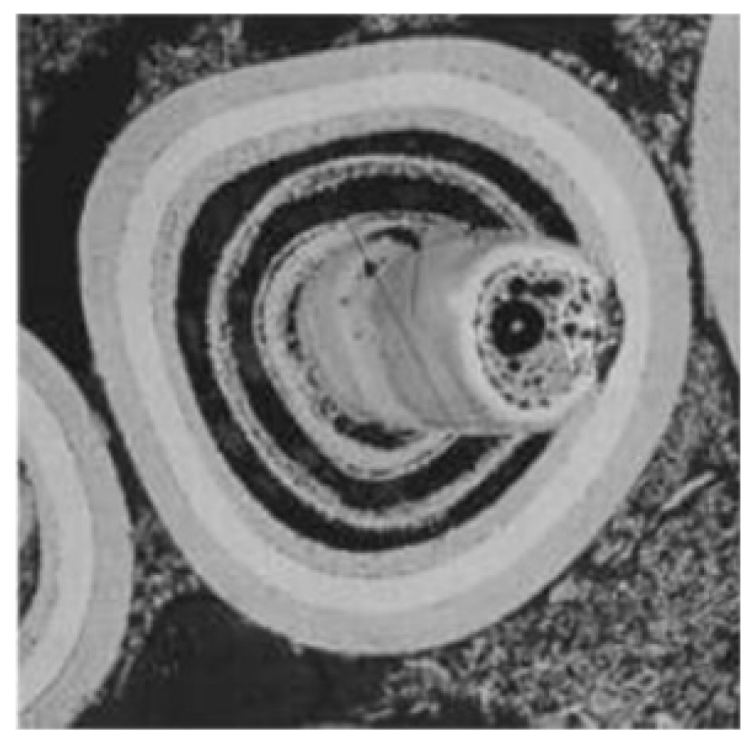

Figure 16. Amoeba effect in coated particle.

Lessons Learned: Fuel experience from Peach Bottom was useful for the development of TRISO fuel, which was the next step and solution to many of the problems with the earlier fuels. The Advanced Gas Reactor Fuel Development and Qualification Program is currently qualifying TRISO fuel for the NGNP design. However, the amoeba effect may still have some impact on TRISO fuel performance.

\subsection{Reactivity Control System}

\subsubsection{Moisture Effects on RCS (FSV)}

One moisture intrusion event required a detailed examination because of the important ramifications and potential consequences arising from the event. On June 23, 1984, a reactor scram occurred. The operators first verified the reactor was subcritical; however, they also noted that six control rod pairs had failed to fully insert in response to the scram signal. The operators immediately attempted to input a manual scram signal, which also failed to insert the six control rod pairs. The operators then pulled the fuses for the scram breakers for the six control rod pairs, but that attempt also failed to insert the control rods. The operators reinserted the fuses and reenergized the control rod drive (CRD) motors. The control rods were then fully inserted using the CRD drive motors about 20 minutes after the initial automatic scram signal. That event was ultimately attributed to moisture collecting on the control rods. ${ }^{7}$

Another concern arising from a partial scram is the effect of moisture on core reactivity. Since moisture appears to play some role in the two failure-to-scram events, the effect of moisture on core reactivity should at least be noted. Water and steam have competing positive and negative reactivity contributions. Positive reactivity, which causes reactor power to increase, results from cooling of the graphite and fuel, the associated moderator temperature negative coefficient of reactivity, and reduced neutron leakage from the core. Decreased resonance capture is also a determining factor, since neutrons lose more energy per collision with hydrogen than carbon and are thereby less likely to be absorbed in the resonance energy region of ${ }^{238} \mathrm{U}$. Negative reactivity, which causes reactor power to decrease, results from the greater absorption of neutrons by hydrogen than by graphite. For relatively small amounts of water or steam, the positive reactivity effects outweigh the negative, and power will increase. For much larger amounts of water, the negative reactivity contribution prevails. ${ }^{7}$ 
Lessons Learned: The moisture intrusion events that occurred at FSV show the effects of moisture ingress on reactivity control. The effects of the moisture intrusion ranged from change in reactivity to swelling and corrosion. This information would benefit the design of future HTGRs where there is a possibility of moisture intrusion.

\subsubsection{Control Rod Cable Failure (FSV)}

A cable for a control rod pair broke and jammed in its guide tube during a test of the CRD. This was also attributed to moisture ingress. ${ }^{7}$

A related problem associated with the moisture ingress is the leaching of volatile chlorides from various sources within the reactor and their deposition throughout the primary system. In August 1984, a stainless steel control rod cable broke and was subsequently found to have chloride-induced stress corrosion cracking. The steel cables were replaced with corrosion resistant inconel cable. The problem represents a failure to recognize the connection between the level of chloride contaminants in various primary system components, the possibility of moisture-induced leaching, and the potential susceptibility of other components to chloride attack. In the past, concern about the effects of moisture ingress had been concentrated almost exclusively on graphite corrosion. ${ }^{53}$

Lessons Learned: Moisture ingress can cause many potential problems including the risk of chloride corrosion. NGNP would benefit by ensuring that potential corrosive contaminates are limited in use and that the location of corrosive chemicals is incorporated into the design, operations, and maintenance procedures.

\subsubsection{Control Rod Temperature Anomalies (HTTR)}

In 1997, nonnuclear heat-up tests were carried out. When the primary coolant temperature reached $110^{\circ} \mathrm{C}$ by heat input from the gas circulators, the helium gas temperature around the control rod drive mechanisms inside the standpipes reached the alarm point of $60^{\circ} \mathrm{C}$. At the same time, the temperature of the primary upper shielding reached about $75^{\circ} \mathrm{C}$, which was higher than anticipated.

The cause of the temperature rise of the primary upper shielding and the helium gas inside the standpipes was investigated and found to be unanticipated bypass flow. The primary helium coolant enters the RPV at the bottom and travels up along the body. At the top, the coolant turns around where the majority of the helium flows through the fuel blocks and some flows through the control rod guide tubes. The rest of the helium, about 4\%, flows between gaps in the columns of blocks. An orifice was used to control the flow rate into the control rod guide block column. This orifice created a pressure drop between the upper plenum and inside the guide pipe for the control rod support cable. "It was calculated that about $87 \%$ of the primary coolant for the control rod guide column goes through the orifice and about $13 \%$ bypasses the orifice."

To reduce the temperature of the primary upper shielding, the two countermeasures were applied to limit bypass flow and enhance heat removal by the vessel cooling system. The first countermeasure involved changes to the inside of the control rod standpipe to prevent bypass flow. Flow rate was controlled by minimizing the pressure drop within specific areas of the control rod standpipe. The countermeasure also included sealing gaps within the control drive mechanism.

The second countermeasure involved heat removal by the vessel cooling system and provided heat release in the standpipe room. Heat removal was enhanced by installing copper plates and insulators in specific regions of the primary upper shielding. This countermeasure prevented heat conduction and radiation from the standpipe. 
Lessons Learned: Hot spots can occur in the reactor because of unanticipated bypass flow of the primary coolant. Future HTGR designs are anticipated to benefit by carefully analyzing reactor coolant flows and incorporating proper cooling for all operational scenarios.

\subsubsection{Control Rods, Reserve Shutdown System, and Lubricants in a Helium Environment (HTR-10)}

HTR-10 was designed to have two methods of controlling the reactivity. HTR-10 safety design criteria specified that the first method to shut down the reactor is the main shutdown system. The main shutdown system, on its own, must be capable of quickly rendering the reactor subcritical by "an adequate margin from operation and accident condition." This first method is used in the HTR-10 with control rods that drop down into channels in the side reflectors. ${ }^{54}$

The second shutdown safety design criterion is the use of a reserve shutdown system. This reserve method is to drop absorber balls into side reflector channels. This would ensure that the fuel elements would not be damaged or impede the movement of the control rods. The control rods still work exceptionally well when inserted into the side reflectors. ${ }^{55}$

The control rods are able to be dropped down by gravity, in case an emergency shutdown is required. To reduce the damage from impact, HTR-10 uses magnetic dampeners to control the drop speed and reduce the shock on the control rods. Under normal operation, the control rods are operated by a drive system located above the RPV. The drive system is also enclosed in a pressure cell to protect it from the pressurized helium in the RPV. ${ }^{55}$

To further reduce contact stresses within the control rod drive mechanism, a stepping motor was used in the drive system. The use of a stepping motor within a control rod drive mechanism is a unique application of this mature technology. ${ }^{55}$ By using the stepping motor, the control rods can be placed in a locking mode for long periods of time, thus allowing the elimination of counterweight or brake-clutch devices within the control rod drive mechanism.

The lubrication for the control rods was a concern because of the requirement to maintain helium purity, high temperature, and high radiation environment. Since there is no oxygen in the system, the side reflectors would not be oxidized or have the moisture to reduce friction. Oils could not be used since they would evaporate and pollute the helium. Molybdenum disulfide was found to be a good solid lubricant and demonstrated to have an effective duty life during radiation tests and friction tests, within the operating environment of helium and at operating temperatures. HTR-10 uses this lubricant per the lubrication process developed by the Institute of Chemicophysics, Lanzhou. ${ }^{55}$

Lessons Learned: Experience with HTR-10 shows that an environment of helium impurities, high temperatures, and high radiation can cause problems with conventional control rod lubricants. NGNP would benefit by considering this experience in selecting control rods, RSS, and lubricants in the design process. Stepping motor technologies in control rod mechanisms may also provide defense-in-depth for the NGNP Design.

\subsubsection{Control Rods Placements (Peach Bottom Unit 1)}

Peach Bottom control rods were placed and operated at the bottom of the reactor to avoid the severe operating conditions imposed by the high temperature and high radiation environments. The location of the control rod assembly caused some licensing issues in that the reactor would not have "an inherent fail-safe shutdown geometry that would insert control rods by gravity in case of loss of actuation power." Demonstrated proof of reliability was required prior to licensing. ${ }^{56}$ 
Lessons Learned: The placement of the control rods at Peach Bottom was not standard and thus required extensive proof of the concept. NGNP would benefit by ensuring designs that are passively safe and acceptable within the current regulatory environment. All current designs for the NGNP include control rods located on top of the reactor.

\subsubsection{Control Rod Lubrication (Peach Bottom Unit 1)}

Conventional lubrication (such as oils) could not be used because of the high temperature, high radiation environment and because of the potential impurities introduced into the helium coolant. During the development period for Peach Bottom, soft metals were contacted against hard metals using a variety of dry film lubrications. None of the commercially available and applied lubricants at that time showed adequate duty life for what was considered a minimum for this application. The helium atmosphere was another challenge that prevented any protective oxide-type surface film to re-form on the metal parts after the lubricant departed. Without the presence of any form of film boundary layer between the metal parts, almost immediate metal adhesion began.

The selection of a dry lubricant entailed a considerable amount of testing and experimenting. The lubricant selected used a compound containing molybdenum disulphide, lead disulphide, and graphite with a modified phosphoric binder system.

Since all the dry film lubricants tested had more or less limited duty life, it was important that a material combination be found that would continue to function without sudden seizure after lubrication had degraded. Testing indicated that material combinations possessing extreme surface hardness of nearly equal value allowed continued functioning, although with a noticeable increase in friction. Nitride surface hardened materials were the most outstanding in this respect and were universally chosen throughout the design where this requirement was a factor.

Lessons Learned: NGNP would benefit by evaluating the past use of dry lubricants in all of the applicable design components that need lubrication.

\subsubsection{Oil Leaks (Peach Bottom Unit 1)}

According to Ledin, "During the initial preoperational testing of the reactor control rod installation, the major problems encountered were in connection with sorting out external and internal oil leaks of the hydraulic system." There were many oil leaks, from the hydraulic drives and their components, which were attributed to manufacturing defects in certain sealing surfaces. "A great deal of effort and time went into tracing and correcting this overall problem area." 56

Several occurrences of oil leaks were found in the hydraulic components at static seal connections and piston seals associated with accumulators that provide the stored energy source for a reactor trip insertion. The piston seal leaks were determined to be caused by defects in the cylinder wall surface machining. "One incident of a burst high pressure hydraulic hose, which was identified as being caused by some previous handling damage, required shutdown."

Lessons Learned: Because of potential oil ingress from hydraulic components, the NGNP design would benefit by eliminating the use of hydraulics or designing the hydraulic systems to prevent oil leaks from occurring.

\subsubsection{Fatigue in Control Rods (Peach Bottom Unit 1)}

When the core was loaded with non-nuclear material and equipment for testing and personnel training, the control rods experienced cyclic loading. It was estimated that the amount of cycling was similar to that of many years of actual operation. "It was not until the reactor had been loaded with fuel 
and low power testing was performed that two of the control rods began to show symptoms of erratic motion during the regulating mode of operation." The rods began to stick and further motion could only be achieved by increasing the hydraulic pressure. After the linear actuators were removed and disassembled, several balls in the ball screw assemblies had broken. Ledin explains, "The exact mechanism of failure could not be precisely identified, but it was believed that the situation was precipitated by a faulty ball or foreign particle becoming jammed into a ball, causing overstressing and fracture. Other actuators were then checked and another ball screw assembly was broken, even though it showed no signs during performance." 56

After an extensive reanalysis of the ball screw design, it was determined that the design was satisfactory but the balls had imperfections. All the balls were replaced with new ones of load carrying size and with a higher grade of precision. After this change, the ball screw components showed no problems.

Lessons Learned: Imperfections in reactor components such as the ball screw assemblies used to actuate the control rods can cause major problems during operation. NGNP would benefit by continuing to incorporate quality assurance to ensure all reactor components precisely meet specifications and requirements.

\subsection{Reactor Cavity Cooling System}

The HTTR's reactor cavity cooling system (RCCS) is cooled by forced circulation of water. A watercooled RCCS is a three-dimensional structure with many parallel channels. There is considerable operating experience for a water-cooled RCCS, but the Japanese experience demonstrates that it can be difficult to operate properly. The water-cooled RCCS has better heat transfer than the air-cooled RCCS.

Lessons Learned: Specific RCCS configurations will require NGNP evaluation to ensure proper operation. NGNP would benefit by analyzing the experience of other reactors, such as the Japanese HTTR, and using this information to improve the NGNP design.

\subsection{Reserve Shutdown System}

\subsubsection{Inadvertent Actuation of RSS (FSV)}

The reserve shutdown system was inadvertently actuated, and the Region 27 reserve shutdown system boron balls (also denoted as boronated graphite balls) were injected into the core. The licensee first observed a slight power tilt on the core outlet thermocouples. A follow-up investigation confirmed that the boron balls had been injected into the core. Even with the boron balls in the core, there was no adverse power peaking. An NRC inspection and enforcement report indicated that the licensee had imposed control rod position limits to compensate for "...the flux tilt due to suspected reserve shutdown material insertion." The boron balls were removed during an extended maintenance outage; the accidental injection of the boronated graphite balls went undetected for almost a month, since there was no indication that the hopper door had failed or was open. It was only noticed after a power heat balance performed using the core outlet thermocouples indicated a core power distribution imbalance. ${ }^{7}$

Lessons Learned: Future HTGR designs would benefit by instrumenting RSS systems to indicate when the system has actuated. While applicable, it is also expected that future designs would benefit by evaluating designs that prohibit accidental injection. Currently, NGNP reactor suppliers are planning to incorporate these features into their designs. 


\subsubsection{RSS Failure to Deploy Boronated Graphite Balls (FSV)}

One reserve shutdown system hopper only discharged about half of the full amount of the poison material (boronated graphite balls) during a test. The more highly boronated material was stuck together, apparently because boric acid crystals had formed. A source of water in the purified helium train was suspected of causing the leaching of the boronated material that formed the acid crystals. The reserve shutdown materials with high boric acid concentrations were located in 18 of the system's 37 hoppers.

The reserve shutdown system was also degraded over a period of time that probably exceeded 2 years. The degradation of the reserve shutdown system was traced back and was also shown to result from small amounts of moisture coming in contact with the shutdown material. This failure to completely guarantee a plant shutdown when required represents a significant safety hazard for plant operations. ${ }^{7}$

Lessons Learned: Moisture in the RSS has adverse effects, as was the case with the boronated absorber balls and the formation of boric acid crystals. The NGNP project would benefit by evaluating design solutions that prevent moisture entering into the RSS, or, if moisture enters into the RSS, prevent the formation of boric acid crystals or other mechanisms which would prevent the neutron capturing spheres from deploying. 


\section{HEAT TRANSPORT SYSTEM}

\subsection{Circulators}

\subsubsection{Bolt Shearing (FSV)}

On July 5,1988 , the plant was shut down for a scheduled 12 -week outage to replace bolting material on the helium circulators in the vicinity of their steam turbine drives. This outage was scheduled when a detailed investigation, following replacement of a circulator in 1987, revealed that the bolts holding the insulation shroud and steam seal in place failed because of stress corrosion cracking brought about by caustic embrittlement. Repairs on the circulators were completed in October 1988, but plant restart was delayed because of another moisture ingress into the primary coolant system. This delay was due primarily to moisture originating from the core support floor section of the liner cooling system. A small breach in this area of the liner had developed a number of years previously, and with the extended shutdown for the circulator repair work, substantial water had passed from the core support floor into the primary system, requiring extended down time for its removal. The plant was subsequently brought back into operation in April 1989.

Lessons Learned: The NGNP design would benefit by taking into account the effect of corrosive environments on fasteners and other mechanical components. Though there is little likelihood of moist, corrosive environments associated with the NGNP design, a review of stress corrosion cracking would be beneficial for the NGNP.

\subsubsection{Circulator Seals and Stress Corrosion Cracking (FSV)}

It was discovered that the $\mathrm{D}$ helium circulator was leaking helium through its seal above the technical specification limit. The $\mathrm{D}$ helium circulator needed to be shut down because of excessive circulator shaft vibration. It was also discovered that the circulator turbine water drain tank was being pressurized with helium. The D circulator had sustained damage and had to be replaced. Metallurgical observations confirmed preexisting cracks in the labyrinth seal mounting bolts, the steam ducting-to-bearing assembly bolts, and the spring plunger. The cracks were likely caused by stress corrosion cracking. ${ }^{7}$

Lessons Learned: FSV had numerous and recurring problems with helium circulators. Much can be learned from this experience. NGNP circulator design would benefit by evaluating and learning from the circulator failures at FSV.

\subsubsection{Use of Active Magnetic Bearings (HTR-10)}

The original HTR-10 used a single-stage centrifugal compressor to circulate the helium through the primary loop. High-performance grease was used for the bearings supporting the compressor. In a subsequent HTR project (HTR-PM), active magnetic bearings (AMB) will be tested and used for the circulator. AMBs do not require lubrication, eliminating the possibility of the lubricant contaminating the coolant. Since there is no mechanical wear on the bearings, an AMB circulator has a longer duty lifetime and less maintenance. ${ }^{57}$ The AMBs are also going to be an important part of the design for HTR-10GT's power conversion unit. ${ }^{11}$

Lessons Learned: AMBs may apply to the NGNP design, and NGNP would benefit from the design and experience gained from the HTR program. 


\subsubsection{Oil Ingress in Compressor (Peach Bottom Unit 1)}

The compressor circulates the helium through the primary system. Near the end of Core 1's life, there was concern about oil ingress. It was shown that the oil ingress originated in the compressor. More specifically, the ingress started from the oil demister/filter, which removes any oil vapor and oil mist from the discharge in the compressor, and the oil lubricant. Since the demister/filter was saturated with oil, it was speculated that oil was discharged into the reactor. ${ }^{58}$ The ingress of the oil lubricant in the main compressor would have originated from back diffusion through its helium buffer.

Approximately $100 \mathrm{~kg}$ of oil entered the reactor. Evidence of the oil ingress was found by observing carbon deposits in the primary circuit metallic surfaces and persistent hydrogen and methane impurities. These deposits did not have any negative effects on the heat exchangers nor the metallurgy. Cesium plateout occurred near these carbon deposits. This ingress did cause a failure of the moisture monitor cells. $^{58}$

Lessons Learned: The oil in circulator bearings is a potential source for oil ingress into the reactor. If the NGNP design incorporates oil lubricated bearings, the design also needs to draw from experience with previous oil lubricated circulators to minimize the likelihood of oil leakage.

\subsubsection{Friction Damage (Dragon)}

The circulators used in the Dragon reactor were single-stage centrifugal blowers. During installation, all the welds were leak tight and passed all tests. After that, the circulators worked well without any distinguishable problems. They were also designed to be removed and checked regularly. ${ }^{59}$ Gas bearings were used in Dragon, but the lubrication could not support the weight without a minimum rotation speed. At low speeds dry friction in an oxygen-free, helium environment in the circulator bearings could lead to damage. Damage was avoided at speeds lower than the minimum by pressing helium as a hydrostatic lubricant during starting and stopping of the circulators.

Lessons Learned: If the NGNP design incorporates gas lubricated bearings, the design should consider the method used to prevent damage to the gas bearings used for circulators in the Dragon Reactor during startup and shutdown. NGNP should evaluate the value of using gas lubricated circulator bearings for its design.

\subsection{Intermediate Heat Transfer}

\subsubsection{IHX Materials (THTR)}

Recent work associated with the advancement of heat exchangers for HTGR research recommends the use of Alloy 617 (nickel base) for temperatures above $850^{\circ} \mathrm{C}$ and Alloy $800 \mathrm{H}$ (iron-base) for temperatures below $850^{\circ} \mathrm{C} .{ }^{60}$ This German research was able to demonstrate stress rupture behaviors of the alloy and how carburization or decarburization occurs, depending on the materials used and on flow rates. Research performed in the 1980s and 1990s showed that "with regard to the effect of decarburization, the more likely interaction in service because of high helium flow rates, the creep strength was found to be dramatically reduced." 00

Lessons Learned: Specific high performance alloys need to be used for the temperatures and environments experienced in HTGR reactor components. Alloy 617 and Alloy $800 \mathrm{H}$ are being considered for use in the NGNP IHX and are part of the NGNP High-Temperature Materials Qualification Program. ${ }^{61}$ 


\subsubsection{Successful Operation at High Temperatures (HTTR)}

HTTR was able to successfully use and test a $10 \mathrm{MW}$ helical coil IHX. The heat transfer tubes and headers were made out of Hastelloy XR with the shell being made of $2-1 / 4 \mathrm{Cr}-1 \mathrm{Mo}$. The maximum operating temperature was $955^{\circ} \mathrm{C}$ for the heat tubes and $430^{\circ} \mathrm{C}$ for the outer shell. The maximum pressure rating was $4.8 \mathrm{MPa}$.

Lessons Learned: NGNP would benefit by evaluating HTTR's IHX materials and construction if it is to operate in similar pressure and temperature regimes.

\subsubsection{Helium Leakage in Secondary Loop (HTTR)}

It was discovered through discussions with personnel who have toured the HTTR facility that there have been problems with helium leaks in the secondary helium coolant system. The helium leaked through flanged pipe connectors, which later needed to be welded to contain the helium.

Lessons Learned: This experience shows a potential source for leakage in the secondary coolant system. NGNP would benefit by reviewing the HTTR experience in the type of connections necessary to avoid any coolant leakage incidents.

\subsubsection{IHX and Steam Generator Integration Design (HTR-10)}

The steam generator and the IHX have been integrated in the HTR-10. ${ }^{54}$

During in-service inspection, tube plates located in the steam generator tube box are approachable when the tube box header is opened (see Figure 17). If the leakage rate is not acceptable, helium leakage inspection equipment can be used to find the leaking tube when the reactor is shut down. The leaking tube can then be plugged on the nonradioactive side in the cold leg tube box and in the hot leg tube box. ${ }^{62}$

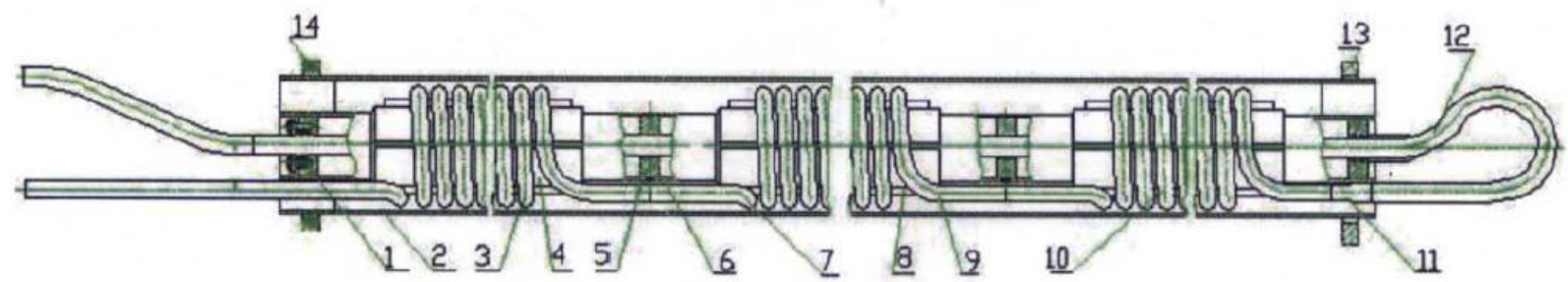

Figure 17. Heat transfer tube set structure for HTR-10. ${ }^{b}$

Lessons Learned: HTR-10 demonstrated the ability to conduct in-service inspections of the IHX. NGNP design should be consistent with applicable requirements from ASME Section XI on in-service inspection.

b. Components for Figure 17: 1-lower end plate; 2-external pipe; 3-first helical tube; 4-internal pipe; 5-fixing ring; 6-central pipe; 7-second helical tube section; 8-support plate; 9-third helical tube section; 10-fourth helical tube section; 11-transition section; 12-connection tube; 13-upper orientation plate; 14-lower orientation plate. 


\subsection{Hot Duct and Cross Vessel}

\subsubsection{Hot Duct Materials (THTR)}

Just like the heat exchanger in Section 3.2.3 above, the preferred candidate materials for the hot duct are Alloy 617 or $800 \mathrm{H}$, depending on temperatures above or below $850^{\circ} \mathrm{C}^{60}$ One important issue to consider for use of Alloy 617 is the high cobalt content:

The high cobalt content in Alloy 617 could pose a potential problem, although in German HTR projects, it was found that Co was not incorporated into the oxide scale and so radioactive Co would not therefore enter the hot gas circuit, even if the oxide spalled off. ${ }^{60}$

Lessons Learned: Specific high performance alloys need to be used for the temperatures and environments experienced in HTGR reactor components. Alloy 617 and $800 \mathrm{H}$ are considered for use in the NGNP hot duct. Thorough evaluation of hot duct materials is part of the materials R\&D plan for NGNP. ${ }^{61}$

\subsubsection{Successful Use of High Temperature Hot Duct (HTTR)}

The HTTR was able to successfully use and test a hot duct constructed with Hastelloy XR as the liner and $2-1 / 4 \mathrm{Cr}-1 \mathrm{Mo}$ for the pressure tube and inner tube. The insulation material was a ceramic fiber composed of $\mathrm{SiO}_{2}$ and $\mathrm{Al}_{2} \mathrm{O}_{3}$.

Lessons Learned: Hastelloy XR and 2-1/4 Cr-1Mo are technically viable candidate materials for HTGRs and the NGNP. The NGNP Project should take these materials into consideration when designing high temperature components such as the hot duct.

\subsubsection{Loadings on Cross Vessel (HTR-10)}

In HTR-10, the cross vessel connects the RPV with the steam generator pressure vessel (SGPV). In the primary circuit, the hot gas flows through the hot duct inside the cross vessel to the steam generator, and the cool gas flows outside the hot duct from the circulator. The cross vessel is constructed from SA516-70 steel and is considered the weak component in the primary circuit. This is because the cross vessel can experience variable loadings, which include pressure, bolt forces, and temperature variations. Other loads could be seismic, which would be caused by an earthquake and the vibrations from the RPV and the SGPV. There could also be a friction load from power changes and installation loads from errors happening during the installation of the cross vessel. From fatigue, the crack growth would be small for the entirety of reactor life and would still be considered in the safe zone for the cross vessel. If a crack did occur, the leak would be large enough to be readily detected. ${ }^{12}$

Lessons Learned: The cross vessel piping can come under variable loadings, pressure, temperature variations, and fatigue. Although NGNP is considering using SA508/533 for the cross vessel, the design still needs to consider the various types of loadings the cross vessel may incur and the potential consequences.

\subsection{High Temperature Valves}

\subsubsection{Mitigating Air ingress Through Valves (HTR-10)}

The safety valves in the HTR-10 are divided into two classes. Class 1 is installed in the primary circuit and discharges the helium if the pressure limit is reached. Class 2 ensures the pressure does not reach the pressure limit of the steam loop. Because of nuclear safety code, there are two sets of both 
classes installed. The life of the valves depends on the surfaces of the sealing parts. If any damage occurs or the matching between the disc and the seat is not rigorous, a leak will form. This leak could potentially grow and disable the valves. According to Xinxin et al., "It is also difficult to reseal a valve when it reseats after an action; several actions may cause the loss of its original tightness." HTR-10 uses a disc guide to prevent the valves from having inner leakage. The disc and the seat are made of materials of different stiffness to further prevent leaking. "Due to the leakiness and penetrability of helium, in order to prevent outer leakage in helium safety valves, a 'skirt sealing welding' structure is used for the connection between the inlet nozzle and the body, the valve body and the middle cover as well as the middle cover and the cover." ${ }^{\prime 3}$

Lessons Learned: Valves are one source for air leakage. NGNP would benefit by evaluating manufacturing tolerances and addressing this issue in the design. The NGNP design will incorporate applicable requirements from the ASME Code in design and manufacture of valves. 


\section{POWER CONVERSION SYSTEM}

\subsection{Steam Generator}

The history of steam generators for gas-cooled reactors provides several lessons and shows that designs constantly improve as a result of these lessons. Magnox reactors, some of the first gas-cooled reactors, were built and operated in the UK as a fleet. These reactors also used a helical coil steam generator, and most remained in operation for the length of their design life. AGR was also part of a fleet of early reactors, which also had helical coil steam generators. "The similarities in design and operating conditions make AGR a good comparison to NGNP." ${ }^{64}$

Table 3 shows the operating experience of several gas-cooled reactors. The majority of the reactors in this table are Magnox and AGR, which used $\mathrm{CO}_{2}$ as a primary coolant. From these operating experiences, it was observed that "...design, construction, fabrication, examination and operating conditions have the greatest influence on failure frequency." Several of the failures were from faulty design or defects in manufacturing, but "...later designs had less steam generator leaks than earlier designs." This shows that designs of steam generators are continually improving from past lessons and implementation of new technology. ${ }^{64}$

\subsubsection{Cracks/Leakage in Steam Generator (FSV)}

A leak in the superheated steam section in one of the steam generator modules occurred late in November 1977. The presence of the leak was readily detectable because of a gradual rise in moisture content of the primary helium coolant. The reactor was manually scrammed without any required action from the plant protective system. The leaking module and tube were identified and the leaking tube was plugged. There was no radiation exposure to plant personnel involved in these repair operations. ${ }^{30}$

Several steam generator heat exchanger tubes leaked purified helium out of the main coolant system. One of the leaks was in a seal weld, which was in a nearly inaccessible location. ${ }^{7}$ Additionally, a main steam isolation valve that had been tagged/closed had drifted open and caused a power transient. ${ }^{7}$ Finally, the event that led Public Service Company of Colorado management to decide to permanently shut down FSV was the discovery of cracks in the main steam ring header. Subsequently, the cracks were determined by metallurgical examinations to be the result of thermal cycling of the header. ${ }^{7}$

Lessons Learned: Tube leaks at FSV required repeated repair. NGNP would benefit by evaluating a comprehensive strategy to avoid moisture ingress, including early leakage detection systems and early mitigation procedures. 
Table 3. Operating experience of HTR Steam Generators up to 1979.64

\begin{tabular}{|c|c|c|c|c|c|c|c|}
\hline 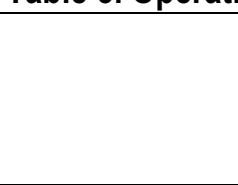 & Online & $\begin{array}{c}\text { Number } \\
\text { of SGs }\end{array}$ & $\begin{array}{c}\text { Years of } \\
\text { Operation } \\
\text { Until } 1979 \\
\end{array}$ & $\begin{array}{c}\text { Years } \\
\text { of SG } \\
\text { Operation } \\
\end{array}$ & $\begin{array}{c}\text { Tube } \\
\text { Failures }\end{array}$ & $\begin{array}{c}\text { Failure } \\
\text { Frequency } \\
\text { per SG per } \\
\text { Year } \\
\end{array}$ & Comments \\
\hline Berkeley* & 1962 & 16 & 16.5 & 264 & 10 & 0.04 & - \\
\hline Bradwell* & 1962 & 12 & 16.5 & 198 & 112 & 0.57 & $\begin{array}{l}\text { Mainly weld defects } \\
\text { leading to leakages in the } \\
\text { high-pressure section } \\
\text { during first few years of } \\
\text { operation }\end{array}$ \\
\hline Hunterston $A^{*}$ & 1964 & 16 & $\begin{array}{c}11 \\
\text { (until1975) }\end{array}$ & 176 & 75 & 0.43 & $\begin{array}{l}\text { Mostly leaks in low- } \\
\text { pressure section in first } \\
\text { few years of operation; } \\
\text { One large leak in the high- } \\
\text { pressure super heater } \\
\text { region }\end{array}$ \\
\hline Hinkley A* & 1965 & 12 & 14 & 168 & 4 & 0.02 & - \\
\hline Trawsfynydd* & 1965 & 12 & 14 & 168 & 39 & 0.23 & $\begin{array}{l}\text { Most leaks in the high- } \\
\text { pressure section and } \\
\text { caused by poor water } \\
\text { quality }\end{array}$ \\
\hline Dungeness A* & 1965 & 8 & 13.5 & 108 & 1 & 0.01 & - \\
\hline Sizewell A* & 1966 & 8 & 13 & 104 & 16 & 0.15 & $\begin{array}{l}10 \text { tube failures in } 7 \text { th and } \\
8 \text { th year (high-pressure } \\
\text { section), } 3 \text { after } 1975 \text { (low- } \\
\text { pressure section) }\end{array}$ \\
\hline Peach Bottom 1 & 1966 & 2 & $\begin{array}{c}7.5 \\
\text { (until1973) }\end{array}$ & 15 & 2 & 0.13 & $\begin{array}{l}\text { Small tolerable leaks on } \\
\text { tube plate }\end{array}$ \\
\hline Oldbury* & 1967 & 8 & 11.5 & 92 & 6 & 0.07 & - \\
\hline AVR & 1969 & 1 & 10 & 10 & 1 & 0.10 & - \\
\hline Wylfa* & 1971 & 8 & 8.5 & 68 & 46 & 0.68 & $\begin{array}{l}\text { Unusual design modified } \\
\text { for want of space; Leaks } \\
\text { caused by corrosion, } \\
\text { erosion, defects in design }\end{array}$ \\
\hline Hinkley B** & 1976 & 24 & 3 & 72 & 0 & 0.00 & - \\
\hline FSV & 1976 & 12 & $\begin{array}{c}5 \\
\text { (until1981) } \\
\end{array}$ & 60 & 1 & 0.02 & - \\
\hline AVERAGE & & & 11.1 & & & 0.19 & - \\
\hline
\end{tabular}

\subsubsection{Tube Rupture (AVR)}

In May 1978, the circulator for the AVR flooded with approximately 27.5 tons of water, enough water to flood the circulator above the shafts. ${ }^{65}$ Water also entered into the oil lubricating systems, which required extensive cleaning, rinsing, and moisture removal, resulting in a several-month delay in reactor operation. The direct cause of the flooding was a leak within the super-heater tube. 
Initial restart went well in January 1979, but water was discovered to have again entered the circulator oil system. It was discovered during the cleaning that a seal had not been tightened enough. Because of this second water ingress, bearing integrity was questioned and circulator disassembly was performed to determine the cause of water ingress. Because of radiation exposure on the various parts within the circulator, repairs took several months.

Because the steam generator was located directly above the reactor vessel, the core and internals were found to be very wet. The reactor remained shut down for 15 months to remove the water and repair the leak. Corrosion was not significant and no safety issues were identified, but one cause of the extended shutdown was the absence of a reactor vessel drain. ${ }^{42}$

The moisture ingress events experienced at AVR became the design-basis accidents for the THTR. ${ }^{60}$

Lessons Learned: This experience shows the extent of damage and time required to recover from a tube rupture. It also shows the need for the repair to be done correctly before returning to operation, or more damage and time may be lost. NGNP designs need to minimize the possibility of tube ruptures and would benefit by exploring methods to mitigate the consequences of a tube rupture event including: in-service inspections, the use of best practices for operations and maintenance procedures, and incorporating a reactor vessel drain into the design. Current proposed NGNP designs locate the steam generator lower than the RPV to eliminate the siphoning effect. NGNP would also benefit from the continued use of design-basis accidents to ensure that the impact of tube ruptures will be minimal.

\subsubsection{Hot Steam Headers for the Steam Generators (THTR)}

An IAEA report discusses the steam header for the THTR steam generators. During the design phase of the steam generators, four specific issues were identified that required special attention:

- The components were the pressure retaining parts with the heaviest wall thickness in the region of the steam generators

- The components were therefore sensitive to thermal transient conditions

- The components were operated in the elevated temperature regime, where creep effects cannot be neglected

- There was almost no service experience from fossil steam generators with this type of material (Alloy 800). ${ }^{66}$

The report addressed two safety considerations:

- Analytical investigations on the cyclic material behavior under all specified operating conditions, taking into account the nonelastic response of the material.

- Limitation of the consequences of a header rupture by installation of heavy whip restraints.

The header design needed to consider 30 different transient operational conditions. The elastic plastic creep analysis was practically impossible to analyze for all transient conditions. Because of the complexity, a filtering system was developed to discern the relevant transient conditions.

Material behavior was evaluated next. Alloy 800, Grade 1 material was used in the header. The material was supposed to have advantages over the commonly used alloy $800 \mathrm{H}$, Grade 2, at the long-term operating temperatures of around $560^{\circ} \mathrm{C}$. Further behavior analysis showed:

At this temperature creep effects are not dominant and therefore the solution annealed Grade 2 form would not be any better. The specified yield strength of the header material is higher than for the solution annealed grade. 
For the inelastic analysis it was decided to use plastic behavior data from uniaxial specimen tests with cyclic strain loading. ${ }^{60}$

Test results showed that at a one-half percent strain range at $550^{\circ} \mathrm{C}$, the material has a "distinct tendency for strain hardening for monotonic and for cyclic loading." The behavior was transferred into the stress-strain curves, which can be used for inelastic analyses.

Lessons Learned: Steam header design considers wall thickness, thermal transients, and creep effects. The NGNP will be designed in accordance with the ASME code. Instrumentation in the steam generator could be useful to help validate NGNP design predictions in the first-of-a-kind NGNP.

\subsubsection{Fatigue Analysis (HTR-10)}

A study conducted by Xiaotian and Shuyan showed that shutdowns can cause fatigue in the steam generator. This fatigue is from the thermal stress of the different temperatures in the primary and the secondary loop. The temperatures are $430^{\circ} \mathrm{C}$ and $100^{\circ} \mathrm{C}$ for the primary and secondary circuit, respectively. A fast start up after shutdown is done to save time and quickly reach full power but does not allow enough time for the primary circuit to cool down. This temperature difference also causes tensile stress at the joints, and the welds at these joints are easily affected by the fatigue. The study also showed that 90 cycles for 1 hour and 880 cycles for 10 hours are the allowable cycles for hot startup after shutdown. ${ }^{67}$

Lessons Learned: The steam generator can come under fatigue stress from cyclic thermal loadings caused by fast startups after a shutdown. NGNP would benefit by evaluating thermal cycling and minimizing this fatigue stress through design, material selection, and in the operating procedure. Thorough stress analysis would be beneficial to the NGNP design.

\subsubsection{Materials Used and Migration of Tritium (Peach Bottom Unit 1)}

The steam generators were forced-recirculation drum-type boilers with a thermal efficiency of $39 \%$, which was the highest at the time in the U.S. Throughout the steam generators' operating life, they did not suffer any tube leaks or plugging. Oxide did form in the economizer and the evaporator carbon steel tubes, but this was because of the fabrication. ${ }^{5}$

The steam generator was constructed of carbon steel, but the tubes were made from $800 \mathrm{H}$. To keep the steel temperature within limits, the steam was contained in concentric ducting and shrouds insulated with metallic thermal barrier. ${ }^{4}$ The $800 \mathrm{H}$ incurred significant age hardening damage but retained its ductility. These results were acceptable and were accurately predicted for Peach Bottom. ${ }^{5}$ From one study, $800 \mathrm{H}$ has a lower oxidation rate if it is noncold rolled instead of cold rolled. ${ }^{68}$

Throughout Peach Bottom's life, the steam generator was monitored for tritium. The tritium would have been released from the helium coolant to the water, which was later drawn into the containment sump for liquid waste. The measurements, however, were affected by operating variables and could be unpredictable at times. ${ }^{50}$ End of life assessments have been conducted to better understand the tritium permeation. It was shown that the permeation rates were not dependent on the operating temperatures, though this pertains to only certain material at certain temperature ranges. It was also shown that if the surface film on the coolant side was removed, the tritium permeation would actually be lowered. ${ }^{69}$

Lessons Learned: Peach Bottom demonstrated successful use of $800 \mathrm{H}$ and also gathered tritium permeation data. The tritium permeation was shown to be independent of the operating temperature, which only pertains to certain materials at certain temperature ranges. Removal of surface film may help lower the permeation. NGNP is using the data as part of the High-Temperature Materials Qualification Program. ${ }^{61}$ 


\subsubsection{Dynamic Stresses and Side Flow Maldistribution (AGR)}

The AGR's steam generators were predominantly helical coil and used carbon dioxide as a primary coolant. AGR's steam generator has similarities to NGNP: ${ }^{70}$

AGR failures associated with the dynamic stress generated by the noise from the gas circulators have highlighted the importance of correctly identifying and quantifying the forces that generate these stresses. The frequency spectrum from the circulators takes the form of broad-band noise with a number of discrete peaks associated with the blade passing frequency and its harmonics. ${ }^{70}$

The AGR's steam generator had some trouble with side flow maldistribution, which lowered the power rating to $58 \%$ and caused the heat exchanger to "...operate outside of the limits imposed by material properties, bimetallic weld and water/steam side stress corrosion concerns." The outer tube rows operated at a high temperature near the creep rupture limit, and several inner tube rows were operating at saturation temperature with bimetallic weld wetted. AGR was able to get the power rating up to $82 \%$ after a reorificing effort within the feed water tube sheet. ${ }^{70}$

From thermocouple readings, the temperature profiles were found to be uniformly maldistributed in the circumferential or radial direction. The circumferential direction was not uniform because of incomplete mixing of the linear up-flow cold gas and hot gas entering the boiler. The radial direction not being uniform was caused by dimensional tolerances and clearances between the outermost tube rows and casings. ${ }^{70}$

Lessons Learned: The NGNP should evaluate vibration induced stresses and the resulting flow maldistribution in the steam generator. This evaluation and the resulting design should benefit NGNP by maintaining the power rating and not allowing it to drop. 


\section{BALANCE OF PLANT (BOP)}

\subsection{Fuel Handling System}

\subsubsection{Design issues (FSV)}

There was a potential for fuel damage during fuel handling maneuvers at FSV. On November 24, 1981, a grappling device was used to remove a core restraint device, called a "Lucy Lock," from the top of the core, and the device was dropped. General Atomics redesigned the fuel handling system to improve efficiency and reliability in future refueling operations. ${ }^{7}$

Lessons Learned: As NGNP designs fuel handling equipment, it would benefit from past experience and minimize the likelihood of drops and accidents through proper design and operating procedures.

\subsection{Instrumentation and Control}

\subsubsection{Instrumentation Failure (FSV)}

Events during the operation of FSV 29 were related to either a moisture incursion or a failure of a moisture detection system. ${ }^{7}$ These events were classed into four general categories: thermal-hydraulic moisture outgassing, tube leaks, moisture detection instrumentation failures, and process line plugging or obstruction. Moisture outgassing events occurred 18 times, moisture detection instrumentation failures occurred five times, tubes failed four times, and plugging occurred twice.

Fifty instrumentation and controls events were distributed among four general areas. ${ }^{7}$ First, 13 events were classified as inoperable instruments that were out of calibration or had drifted from their correct set points. The next classification was for events where instruments were moved, disturbed, or otherwise subjected to physical motion that produced an erroneous or false signal from the instrument; eight events were in this group. Five events were then grouped together because instruments failed, sent a false signal, or tripped because of a short between contacts or because the instrument had dirty contacts. The final grouping of events contained by far the largest number; there were 24 events in this last group, all resulting from instrument "noise" or a spike on an instrument's output signal. ${ }^{7}$

The pressurization gas flow monitoring system was deficient at FSV. Purified helium flow is typically measured instantaneously, and the flow is constantly fluctuating. These flow fluctuations were caused by PCRV pressure changes and previously identified leakage in the Loop 2 steam generator penetration interspace. These fluctuations also caused intermittent actuations of the high flow alarm. It was also possible, therefore, that the intermittent alarms could actually mask a larger or additional leakage problem. The principal investigator for the project pointed out that this masking could hide more serious issues depending on, among other things, how long the alarm condition had existed. For example, the governing Technical Specifications Limiting Conditions for Operations for instrumentation systems may have needed clarification or could have been subject to interpretation, which could have resulted in or contributed to a delayed response by the operators. ${ }^{7}$

An electrical system upset was caused by a cooling oil pressure sensor on a newly installed $4160 / 480$ volt load center transformer. The fault occurred twice, leading to transients on instrument busses that caused circulator trips, which resulted in moisture ingress. ${ }^{53}$

Lessons Learned: NGNP instrumentation would benefit by being tested in relevant environments, being proven prior to installation, and by including a method to detect failed instruments. NGNP should evaluate the use of resilient controls, including inferred signals upon failure of primary instrumentation. 


\subsubsection{Core Temperature Instrumentation (AVR)}

One concern with the AVR is that there was not enough instrumentation to monitor the core temperature of the fuel. It is theorized that the fuel exceeded $1600^{\circ} \mathrm{C}$, which may have caused the graphite dust generation and problems with the TRISO layers failing, thus releasing fission product gases.

Lessons Learned: NGNP's design may benefit by evaluating the inclusion of temperature monitoring capability in the core. This is very challenging to implement, but determining new methods of core temperature monitoring may be an area for future research.

\subsection{Other}

\subsubsection{Helium Purification System Issues (FSV)}

Excessive moisture caused the operating helium purification train at FSV to "ice-up" (moisture had bypassed the chiller that is used to precipitate water from the helium purification system so that ice formed on the liquid-nitrogen-cooled krypton trap downstream of the chiller. $)^{7}$

Lessons Learned: This experience demonstrates a possible problem that could occur in a helium purification system. NGNP would benefit by evaluating effective helium purification systems, which maintain helium coolant chemistry within limits and do not introduce contaminants into the system.

\subsubsection{Chemical Cleanup (Peach Bottom Unit 1)}

Helium gas leaving the steam generator flows into the chemical cleanup system. The first part of the cleanup system is the oxidizer, in which tritiated hydrogen gas becomes tritiated water. The tritiated water is then removed by a molecular sieve-dehydrator. The rest of the helium continues from the sieve dehydrator to the fission product trapping system. ${ }^{50}$

Lessons Learned: Peach Bottom demonstrated a potential method for cleaning tritium from the primary loop. This experience may help NGNP determine the best method for trapping tritium.

\subsubsection{Helium Purification Piping (Dragon)}

Several leaks were found in the Dragon helium purification system. These leaks were originally discovered because the leak rate went from $0.2-\mathrm{kg} /$ day to $2.0-\mathrm{kg}$ /day. This increase was enough evidence that a leak had occurred. The leak was found to have been caused by chloride corrosion. It was also found that the leak had occurred at points in the piping that were marked with polyvinyl chloride (PVC) tape. The piping reached temperatures that ranged from 80 to $120^{\circ} \mathrm{C}$, which was enough for the PVC tape to decompose. This decomposition created gas pockets of hydrochloric acid between the tape and the surface of the pipe. Over time, many small cracks formed causing the leak. All the tape was removed, and the suspect piping was replaced. After that, the helium losses returned to normal $(0.2-\mathrm{kg} / \mathrm{day}){ }^{24}$

Lessons Learned: The NGNP can benefit from material compatibility assessments during design, operations, and maintenance within the helium purification system.

\subsubsection{Auxiliary Systems Failures (FSV)}

Thirty-nine events occurred concerning auxiliary systems at FSV. Seven of these events were related to inoperable snubbers on auxiliary piping and six events reported failure associated with a valve. Another event involved the failure of a joint in the circulating water system, resulting in flooding in a pump room. Eight other events were randomly distributed among various types of components. For example, a compressor malfunctioned in the helium purification system and charred and burned cables on several 
components of support systems to the helium circulators. Examples of these support systems include the circulator cold reheat drain valve, bottom head cooling system valves, and drain valves for the helium moisture separator.

Several other occurrences involved fire seal penetrations or fire barriers problems. However, events associated with a whole-system problem were the most numerous in this subcategory. For instance, one of the subjects examined was the "frequency of the unavailability of the emergency feed water supply header to the helium circulator water turbine drives." In essence, the safe shutdown analysis performed by the licensee depended on the emergency firewater system to provide decay heat removal following a shutdown; however, the system as configured may have been unable to perform its intended safety function. ${ }^{7}$

Lessons Learned: This experience showed that various areas of the auxiliary systems have a potential to fail with significant consequences to plant operations. The auxiliary systems should be designed or selected to operate in operational conditions and tested prior to operation in the NGNP.

\subsubsection{Electrical Arcing (FSV)}

On March 9, 1983, with the reactor at 30\% thermal power while moisture was being removed from the primary coolant, a phase-to-ground fault occurred on the unit auxiliary transformer because of an arcing short caused by the moisture leakage into an electrical bus from the building cooling duct system (not connected with the primary coolant system). There were no moisture detectors within the building cooling system. The damage included burned cables and melted insulators and required 10 days for repairs. Essential loads were being carried by offsite power from the reserve auxiliary transformer (RAT) at the time of the incident, so no transient resulted. ${ }^{53}$

Lessons Learned: Moisture in the duct cooling system caused electrical arcing. This may have been prevented if moisture detectors had been installed in the system, which would have allowed a rapid system repair. NGNP would benefit by considering proper placement of sensors to ensure timely response.

\subsubsection{High Winds (FSV)}

On December 8, 1983, high winds at the FSV site caused a fire detector to come loose and malfunction, activating the RAT deluge system. Since most of the essential loads were being carried by the unit auxiliary transformer at that time, there was only a minor transient involving some building cooling systems, and the RAT was restored within 20 minutes. Both of these incidents illustrate the susceptibility of the plant auxiliary transformers to externally induced events, which could have led to more severe transients or loss of essential power if a combination of these or other events had occurred. ${ }^{53}$

Lessons Learned: Meteorological conditions can affect siting considerations. As NGNP nears choosing a site to build the reactor, weather (winds, ice storms, tornados, etc.) conditions will have to be taken into consideration. 


\section{GENERIC NGNP LESSONS LEARNED}

\subsection{Generic Technical Lessons Learned}

\subsubsection{Human Error (FSV)}

Forty-seven events were reported in monthly reports that resulted from human factors or some other sort of personnel error. It is recognized that the "root cause" for all events can ultimately be traced back to some type of human error - a manufacturing error, engineering design error, installation error, etc. For this review, it was decided to classify only those events resulting directly from a human error and to group these events as follows:

- Licensed operator error

- Testing activity error

- Maintenance or repair activity error

- Installation activity error

- Radiation protection activity error

- Other activity error.

The 47 events are distributed as shown in Table 4.

Table 4. Event distribution for FSV.

\begin{tabular}{|lcc|}
\hline Personnel Activity Error & $\begin{array}{c}\text { Number of } \\
\text { Events }\end{array}$ & $\begin{array}{c}\text { Percent } \\
(\mathbf{\%})\end{array}$ \\
\hline Licensed Operator & 6 & 13 \\
Testing & 22 & 47 \\
Maintenance/Repair & 5 & 11 \\
Installation & 2 & 4 \\
Radiation Protection & 2 & 4 \\
Other & 10 & 21 \\
\hline
\end{tabular}

Human error can never be eradicated, but a dedicated and rigorous program to reduce human error can be expected to reduce the human error rate to an acceptably low level. For example, the commercial nuclear industry has a good track record over the past 10 to 15 years regarding testing and calibration of equipment. The testing and calibration of instruments and systems in this industry during this time has resulted in a very low human error rate. Inadvertent Technical Specifications Limiting Conditions for Operations resulting from testing or surveillance or from accidental scrams or initiations during surveillance or testing, have become virtually zero. The techniques, training, and attention to detail exhibited or practiced in the commercial nuclear industry could be implemented or applied for all future gas-cooled reactor designs. This same sort of exemplary performance record could be also accomplished for future gas-cooled reactors. ${ }^{7}$

Lessons Learned: NGNP would benefit by incorporating human performance into the design, construction, operations, and maintenance activities in order to prevent major issues associated with human error. 


\subsubsection{Licensing Issues and Safety Features (FSV)}

According to the NRC:

In initially implementing the provisions of The Code of Federal Regulations, Title10-Energy, Part 50, Section 71, "Maintenance of Records, Making of Reports" (10 CFR 50.71), issued in July 1980, with regard to updating and maintaining current the [Final Safety Analysis Report (FSAR)], the FSV initial update did not include a comprehensive revision of changes made in the NPP's licensing basis between 1974 and 1982.[...] It became evident during the FSAR review that in many cases, there were technical specifications that had been implemented since FSV start-up where no bases were documented in the FSAR. One of the most interesting examples was the base reactivity curve that had been implemented to address the large reactivity change observed in the expected critical position following a major water ingress event in 1974. The base reactivity curve was not explained in any documentation in the FSAR nor in any other topical report. The base reactivity curve was generated by the designer, General Atomics, reviewed by the FSV Nuclear Facility Safety Committee in which a staff person from General Atomics was required by the technical specifications to participate by direction of NRC, and was submitted to NRC Region IV but was never sent on to [Nuclear Regulatory Research (NRR)] for review. The exact purpose, meaning and utility of the curve to the safety of plant operations and how the curve related to any measurable parameter of the reactor were not obvious due to lack of documentation other than the cursory bases accompanying the technical specification, but it was a technical specification limiting condition for operation nonetheless.

Besides the issue of the base reactivity curve, there were other aspects of the safety-related reactor physics and nuclear design that were different from most other contemporary licensed NPPs. The information documented in Section 4.3 of the FSV FSAR had little to do with the nuclear analysis techniques actually used by the designer and the licensee for the analysis of FSV, including generation of the base reactivity curve. The core reload nuclear design reports were proprietary to General Atomics and were not submitted to NRC for review. The nuclear design-related start-up test data were reported as required by NRC Regulatory Guide 1.68, but were reported only as lists of calculated and measured data with no documentation nor analysis as to how the values reported were calculated, measured, or reconciled. This approach was distinctly different from that of other Power Reactor Demonstration Projects such as Yankee-Rowe where extremely detailed start-up testing reports were generated. ${ }^{1}$

According to J. K. August:

In 1981 when ASTA, Inc. reviewed the licensee-proposed FSV in-service inspection requirements for the NRC under contract through Los Alamos National Laboratory, ASTA concluded (ACN 8201130206) that, for the PCRV penetration double closures, the requirements of Section XI of the American Society of Mechanical Engineers Boiler and Pressure Vessel Code for Category I and II structures would not be met by the external visual inspections only (i.e., no surface or volumetric inspections) of the outer closure as proposed by the licensee. However, consistent with the regulatory latitude afforded under FSV's Class 104(b) license, NRC (ACN 8303150001) accepted the licensee proposal for visual inspections only without further addressing or reconciling the 
regulatory conclusion with the technical opinion from ASTA. Although not documented in the record, NRC recognized that the ASTA recommendation would have been extremely difficult to implement due to limited access for performing volumetric inspections, and thus NRC granted a less stringent requirement consistent with the plant's Class 104(b) license and the recognition that a closure failure was unlikely to occur and equally unlikely to cause significant off-site exposures.

The single most important lesson learned from Fort St. Vrain is the need for total commitment from the regulator and licensee. No one wants to design, build and operate an unsuccessful plant. There is a need for an independent reviewer's perspective. Also, it is important to limit technology advances in one single step. In the end Fort St. Vrain had all the LWR features and liabilities, despite the passive safe design. People are the most important safety design feature.

Complexity is alluring but it must be managed for the end objective.

Organizational factors can weigh in as much as design. Designs never turn out as predicted, therefore you need to use all sources of experience including previous designers and operators. Plan maintenance into design. It doesn't matter if you have $40+\%$ efficiency if it available less than $10 \%$ of the time. ${ }^{71}$

Lessons Learned: FSV experienced licensing issues that dealt with proper documentation; because of missing or incomplete documentation and safety features, it is difficult to fully verify some of the design decisions. NGNP would benefit by continuing to adhere to licensing documentation guidelines and requirements to ensure a high-quality, safe product and a traceable history.

\subsubsection{Licensing (HTR-10)}

The HTR-10 was issued a Construction Permit in 1994 by the Chinese nuclear licensing authority. This license had some hurdles to get over since the reactor was the first HTGR in China. The reactor showed many advanced designs towards safety both passive and active, but there was still little experience with licensing. Part of the lack of experience was that the licensing authority did not know how to treat the passive safety features. Before the licensing began, the National Nuclear Security Administration wrote two documents that were supposed to be a basis for HTR-10. China also referenced international and foreign codes and guides on HTGRs. HTR-10 was given special treatment because of its small size, but was not regarded as a test reactor since it was to test power generation. ${ }^{72}$

The licensing followed a procedure starting with the preapplication. The preapplication was made up of the two documents produced by National Nuclear Security Administration. "Standard Contents and Format of the Safety Analysis Report" was the more closely scrutinized of the two, because it defined the framework of the Preliminary Safety Analysis Report. After review of the two documents, a reviewer asked more than 700 technical questions in writing. The HTR-10 engineers answered all the questions also in writing. Then the reviewer and the engineers met to discuss the technical issues and questions. Another meeting was held for special issues that were tracked by the Nuclear Safety Expert Committee. This cycle was repeated until a favorable Safety Evaluation Report was reached. ${ }^{72}$

Some of the main licensing safety issues discussed were fission product retention and the source term. Accident analyses also tested different scenarios, such as: decreased heat removal capacity, decreased primary flow rate, abnormal reactivity, and anticipated transient without a scram. A few highly hypothetical accidents were also analyzed. HTR-10 was designed against these accidents and was awarded the license. ${ }^{72}$

Lessons Learned: HTR-10 was the first HTGR built in China, and licensing procedures and regulations had to be developed. China looked to what other countries had done to help develop the licensing for HTR-10. NGNP would benefit by collaborating with NRC in updating the process for 
licensing HTGRs in the United States and by learning from international efforts. The NGNP will be licensed by the NRC.

\subsubsection{Protection Mechanisms Experience (AVR, THTR)}

A report from the core research plant in Jülich Germany documents the evaluation of the inherent protection mechanisms for HTGR safety and safety concept for nuclear process heat. ${ }^{73}$ The experience with AVR and THTR provides the basis of this report. To have excellent safety protection for future pebble bed HTGRs, the Germans determined the basic design needs and issues needed to be resolved are as follows:

- Automatic after-heat removal procedures result in a quick cooling of the fuel to avoid flow-instability and to prevent graphite corrosion in the case of water or air ingress. This fact limits the use of the auto-shut down potential of the core, which is based on the negative temperature coefficient of reactivity.

- A reliable after-heat removal with natural convection of the coolant gas can hardly be realized because core up-flow has to be avoided. Moreover, coolant mass flow must control structural and main-loop temperature transients during after-heat removal.

- Use of the temperature stability of ceramic fuel and core structure for radiation heat removal and temperature stabilization within after-heat removal strategies is limited because of possible damage of in-core rods and metallic core structural components (top reflector, thermal shield, etc.).

Features of the proposed German $350 \mathrm{MW}(\mathrm{t})$ annular core that address the above design needs and issues are as follows:

- Central graphite column with coolant ducts (low bypass cooling) and cylindrical ducts for ceramic absorbers

- Down-flow of the core coolant within the pebble-bed

- Side reflector with control rods and main cold gas up-flow

- Radial coal stone thermal insulation adjacent to the side reflector

- Top reflector cantilever beam construction without metal tie bars

- Cold thermal shield with water cooling system (structural cooling system)

- PCRV with non-insulated liner and liner-cooling system.

Lessons Learned: NGNP would benefit from considering the protection mechanism needs and issues that were developed as a result of AVR and THTR experience.

\subsubsection{Graphite Disposal for German HTGRs (AVR, THTR)}

Large quantities of radioactive graphite resided in the German inventory because of the decommissioning of AVR and THTR, as well as other research reactors. Because of the volume of graphite, existing containers could not handle all of the accumulated radioactive graphite, mostly because of the dimensional size and available containment casket. Thus, cutting the graphite into smaller sizes is imperative. By changing the dimensions of the various graphitic reactor components, the Germans will be able to dispose of the various components within the existing MOSAIL II containment caskets available.

Various cutting techniques are currently under consideration, including "the hydraulic technique water jet cutting and the thermal cutting technique plasma arc cutting because of their narrow cutting kerfs, flexible operability, lightweight cutting tools, small tool sizes and negligible recoil forces. Thus, 
minimization of personnel radiation-exposure as well as minimized secondary waste production during dismantling of graphitic nuclear components can be achieved." ${ }^{, 74}$ The best suitable cutting techniques are being tested and evaluated to with the minimum of waste production rate in mind. Subsequent evaluations planned for the future will concentrate on dust production, minimized irradiation exposure to staff, and time and practicability under various constraints associated with the varying sized graphite components.

Lessons Learned: The NGNP project should monitor the German's progress in the area of graphite disposal, particularly as it relates to limiting exposure to workers. NGNP would benefit other's experience in disposal and considering various alternative disposition pathways for graphite as well as other major components during the full system life cycle.

\subsection{Programmatic Lessons Learned}

The programmatic lessons learned from HTGRs are that (1) political and community opinions and fears can drastically change the favoring of nuclear power, and (2) funding for such advanced or new nuclear technology can be quickly removed.

Even though HTGRs in Germany proved to be safe and efficient in their varieties of fuel types and combinations, it was not enough to keep the public from fearing nuclear power. The resulting effects were the shutdown of AVR (R\&D missions completed) and defunding of continual research for HTGRs by the German government. Eventually, the German government determined to stop all new nuclear research and created plans to shutdown remaining commercial nuclear reactors within a given time period. The latter decision was reversed in 2009 with the support of Chancellor Merkel and her administration, with large support by the German people. The reestablishment of support for nuclear power hinges upon realizing the benefits of HTGRs, including:

- Reduced greenhouse gas emissions

- Alternative heat source to reduce reliance on single volatile source

- Reduced reliance on foreign energy

- Retention of premium fuel.

\subsubsection{Decommissioning AVR}

AVR was shutdown and scheduled for decommissioning after 21 years of operation in meeting its design and research objectives. Because of the political and economical difficulties, including unification of the two Germanys into a single governmental state, the amount of time to decommission the AVR was longer than necessary. Funding to determine how and when the final decommissioning activities would take place was also an issue. Eight years passed between application of the license to decommission and application approval. Because of this long time period, defueling the AVR and dismantling the reactor building were a major concern and factored into several unanticipated issues. ${ }^{75}$ The spent fuel remained in the reactor core after shut down and resulted in fission product formation and plating. Further, the higher levels of activation and radioactivity led to the need to create unique casks and handling systems to manage the spent fuel outside of the planned method, and fuel pebbles had to be removed despite failure of the ring channel machinery. ${ }^{75}$ Because of the length of time and the different kinds of fuel in the AVR, the decommissioning agents addressed two significant problems:

1. Since the reference fuel of the AVR had always been highly enriched uranium fuel but the AVR core consisted in the end of about $50 \%$ of low enriched fuel, the Research Center needed an extra license to transfer that fuel through the water basin of their Hot Cells facility on the way to its storage in above ground casks (CASTOR). 
2. Displacement of pebbles in the core during defueling would lead to an increase in the fuel concentration in the core center so that an increase of reactivity during defueling could not be ruled out.

Lessons Learned: The AVR experience demonstrated that decommissioning can become a lengthy and costly procedure and unforeseen difficulties can hinder the decommissioning process. NGNP would benefit by considering all aspects of its full system life cycle, including decommissioning.

\subsubsection{Political Shutdown of THTR}

Shutdown and decommissioning of the THTR was a political action. Because of the political influence of environmental groups, Germany's governing bodies deemed nuclear power was not acceptable and decided to shutdown the reactor after only 432 power days of operation. Additionally, the Chernobyl incident caused many German citizens to become afraid of nuclear power. Because of these events, THTR did not fulfill its mission to provide commercial power via pebble-bed HTGR technology for a long period of time.

Lessons Learned: THTR showed how the life of a plant is affected by political decisions. NGNP would benefit by securing a financial risk mitigation strategy to protect the owner's investment.

\subsection{Noteworthy HTGR Lessons Learned}

Below is a set of lessons learned included as noteworthy information, but are not directly applicable to the NGNP.

\subsubsection{Fuel Performance (THTR)}

Fuel for the THTR ${ }^{76}$ was based on the experience and lessons learned from the AVR. Nine noble fission gas nuclides were measured quasicontinuously during THTR commissioning and it's short-lived 423 full-power days to establish fuel performance. During this time, there was an observed temperature increase and failed particles, but these could not be explained from their calculated model. According to Röllig, "The model [that] guided analysis of the THTR coolant gas activity enables a comprehensive understanding of the actual status of the fuel elements performance." THTR's experience was the background for this model, which showed that fuel elements were being damaged by mechanical forces. These mechanical forces were attributed to the control rods being inserted directly into the core during unfavorable conditions. Most of the damaged elements did not expose the fuel kernel, yet some of the elements were damaged right through the inner fuel zone. Röllig further added, "Practically all fission products recoiled from the exposed kernel surfaces are stopped in the coolant. The damaged fuel was then sorted out from recirculation at the core exit." Despite the damage fuel elements, the measured activity in the coolant was only $4 \%$ of the licensed value. ${ }^{76}$

\subsubsection{Corrosion Issues in Tendon Wires (FSV)}

On March 28, 1984, the licensee reported, in accordance with 10 CFR 50.72, that it had discovered that a "significant" number of the tendon wires used in the FSV PCRV were either corroded or failed. The discovery occurred during the 10-year surveillance inspection of the PCRV. The tendon wires are used to create an initial compressive stress on the concrete and allow the vessel to contain gas at higher internal pressures. The PCRV tendon system consists of 448 tendons and each tendon consists of 152 or 169 one-quarter-inch wires. The 448 tendons may be classified into four distinct groups: 24 each in the top cross head and bottom cross head classes, 90 in the vertical or longitudinal class, and 310 in the circumferential class. Twenty-seven load cells are used to detect any loss of prestress in the PCRV and are installed on selected tendons. The top cross-head and bottom cross-head classes have two load cells 
each, while the vertical class has six load cells. The remaining 17 load cells are associated with the circumferential class of tendons. ${ }^{7}$

The tendons are in sealed boxes that were opened for the inspection, and selected sample wires were removed for further inspection. None of the sample wires showed signs of corrosion, but the licensee found broken or corroded tendon wires in the center of at least six tendons, and up to 30 of a possible 169 wires were found broken in a single tendon. ${ }^{11}$ Investigation determined that a microbiological agent was at work in the presence both of the sulfonate grease used on the tendon wires and of oxygen from air ingress into the tendon enclosures. The steel wires were being attacked by acetic and formic acids formed by the bacteria. ${ }^{53}$

\subsubsection{Coated Particle Fuel Options}

A paper from the $2^{\text {nd }}$ International Topical Meeting on High Temperature Reactor Technology, held in Beijing, China in September 2004 discusses the status of the SiC TRISO-coated particle fuel and the concept for developing the fuel further. ${ }^{77}$ The paper's intent is to address the lack of irradiation data on TRISO, since there had been very little data at that time. Additionally, the paper suggests:

Very little fuel irradiation and testing has been conducted since the mid-1990s when the gas turbine concepts were adopted. As a result, fuel irradiation and testing data are not currently available to support a prismatic core commercial application for either a gas turbine cycle or thermochemical water splitting. This paper briefly assesses the required fuel service conditions, applicability and limitations of existing data and fuel performance models, and uncertainties in the ability of low enriched uranium SiC TRISO fuel to perform acceptably under the required service conditions, as a basis for considering advanced fuel options.

The alternative conclusions of the authors are summarized as follows:

Because of the markedly improved fission-product retention of $\mathrm{UO}_{2}$ TRISO particles with thin $\mathrm{ZrC}$ layers applied directly over $\mathrm{UO}_{2}$ kernels with thin carbon seal coats in both HRB-15B and 15A irradiation capsule tests [conducted in the High Flux Isotope Reactor (HFIR)], compared to other fuel designs, and because of the uncertainties as to why this occurred, it seems highly desirable to conduct irradiation tests at higher temperatures, followed by post-irradiation heating, for $\mathrm{UO}_{2}$ particles with sturdier $\mathrm{ZrC}$ layers of various thicknesses and with thinner buffer layers. This would include the seemingly radical design in which the buffer layer is eliminated entirely. This would constitute a new design concept in which the goal would be to constrain kernel expansion of the $\mathrm{UO}_{2}$ kernel during irradiation with a thickened $\mathrm{ZrC}$ layer, rather than accommodating it with a highly porous crushable buffer layer. This would probably allow the particle diameter to be decreased considerably, perhaps allowing for both an inner and outer $\mathrm{ZrC}$ layer to be evaluated for $\mathrm{ZrC}$ TRISO $\mathrm{UO}_{2}$ fuel. ${ }^{77}$

\subsubsection{Reactor Cavity Cooling System Leakage (FSV)}

A crack in a weld on a PCRV liner cooling tube allowed moisture into the helium. Thermal expansion caused small leaks in welds to seal up when they are exposed to high power. ${ }^{7}$ Additionally, a cooling tube on the enclosure liner of the core support floor leaked water. By the end of November 1988, it was reported that 1,000 gal of water resulting from the leak had been removed from the reactor primary system. ${ }^{7}$ 


\subsubsection{Water-Cooled Bearing Leaks (FSV)}

Another source of moisture ingress at FSV was from circulator bearing water and proved to be a common problem at FSV. At least four times, when a helium circulator tripped, it caused a loop shutdown and a subsequent moisture incursion. ${ }^{7}$

On January 23, 1978, the failure of a level control valve and the back-up in the helium circulator bearing-water surge tank resulted in an upset in the circulator bearing water/buffer helium system. This allowed a small amount of primary coolant helium to flow into the buffer system and, subsequently, into the reactor building. The contaminated helium then traveled through the filtered building ventilation system to the atmosphere. There was no detectable increase in activity found in environmental samples. Plant safety devices worked as designed, and cleanup and repair were affected within allowable guidelines for nuclear plant personnel. ${ }^{30}$

The plant was operating at $50 \%$ power on June 22,1984 , when an auxiliary transformer sudden-pressure (or rapid-rise pressure) relay tripped. This caused a temporary loss of a 480 Vac essential bus, which in turn tripped the normal bearing water supply for the A and B helium circulators (Loop 1). When the backup bearing water supply came on line, there was a surge or upset in the buffer helium system. The preliminary moisture indication for the primary system was greater than $100 \mathrm{ppm}{ }^{7}$

\subsubsection{Containment (Peach Bottom Unit 1)}

During power operations, the containment vessel for Peach Bottom had to be inerted. Several problems developed in this inert nitrogen space in the form of steam and water leaks. The plant had to shutdown to repair these leaks since the nitrogen area had to be deinerted to ensure maintenance personal's safety was not put at risk. Most of the leaks were repairable with the plant at full power, were it not for the nitrogen containment. 


\section{CONCLUSION}

Past reactor design, construction, and operational experiences can help pave the path forward for the NGNP and future reactors. This report documents research on the lessons learned from HTGRs. The majority (33 of 68) of the lessons learned were associated with the Nuclear Heat Supply System. Most of these 33 could be summarized in the following three areas:

- Ingress or leakage events such as moisture ingress

- Primary coolant flow issues such as bypass flow and flow induced vibrations

- Fuel performance, fission product release, and graphite dust generation.

These lessons show the benefits of evaluating lessons from past HTGRs in achieving a safe and reliable nuclear plant.

Moisture ingress caused a number of problems in the reactors, especially at FSV. Not only did the moisture affect the reactivity control system, but it also directly affected the reactivity by acting as a moderator and absorbing neutrons. Further, moisture can cause graphite to oxidize and other components to corrode. Moisture can also be out-gassed from graphite when it is heated, referred to as drying out. NGNP would benefit by recognizing and mitigating these sources of moisture ingress including minimizing the possibility of leaks. Other impurities could contaminate the primary helium coolant (such as air or oil) which could cause damage and/or corrosion.

The primary coolant was shown to not always flow as predicted. In several cases, the helium would flow through the gaps within the core, known as bypass flow. Bypass flow has been shown to cause high stresses in the fuel elements and temperature fluctuations in the core. Helium impurities resulted in plateout on the heat transport surfaces and reduced their effectiveness. Bypass flow and helium impurities altered the efficiency of the heat exchangers and caused some walls to operate at temperatures that could cause material creep. These experiences show that NGNP would benefit by taking the flow of helium into consideration.

Another common concern found in these reactors was fuel performance and fission product release. Fuel damage can cause graphite dust to form and transport fission products throughout the primary loop, specifically for the pebble bed reactors. Dust is also a concern for prismatic designed HTGRs due to movement and shifting of blocks during operations. NGNP would benefit by recognizing these events and mitigating dust and its potential issues.

The remaining 35 lessons learned will help to inform the design of other reactor components such as circulators, heat transfer systems, and power conversion systems. Past experience will also benefit balance of plant systems and auxiliary systems. Important lessons were also learned other areas not directly applicable to reactor components such as human error, licensing issues, and safety features.

Evaluating these lessons provided by previous and current HTGRs will benefit the NGNP design. The lessons also serve to inform the current design data needs and design philosophy. In the end, all the lessons will help ensure a more reliable design for the next generation of reactors.

It is recommended that NGNP Project develop an implantation status summary of the lessons learned to document the current status of lessons learned implementation applicable to the NGNP. It is further recommended that $R \& D$ activities that address these lessons learned be continued. Overcoming key technology challenges and providing advancement in those areas of concern will improve future HTGR designs and reduce the risks associated with the NGNP and other HTGR technologies. 


\section{REFERENCES}

1. Reutler, H., and G. H. Lohnert (2004, April). "Advantages of going modular in HTRs." Nuclear Engineering and Design 78:2, pp. 129-136.

2. Hildebrandt, Phil, et al. (2004, June 30). Design Features and Technology Uncertainties for the Next Generation Nuclear Plant. Idaho National Engineering and Environmental Laboratory. Idaho Falls, Idaho. INEEL/EXT-04-01816.

3. Terry, W. K., J. K. Jewell, J. B. Briggs, T. A. Taiwo, W. S. Park, and H. S. Khalil (2004, September 15). Preliminary Assessment of Existing Experimental Data for Validation of Reactor Physics Codes and Data for NGNP Design and Analysis.

4. Kingrey, K. I. (2003, April). Fuel Summary for Peach Bottom Unit 1 High-Temperature Gas-Cooled Reactor Cores 1 and 2. Idaho National Engineering and Environmental Laboratory, INEEL/EXT-03-00103. Idaho Falls, Idaho.

5. Steward, K. P. (1978, July). Final Summary Report on the Peach Bottom End-of-Life Program. San Francisco, California.

6. Wimmers, C. Marnet, AVR GmbH, Dusseldorf, Germany; and U. Birkhold, ISE GmbH; Decommissioning of the AVR Reactor, Concept For The Total Dismantling; International Atomic Energy Agency, XA9848060.

7. Nuclear Regulatory Commission (2004). Fort Saint Vrain gas cooled operational experience. NUREG/CR-6839, January. Washington, DC.

8. Stithem, A. R., Wong, A. H. (February 1990). Summary Description of Operating Experience at the Fort St. Vrain (FSV) Nuclear Generating. Public Service Company of Colorado, Denver, Colorado.

9. "Chapter 2: HTGR Development and General Features", Current Status and Future Development of Modular High Temperature Gas Cooled Reactor Technology, IAEA-TECDOC-1198, ISSN 1011-4289, International Atomic Energy Agency, Vienna, Austria, February 2001, pp. 5-18.

10. Fujikawa, J.S., et al. (2004, December), “Achievement of Reactor-Outlet Coolant Temperature of 950C in HTTR," Journal of Nuclear Science and Technology, Vol. 41, No. 12.

11. Huidong, G., Z. Lei, D. Xingzhong, Y. Suyuan, and Z. Hongbin (2004, September). A Flexible Rotor in HTR-10 Passing Through the First Bending Critical Speed 24,000 RPM. Beijing, China.

12. Zhengming, Z., and H. Shuyuan (2004, September). Leak-Before-Break Analysis of the HTR-10's Hot-Gas Duct Vessel. Beijing, China.

13. Zhang, Z. (2007, May 15). Chinese HTR Program: HTR-10 Results \& Work Progress on HTR-PM. Beijing, China.

14. Jie, W., H. Zhiyong, S. Zhu, and Suyuan, Y. (2004, September). Design Features of Gas Turbine Power Conversion System for HTR-10GT. Beijing, China.

15. Goodjohn, A. (1991). Summary of Gas-Cooled Reactor Programs. Energy Vol.16, 79-106.

16. Shropshire, D. (2004, April). Lessons Learned From GEN I Carbon Dioxide Cooled Reactors. Arlington, Virginia.

17. Ball, S. (2004). Sensitivity Studies of Modular High-Temperature Gas-Cooled Reactor (MHTGR) Postulated Accidents. Oak Ridge, Tennessee.

18. Maki, J. T., Petti, D. A., Hobbins, R. R., McCardell, R. K., Shaber, E. L., \& Southworth, F. H. (2002, October). NP-MHTGR Fuel Development Program Results. Idaho Falls, Idaho.

19. General Atomics. (1988, March). MHTGR- New Production Reactor Summary of Experience Base. 
20. Shropshire, D., and S. Herring (2004, October). Fuel-Cycle and Nuclear Material Disposition Issues Associated with High-Temperature Gas Reactors. Idaho Falls, Idaho.

21. General Atomics Energy Group. Retrieved March 2, 2010, from GT-MHR: http:/gt-mht.ga.com.

22. Kadak, A. High Temperature Gas Reactors.

23. Yu, S., J. Liu, W. Zuo, and H. Shuyan (2002, January). Sealing Behavior of the HTR-10 Pressure Vessel Flanges. Beijing, China.

24. Simon, R. (2006, August). The Primary Circuit of the Dragon High Temperature Reactor Experiment.

25. Fujimoto, N., et al. (2004), "Experience of HTTR construction and operation-unexpected incidents," Nuclear Engineering and Design, Issue 233.

26. Halvers, L. J. (1977, March). Flow-Induced and Acoustically Induced Vibration Experience in Operating Gas-Cooled Reactors. GA-A14291. General Atomics.

27. Melese, G., and R. Katz (1984). Thermal and Flow Design of Helium-Cooled Reactors. La Grange Park: American Nuclear Society.

28. HTGR Preliminary Safety Information Document for the Standard MHTGR. DOE/HTGR-86-024. Volume 1. October 6, 1986. Bechtel National Inc., Combustion Engineering, Inc., Department of Energy, EG\&G Idaho, Inc., GA Technologies, Inc., Gas-Cooled Reactor Associates, General Electric Company, Oak Ridge National Laboratory, Stone \& Webster Engineering Corp.

29. Williams, P. M., King, T. L., Wilson, J. N. (1989, March).Draft Preapplication Safety Evaluation Report for the Modular High-Temperature Gas-Cooled Reactor. NUREG-1338. U.S. Nuclear Regulatory Commission.

30. Bramblett, G. C., C. R. Fisher, and F. E. Swart, Operational Experience at Fort St. Vrain, General Atomics.

31. Schultz, Richard, et al. (2010, August 11). Next Generation Nuclear Plant Methods Technical Program Plan. Idaho National Engineering and Environmental Laboratory. Idaho Falls, Idaho. INL/EXT-06-11804.

32. Haag, G., W. Delle, N. Kirch, H. Nickel, K. Reinhart, and E. Ziermann. Results of the Visual In-Pile Inspection of the Inner Graphite Reflector of the AVR, JAERI-M 86-192, Kernforschungsanlage Jülich GmbH, Jülich, Germany, SIGRI GmbH, Meitingen, Germany, Arbeitsgemeinschaft Versuchs-Reaktor (AVR) GmbH, Jülich, Germany.

33. Luo, X., Zhang, L., \& Yu, S. (2004). The wear properties of nuclear grade graphite IG-11 under different loads. Int. J. Nuclear Energy Science and Technology, Vol. 1, No.1 , 33-43.

34. Cobb, H. R. (1970, February 1). Postirradiation Examination of Peach Bottom Reflector Element B16-01 After Exposure to 300 Effective Full Power Days.

35. Windes, W. E. Graphite Technology Development Plan, PLN-2497, Revision ID: 1, Effective Date: 10/04/2010. Idaho National Laboratory. Idaho Falls, ID.

36. International Atomic Energy Agency (1997, November), Fuel performance and fission product behaviour in gas cooled reactors, IAEA-TECDOC-978.

37. Moormann, R., A safety re-evaluation of the AVR pebble bed reactor operation and its consequences for future HTR concepts, Forschungszentrum Jülich, Germany, ISSN 0944-2952, Jül-4275.

38. Schenk, W., D. Pitzer, and H. Nabielek. Fission Product Release Profiles from Spherical HTR Fuel Elements at Accident Temperatures, Kernforschungsanlage Jülich GmbH, September 1988, Jül-2234, ISSN 0366-0885. 
39. Kendall, J. M., and R. E. Bullock (2004, September 22-24). "Advanced Coated Particle Fuel Options," Global Virtual, LLC, Prescott, Arizona, Sigma Science Inc., Albuquerque, New Mexico, $2^{\text {nd }}$ International Topical Meeting on High Temperature Reactor Technology, Beijing, China.

40. Gottaut, H., and K. Krüger (1989, December). Results of Experiments At The AVR Reactor, Forschungszentrum Jülich GmbH, Germany, and Arbeitsgenmeinschaft Versuchreaktor GmbH, Jülich, Germany.

41. Petti, D., Bell G., (2005, May). The DOE Advanced Gas Reactor (AGR) Fuel Development and Qualification Program. Idaho National Engineering and Environmental Laboratory. Idaho Falls, Idaho. INEEL/CON-04-02416.

42. Schulten, R., "Possible New Developments Based on HTGR Technology and Operating Experience", Institute for Reactor Development, Kernforschungsanlage (KFA), Jülich, Germany, IAEA Bulletin, 3/1989.

43. Tang, C., X. Fu, J. Zhu, T. Liang, K. N. Koshcheyev, A. V Kozlov,. O. G. Karlov, Y. G. Degaltsev, and V. I. Vasiliev (2006). "Fuel irradiation of the first batches produced for the Chinese HTR-10", Elsevier, Nuclear Engineering and Design 236 (2006) 107-113, www.sciencedirect.com.

44. Schlögl, Bärbel, "Graphite Dust in AVR,” Jülich Forschungszentrum, Germany, Introduction Meeting on the Planned PSI Research Project on HTR Graphite Dust Issues, Paul Scherer Institute, Villigen, Schwitzerland, 26-27 November 2009.

45. Schlögl, Bärbel (2009, November). “Graphite Dust in AVR”. Introduction Meeting on the Planned PSI Research Project on HTR Graphite Dust Isues. Paul Scherer Institute, Villingen, Switzerland.

46. Liao, Y., "PSI Project on HTR Graphite Dust Generation and Transport Air Ingress Interaction with Confinement Gas Mixing and Recirculation", Introductory Meeting on the Planned PSI Research Project On HTR Graphite Dust Generation and Transport, Paul Scherer Institute, Villigen, Switzerland, 26-27 November 2009.

47. "Workshop on Nuclear Graphite Research", ORNL/NRC/LTR-09/03, September 9, 2009, Oak Ridge National Laboratory and Nuclear Regulatory Commission.

48. "Dust Generation and Transportation Behavior in the Primary Circuit," Meeting Between INL, GA and JAEA held at the Capabilities Matching Workshop for Utilization of HTTR and Other JAEA Facilities to Support the NGNP Project, Oarai Research and Development Center, Japan Atomic Energy Agency, October 20 -October 22, 2009.

49. Hanson, D. L., N. L. Baldwin, and D. E. Strong (1980, November). Fission Product Behavior in the Peach Bottom and Fort St. Vrain HTGRs. San Diego, California.

50. Wicherner, R. P., and F. F. Dyer (1979, August). Distribution and Transport of Tritium in the Peach Bottom HTGR. Oak Ridge, Tennessee.

51. Foster, A. R., and R. L. Wright (1983). Basic Nuclear Engineering. Newton, Massachusetts: Allyn and Bacon, Inc.

52. International Atomic Energy Agency. (1997, November). Fuel Performance and Fission Product Behaviour in Gas Cooled Reactors. IAEA-TECDOC-978. Vienna, Austria.

53. Moses, D.L., and W.D. Lanning, The Analysis And Evaluation of Recent Operational Experience From The Fort St. Vrain HTGR, NRC, Washington, D.C.

54. Xu, Y., and Y. Sun. HTR-10 Severe accident management. Beijing, China.

55. Yuanqiang, W., D. Xingzhong, Z. Huizhong, and H. Zhiyong (2002, March). Design and Tests for the HTR-10 Control Rod System. Beijing, China. Elsevier Nuclear Engineering and Design 218 (20020 147-157. www.elsevier.com/locate/nucengdes. 
56. Ledin, E. (1973, July). Control Rod Drive System for a High Temperature Gas-Cooled Reactor.

57. Xingzhong, D., Z. Lei, Z. Huizhong, Z. Meisheng, W. Jie, and Y. Suyuan (2004, September). Design of the HTR-10 Helium Circulator with the Active Magnetic Bearings. Beijing, China.

58. Burnette, R. D., and N. L. Baldwin (1980, November). Primary Coolant Chemistry of the Peach Bottom and Fort St. Vrain High-Temperature Gas-Cooled Reactors. San Diego, California.

59. Rennie, C. A. (1978). Achievements of the Dragon Project. Great Britain.

60. Makhel-Lekala, L., P. Ennis, and F. Schubert (2005, August 7-12) "Candidate Materials for Advanced HTGRs", Forschungszentrum Jülich IWV-2, Jülich, Germany, 18th International Conference on Structural Mechanics in Reactor Technology (SmiRT 18), Beijing, China, SmiRT18-S06-3.

61. Hayner, G., et al. (2005, September). Next Generation Nuclear Plant Materials Research and Development Program Plan. Idaho National Engineering and Environmental Laboratory. Idaho Falls, Idaho. INL/EXT-05-00758 Rev. 2.

62. Jianling, D., M. Yang, Y. Suyuan, and F. Jiyang (2001, August). Feasibility Analysis of Method to Avoid Tube Rupture in HTR-10 Steam Generator. Beijing, China.

63. Xinxin, W., D. Jianling, and L. Rizhu (2004, September). The Full Performance Test for the Safety Valves of HTR-10. Beijing, China.

64. AREVA NP Inc. (2008, September). NGNP with Hydrogen Production Conceptual Design Studies Power Conversion System Study.

65. Ziermann, E. L., Engel, J. Two Decades of Excellent AGR Circulator Operating Performance at AVR Jülich, Arbeitsgemeinschaft Versuchsreaktor AVR GmbH, Jülich Germany, Brown, Boveri, und Cie AF, Mannheim, Germany.

66. Blumer, U., and M. Stumpf. Mechanical Design of the Hot Steam Headers of the THTR-300 Steam Generators, Sulzer Brothers Ltd, Winterthur, Switzerland, EVT Stuggart, Stuggart, Germany, IAEA XA0056042.

67. Xiaotian, L., and H. Shuyan (2004, September). Fatigue Analysis of Steam Generator in HTR-10. Beijing, China.

68. Yamawaki, M., M. Mito, and K. Masayoshi (1977, February 4). Oxidation of Heat-Resistant FeBased Incoloy 800 Alloy. Japan.

69. Yang, L., and W. A. Baugh (1977, June). Study of Tritium Permeation Through Peach Bottom Steam Generator Tubes. San Francisco, California.

70. Idaho National Engineering Laboratory. (1990). Lessons Learned from the Design and Operation of Steam Generators for High Temperature Gas-Cooled Reactors. Idaho Falls: EG\&G Idaho.

71. August, J. K., Fort St. Vrain Lessons Learned: Management Perspective, Core Inc., Arvada, Colorado.

72. Sun, Y., and Y. Xu (1995). Licensing Experience of the HTR-10 Test Reactor. Beijing, China.

73. Petersen, K., Büscher, R., Gerwin, H., Schenk, W., "Efficiency of Inherent Protection Mechanisms For An Improved Safety Concept, Institut für Reaktorentwicklung, Kernforschunganlage Jülich, Jülich, Germany, date unknown.

74. Holland, D., Quade, U., Bach, F. W., Wilk, P., "A German Research Project About Applicable Graphite Cutting Techniques”, Siempelkamp Nuklear und Umwelttechnik GmbH \& Co., Krefeld, Germany, University of Dortmund, Institute of Materials Engineering, Dortmund, Germany. 
75. Pohl, P., "AVR Decommissioning Achievements and Future Programme", Arbeitsgemeinschaft Versuchsreaktor AVR GmbH, Düsseldorf, Germany, IAEA report XA9848061.

76. Röllig, K. The THTR-300 Coolant Gas Activity, an Indicator of Fuel Performance, Hochtemperatur-Reaktorbau GmbH, Mannheim, Germany.

77. Kendall, J. M., and R. E. Bullock (2004, September 22-24). "Advanced Coated Particle Fuel Options," Global Virtual, LLC, Prescott, Arizona, Sigma Science Inc., Albuquerque, New Mexico. 2nd International Topical Meeting on High Temperature Reactor Technology, Beijing, CHINA, Paper B09. 